NBSIR 78-1468-2

\title{
Committee on the Challenges of Modern Society Rational Use of Energy Pilot Study Modular Integrated Utility Systems Project Final Report
}

VOLUME 2 MINUTES OF PROJECT MEETINGS

Prepared by:

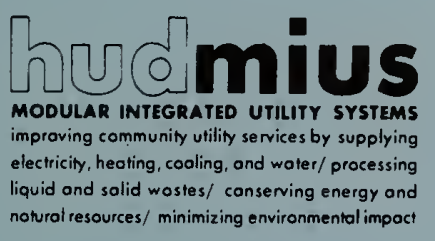

U.S. Department of Commerce

National Bureau of Standards

Center for Mechanical Engineering and Process Technology

Washington, D.C. 20234

June, 1978

Prepared for:

U.S. Department of Housing and Urban Development Division of Energy, Building Technology and Standards Office of Policy Development and Research

Washington, D.C. 20410

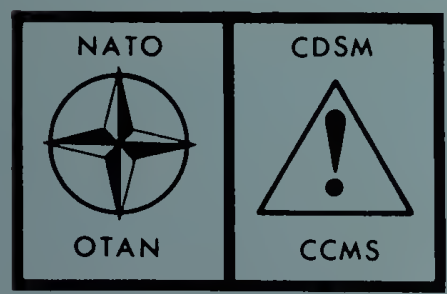





\section{COMMITTEE ON THE CHALLENGES}

OF MODERN SOCIETY RATIONAL

\section{USE OF ENERGY PILOT STUDY}

MODULAR INTEGRATED UTILITY

SYSTEMS PROJECT

FINAL REPORT

VOLUME 2 MINUTES OF PROJECT MEETINGS

M.H. Nimmo, Secretary, CCMS-MIUS Project National Bureau of Standards

C.W. Phillips, Chairman, CCMS-MIUS Project and Manager of Integrated Energy Systems National Bureau of Standards

Prepared by:

U.S. Department of Commerce

National Bureau of Standards

Center for Mechanical Engineering and Process Technology

Washington, D.C. 20234

Prepared for:

U.S. Department of Housing and Urban Development

Division of Energy, Building Technology and Standards

Office of Policy Development and Research

Washington, D.C. 20410

June, 1978

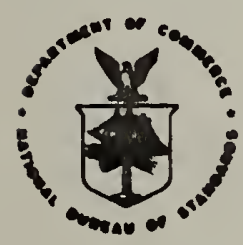

U.S. DEPARTMENT OF COMMERCE, Juanita M. Krops, Secrotary

Dr. Sidnoy Harman. Undor Secrotany

Jordan J. Baruch, Assistant Secrotary for Science and Technology

NATIONAL BUREAU OF STANDARDS. Emost Ambler, Director 

The Committee on the Challenges of Modern Society - Modular Integrated Utility System (CCMS-MIUS) Project was established by the NATO CCMS in 1974 as a result of strong international interest in improving methods for providing better utility services to communities. The CCMS-MIUS Project is a sub-project of the pilot study Rational Use of Energy. Both are piloted by the United States.

The CCMS-MIUS Project has been carried out under the leadership and sponsorship of the United States Department of Housing and Urban Development (HUD), Divisinn of Energy, Building Technology and Standards, Office of Policy Development and Research. The National Bureau of Standards provided technical support to HUD.

The major objective of this project was to develop and implement a mechanism for the exchange of technical information on Modular Integrated Utility Systems (MIUS) Type of Projects in participating countries. During the project several important products were developed, including a glossary of special terms, a catalog of project descriptions and a standard methodology for reporting the performance of MIUS Type of Projects.

This project marks the beginning of a significant exchange of information. Further work is required to develop the mechanism more completely and bring about actual exchanges of technical information. This is reflected in the recommendations of the CCMS-MIUS Project committee at its last meeting July 12-14, 1977 in Turin.

This report is in two volumes. The first volume includes a chronology and description of the project, its activities, and products, and a copy of each product developed. Volume two includes the minutes of the CCMS-MIUS Project meetings. 


\section{CONTENTS}

VOLUME 2

Page

APPENDICES

$$
\begin{aligned}
& \text { F - Minutes of CCMS-MIUS Project Meeting } \\
& \text { April 10-11, } 1975 \text { (Brussels, Belgium) . . . . . . . F1 } \\
& \text { G - Minutes of CCMS-MIUS Project Meeting } \\
& \text { December 9-10, } 1975 \text { (Apeldoorn, The Netherlands) . . . G1 } \\
& \text { H - Minutes of CCMS-MIUS Project Meeting } \\
& \text { May 18-19, } 1976 \text { (Moret-sur-Loing, France) . . . . . H1 } \\
& \text { I - Minutes of CCMS-MIUS Project Meeting } \\
& \text { December 7-9, } 1976 \text { (Juelich, W. Germany) . . . . . I1 } \\
& \text { J - Minutes of CCMS-MIUS Project Meeting } \\
& \text { July 12-14, } 1977 \text { (Turin, Italy) . . . . . . . . . J1 }
\end{aligned}
$$




\section{APTENDIX F}

MINUTES

OF THE

CCMS-MIUS PROJECT MEETING

April 1975 (Brussels) 
MINUTES (Summary Form)

April 10-11, 1975

horular Inteprated Utility System Project (MIUS)

of tine

Ratiorial Use of Energy Pilot Study

of the

Committee on the Challenges of Modern Society (CCMS)

The first meeting of the CCMS-MIUS Project was held April 10-11, 1975 at NATO-CCMS Headquarters in Brussels. Twenty experts from seven countries were in attendance. A list of attendees is attached (Attachment A). C.W.Phillips, Manager of the NBS/HUD-MIUS Program chaired the meeting.

The experts in attendance were welcomed to NATO Headquarters, Brussels by Mr. $\mathrm{T}$. Kester, NATO Scientific Affairs Division. Mr. F. Sudarski cf the NATO Executive Secretariat assisted in arrangements for the meeting.

Mr. F. Allen Harris, Special Assistant to the Honorable Russel E. Train, Head of the United States Delegation to CCMS and Mr. Cameror Sanders, U.S. CCMS Officer at NATO in Brussels described the current status of CCMS and of the pilot project on Rational Use of Energy, of which the CCMS-MIUS Project is a part. Mr. J.H.Rothenberg, Director of the MIUS Program in the U.S. Department of Housing and Urban Development, and principal U.S. representative to the CCMS-MIUS Project, described, on behalf of the U.S.in its lead role, the goals and objectives of the CCMS-MIUS Project. He further described, as part of the committee's agenda on technical presentations of MIUS type of projects by experts in the participating countries, the HUD-MIUS Program in the U.S. He specifically discussed its goals and previous achievements.

The experts in attendance from the participating countries described the MIUS type of projects in their countries.

Mr. Harris, the U.S. CCMS Coordinator, and Mr. Phillips, the Chairman, presented a draft Memorandum of Understanding (MOU) for consideration by the experts representing the participating countries. The experts elected to operate on an informal basis employing a roundtable discussion technique rather than on a formal basis.

Mr. Phillips presented a draft glossary of terms unique to integrated utility systems prepared by the U.S. delegation. The preparation of this document had been prepared in three languages to provide a common understanding of terms unique to integrated utility systems. Mr. Phillips and $\mathrm{Mr}$. Leighton of HUD toured Europe in December, 1974 to locate and learn of integrated utility systems interest and to seek and encourage representation to the CCMS-MIUS Project Committee meetings. During this period those who were contacted agreed that the glossary should be prepared as the first task. The draft glossary of terms was discussed and comments were recorded. The U.S. agreed to prepare a revised draft including comments and some additional terms for submission to the committee at their second meeting for approval.

The committee further discussed the needs and tasks to facilitate the exchange of information on integrated utility systems. 
The U.S. agreed to prepare a draft for submission to the committee at. their second meeting the following:

a) Standard Methodology for reporting information on projects

b) Standard data units

c) Format for a one-page sheet describing any on-going or planned project for which data is to be made available to other participants.

Subsequent to the meeting the U.S. prepared three documents in draft form for submittal to the December 1975 meeting. They were a one page reporting form, Project Summary Form, to provide the basis of the "Project Catalof", an evaluation form, and an outline describing the elements of a uniform methodology for measuring performance resulting from testing and demonstration of CCMS-MIUS related projects. Refer to the agenda attached. 


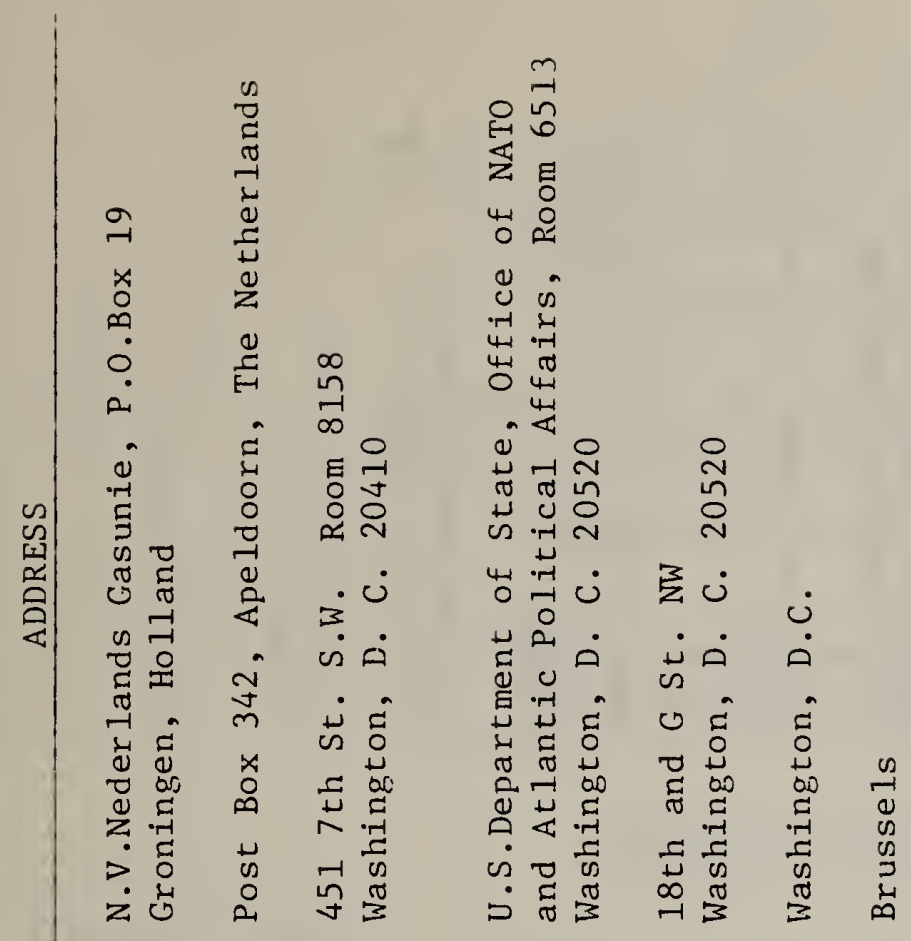
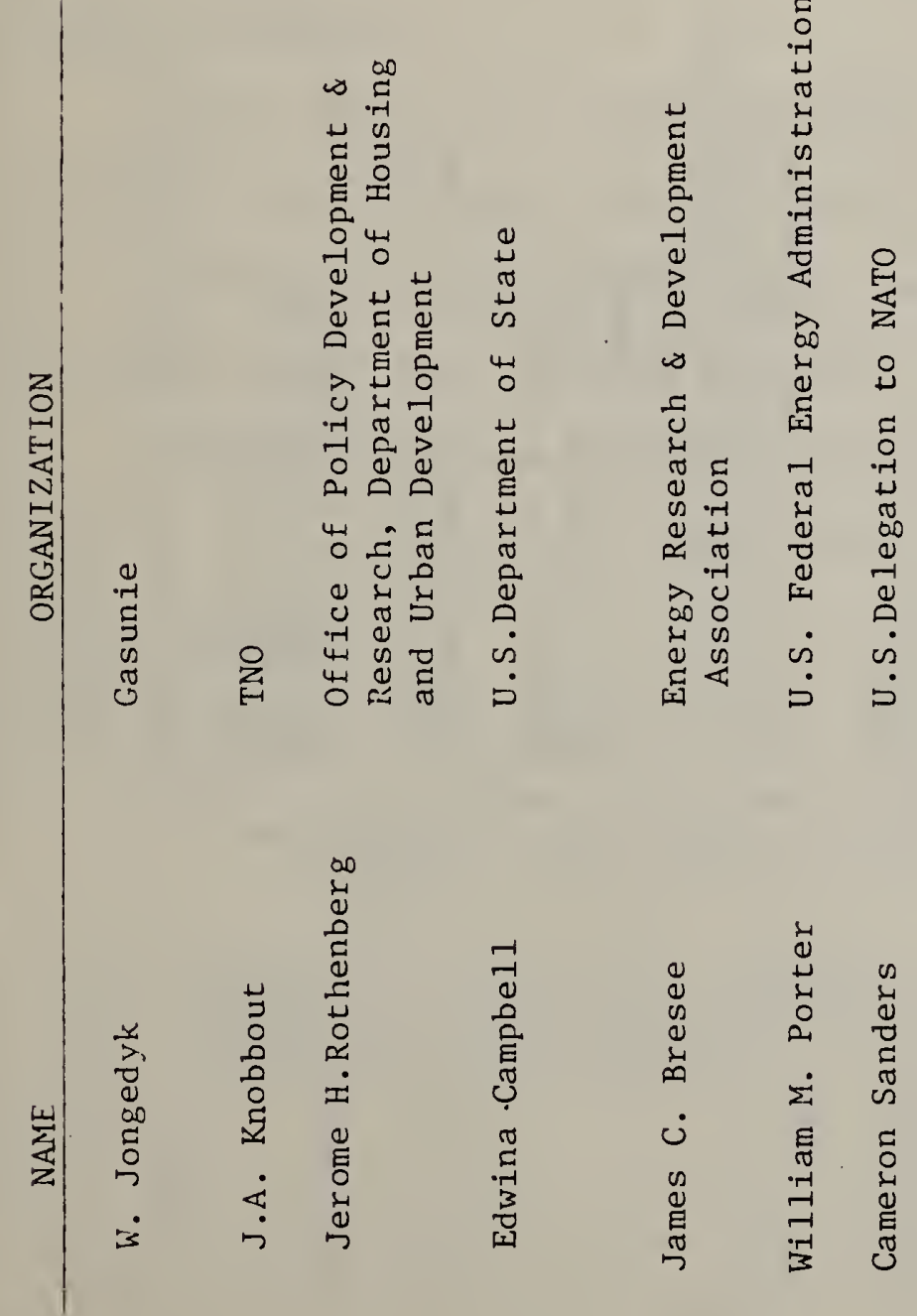


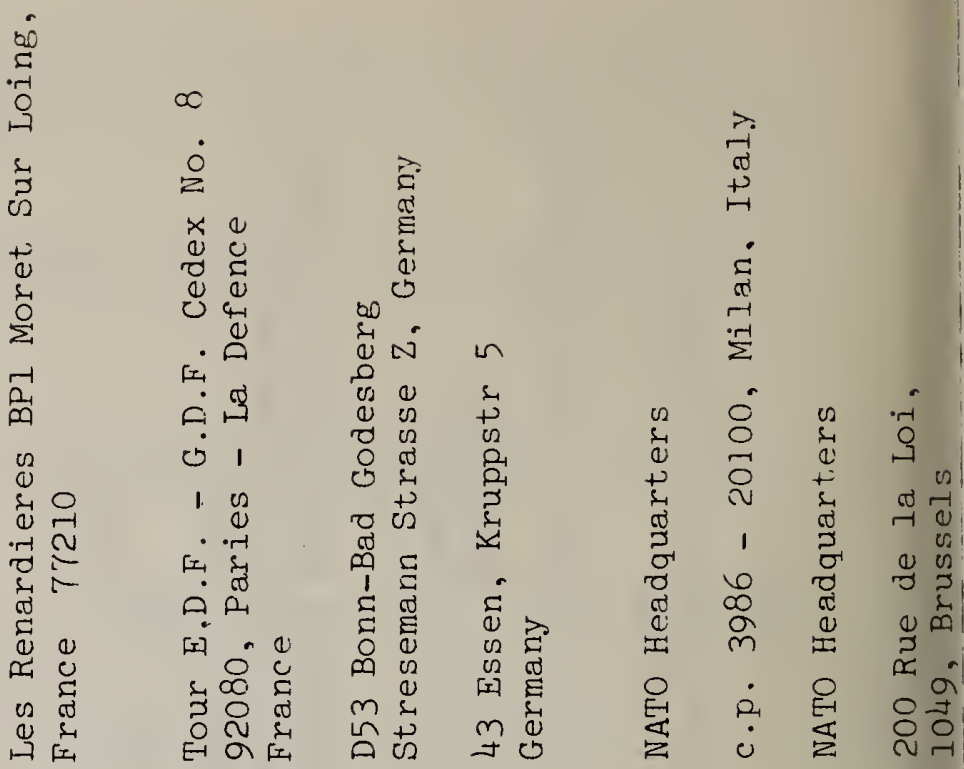

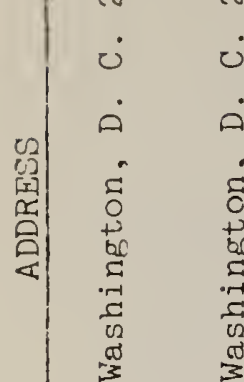
西

递

$\frac{g}{d} 8$

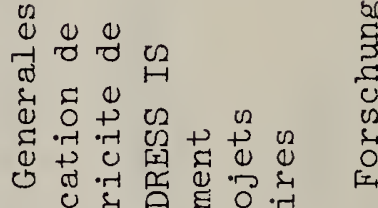

w.

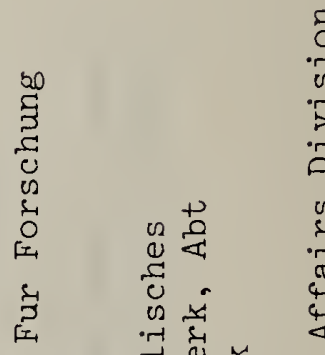

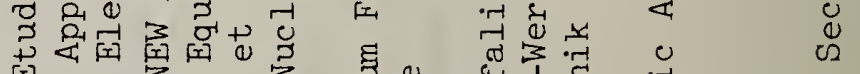

20.

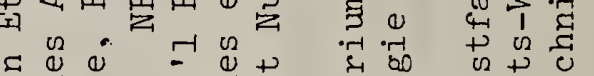

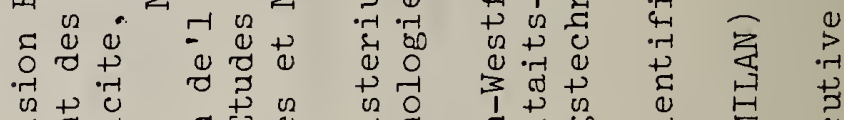

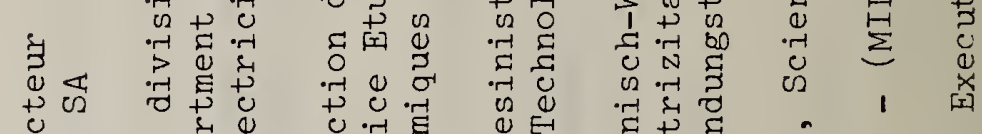

एथ व

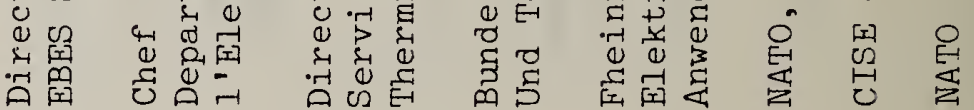

.

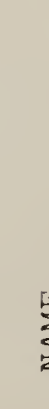

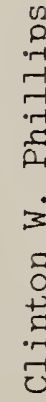

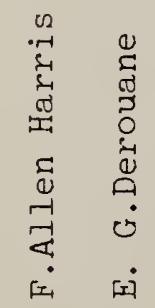

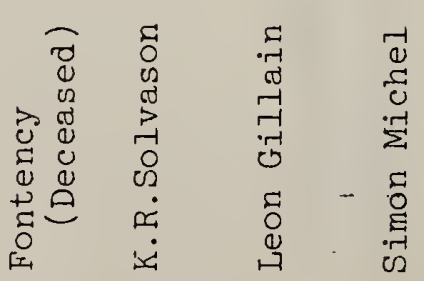

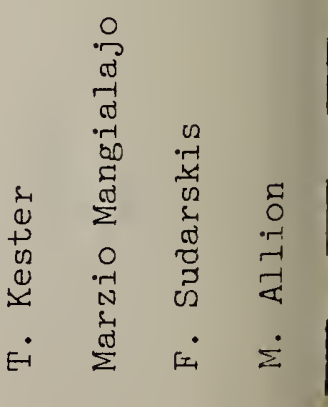




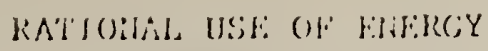

CCMS-rilus (Modular Jntcegrated Utillty Systems)

EXPERTS NEETING

April 10 and 11, 1975

Room 17 (Next to Press Theater - Use Press Entrance)

NATO HEADQUARTERS BUILDING

BRUSSELS, BELGIUM

Meeting Hours: Thursday, April 10; 1000 to 1200 and 1400 to 1630

Friday, April 11; 0930 to 120: and 1330 to 1500

Simultaneous Translation (French-English, English- French)

Neeting Chairman - Clinton W. Phillips, Sr. Mechanical Engineer

Office of Energy Conservation, U.S. National Bureau of

Standards

Menager, NBS Team, HUD-MiUS Program

\section{TENTATIVE AGENDA}

Apri1 $10-1000$

WELCOMING REMARKS ---

- F. A. Harris, U.S. CC.YS Coordinator

OVERVIEW OF RATIONAL USE OF ENERGY PILOT STLDIES ---

- Wlliam M. Porter, U.S. Federal Energy Administration

NEW DEVELOPMENTS IX INTEGRATED UTILITIES ---

- Brief Discussions of current activities by representatives in attendance RECESS FOR LUNCII -..-

APY:- $10-1400$

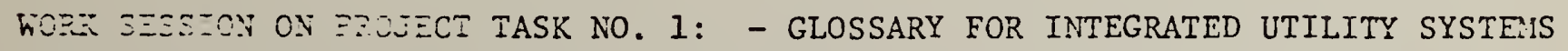

Note: $D=Z Z=$ copies distributed to most participants in advance of meet:ng. Extra copies in French, German and English will be availajie at the meeting).

- Detziled Re: iew of Draft Glossary by Participants

- Pesolution of ccments; additions, changes and deletions

- Further Action on Glossary 
Apr11 11. -0930

NEXT CC:IS-MIUS PROJECT TASKS ----

- Standard Methodologies for evaluation

- Unfform Data Format

FU'JURE POSSIBLE CCMS-MIUS PROJECT TASKS ---

- Demonstrations of Integrated Utility Systems or Subsystems

- Innovativ Technology Demonstrations

- Identification of On-going or Pl.anned Research

- Other

OTHER BLSIIVES

DATE OF NEXT MEETING

ADJOURMENT (Not later than 1500 hours, Apri1 11) 


\section{APPENDIX G \\ MINUTES \\ OF THE \\ CCMS-MIUS PROJECT MEETING \\ December 1975 (Apeldoorn)}

GI 



\title{
MINUTES (Summary Form)
}

December 9 - 10, 1975

\author{
Modular Integrated Utility System Project (MIUS) \\ of the \\ Rational Use of Energy \\ of the
}

Committee on Challenges of Modern Society (CCMS)

The second meeting of the CCMS-MIUS Project was held on December 9 and 10, 1975, at the laboratories of the Netherlands Organlzation for Applied Science Research (TNO) in Apeldoorn, the Netherlanas. Twenty-six experts from eight countries were in attendance. A 1 ist of the attendees is attached (Attachment A). A copy of the agenda is attached (Attachment B).

The experts in attendance were welcomed to the Netherlands by the Honorable Kingdon Gould, Jr., United States Ambassador to the Netherlands, and to TNO by Mr. J.A. Knobbout, of the Centre for the Study of Energy Problems (TNO). C.W.Phillips (USA) was the meeting Chairman.

Mr. F. Allen Harris, Special Assistant to the Honorable Russell E. Train, Head of the United States Delegation to CCMS, and Mr. Cameron Sanders, U.S. CCMS Officer at NATO in Brussels described the current status of CCMS and of the pilot project on Rational Use of Energy, of which the CCMS-MIUS Project is a part. Mr. J.H.Rothenberg, Manager of the MIIUS Program in the U.S. Department of Housing and Urban Development, and principal U.S. representative to the CCMS-MIUS Project, described, on behalf of the U.S. lead role, the goals and objectives of the CCMS-MIUS Projeci.

Principal business of the two-day meeting included:

1. Approval for completion and issuance of the CCMS-MIUS Glossary. Comments received by February 1, 1976, to be incorporated in the final version.

2. Discussion in detail of the purposes, data forms and procedures for development of a "Project Catalog" of on-going or planned projects in any of the participating countries, from which technical data of value in evaluating or comparing integrated utility systems, would be listed. A committee titled "Data Format Committee" charged with responsibility to produce and maintain this "Project Catalog" was established with the U.S. in the lead role. The committee consisted of C. W. Phillips (U.S.A.), Chairman, K.R. Solvason (Canada), M. Mangialajo (Italy), J.W.H. Van Den Bergh (Netherlands), and P.J. O'Neill (United Kingdom). The committee is open for additional countries/experts who wish to participate.

3. Discussion of the need for and the meaus to accomplish development of a uniform methodology for measuring and reporting the performance of the various projects related to MIUS technology underway in the various countries. A committce titled "Mcasurement Technology Committee" was established with the Netherlands in the lead role. The committee consisted of J.A. Knobbout, (Netherlands), Chairman, M. Simon (France), H. Klein or G. Richter (Federal Republic of Germany), U. Renghold (Sweden), and $C$. W. Phillips (USA). This cumnitee also is open for additional countries/experts who wish to participate. 
4. Bricf reports on on-going projects of interest in the several countries represented by experts in attendance. Major projects in France, Belgiun, Italy, Federil Republic of Cermany, United States, United Kingdom, Netherland: and Sweden were discussed. Related activities in the Commission of the European Comnunities was described.

5. Tour of the laboratory facilities of TNO in Apeldoorn including separation of paper from solid waste; testing of refrigerators and refigeration systems; development of standards for defrosting of air coolers; advanced heat pump technology and combination with solar heat collection; testing of air heaters recovering latent heat in the exhaust gas; calorimeters for determination of energy balances; fluidized bed burners; advanced electron microsopy; testing of mechanical structures

6. The final business action was to accept the French invitation to hold the next CCMS-MIUS Project meeting at Electricite de France, at Centre des Renardieres on May 18 and 19, 1976. 
BELC:IU⿴囗十

M. ALLION

E.E.C. Dircctorate General Energy

200 Rue de la Loi

1049, Brussels, Belgium

H.J. FONTENOY

Programation de la Politique Scientifique

8, rue de la Science

1040 Bruxelles, Belgium

J.A. MICHEL

Department Thermodynamique UCL

Louvain-La-Neuve, Belgium

\section{FRANCE:}

MICHEL SIMON

Chef division Etudes Generales

Department des Application de

1'Electricite, Electricite de France

Les Renardieres BP1 Noret-sur-loing

France 77210

\section{GERMANY :}

PETER GORICKE

Rheinisch-liest folisches

Elektrizitaits-Werk, Abt

Anwendungstechnik

43 Essen, Kruppstr 5, Germany

Dip1.Ing. GERHARD RICHTER

Forschungsstelle fur Energiewirtschaft

8 Munchen 50

Am Blutenanger 71, Germany

ITALY:

MARZIO MLANGIALAJO

CISE- (MILAN)

c.p. 3986 Milan, Italy 20100
ATTENDEES AT CCMS-NIUS PROJECT MEETING Apeldoorn, The Netherlands December 9 and 10, 1975 
NFTHERLANDS:

J.A. KNOBBOUT

Centrum voor Energievraagstukken TNO

P. 0. Box 342

Apeldoorn, Netherlands

W. JO:IGEDIJK

Gasunic

N.V. Nederlandse Gasunie

P. 0. Box 19

Groningen, Netherlands

J. SCOTT MONIER- ECON

Hague Embassy of the United States of America

102 Lange Voorhout

The Hague, Netherlands

APO New York 09159

J.DE JONG

Technisch Phvsische Dienst TNO-TH

Stieltjesweg 1

P. 0. Box 155

Delft, Netherlands

J.A. BANCK

Ministerie van Economische Zaken

Bezuidenhoutseweg 30

The Hague, Netherlands

B.A. KLEINBLOESEM

N. V. KENA

Utrechtseweg 310

Arnhen, Netherlands

P.J. COLLET

Institutuut TNO voor Werktuigkundige

Construeties

Leeghwaterstraat 5

P. O. Box 29

Delf $t$, Netherlands

F.C. VAN BELEERTNG

Instituut voor Milieuhygiene en

Gezondheidstechnick TNo

Schoemarkerstraat 97

2. 0. Box 214

Delft, Netherlands 
Netherlinds (Continued)

J.W.H. VAN DEN BERGH

Reactor Centrum Nederland

Westerduinweg 3

Petten, Netherlands

W. SMIT

Centrum voor Energievraagstukken TNO

P. O. Box 342

Apeldoorn, Netherlands

J. QUALERNAAT

Centrum voor Energievraagstukken TNO

P. 0.Box 342

Apeldoorn, Netherlands

\section{United Kingdom}

PETER J. O'NEILL

Directorate of Research Requirements

Department of the Environment

2 Marsham Street, SWI

London, England

\section{United States}

C.W.PHILLIPS

Office of Energy Conservation

National Bureau of Standards

Room A146, BIdg. 225

Washington, D. C. 20234

\section{S.N.CAVROS}

Chief, Community Systems Branch

Energy Research and Development Administration

20 Hassazhusetts Avenue NW.

Washington, D. C. 20545

\section{F.A. IHARIS}

Special issistant to the Administrator

Environmental Protection Agency

Room 1025A East Tower A-I00

401 N Strect SW

Washington, D. C. 20460 
United States_(Continued)

JEROME: H. ROTHENBERG

IIUD-iIIUS Program Director

Department of Housing and Urban Development

4517 th St. S.W.

Room 8158

Washington, D. C. 20410

\section{ERO: SANDERS}

U. S. CCMS Delegation to NATO

Brussels

Autoroute Brussels --Zaventum

APO New York 09667

Dr. FRANK GOLDNER

U.S. ERDA Office, Brussels

c/o U.S. Mission to the European Communities

40, Blvd du kenge - B3

1000 Brussels, Belgium

APO New York 09667

\section{SWEDEN :}

ULF RENGHOLD

Assocation of Swedish Heating and Ventilation Engineers Hantverkargatan 8

Stockholm, Sweden 
Committee on Challenges to Modern Society (CCMS)

- Rational Use of Energy CCMS-Modular Integrated Utility Systems (:IUS)

Meeting: December 9 and 10, 1975 at

Center for the Study of Energy Problems, TNO

Laan Van Westenenk 501

P.0. Box 342, Apeldoorn - Zuid

The Netherlands

Agenda

Tuesday, December 9, 1975

$0900 \quad$ Call to order and Introductions

Welcome to the Netherlands and TNO

Review of CCMS Activities,

F. Allen harris, Special Assistant to the Administrator of EPA for Coordinating CCMS activities

CCMS-MIUS Project Goals, Objectives and Schedule - J. H. Ro:LEニうこ=ミ, Manager, U.S. HUD-MIUS Program (HUD is the U.S. DEpar:ニะ:ニ of Housing and Urban Development)

Meeting agenda and arrangements

TASK 1: Final Review and Discussion of Glossarv of Teris; approval for distribution (See Attachuent 1)

1215 LUNCH--Courtesy of TNO (Coffee Break at 10:30 am)

1345 TASK 2: Listing. of projects by COMS-MIUS participating coun:ries;

Preparation of Project Catalog; Review of draft o project reporting form (see dttachment 2); Selectics of Task Committea.

TASKS 3

AND 4: Discussion of Standard Nethodology for Project Yeastire= $==$ and Reporting; Review of draft summary project ze=artin form (see Attachment 3); Selection of committees for completion of these tasks.

1645 ADJOURI FOR THE DAY

SOCIAL HOUR AND DINNER.

- Wednesday, Decenber 10, 1975

0900

Tour of TNO laboratcries

- testing and development of heat pumps, domestic refrigerators =-: freczers, etc. 
- development of heat pump with solar collector

- development and testing of air coolers and other unit cozpozen:s

- gas fircd heating units and oil-fired small boilers

- fluidized bed burner under construction

- testing of solar collectors (underway at other locations)

- metal institute; general research, welding research, wear reses:=

- mechanical testing of large components

- electron microscopes (number of types, one very special)

- separation of muricipal waste for recycling of paper

- other special facilities

1145 LUNCH (Courtesy of TNO) NOTE: (Coffee Break during Tour)

$1300 \quad 3$ and 4: Further discussion (if any) and committee selection (see page 1)

NATIONAL INTEGRATED UTILITY SYSTEM PROJECTS :

Brief reports of on-going projects in the several countries by representatives in attendance

OTHER BUSINESS: Determination of date and location of next eeetin ADJOURNMENT Not later than 1600 (Coffee Break at 1415)

NOTE: Meeting will be chaired by Clinton W. Phillips, Manager, Naticnal Bureau of Standards' Team, U.S. HUD-MIUS Project.

Arrangements for housing and local transportation in Apeldoorn should be made as soon as possible with Mr. J. A. Knobbout, Center for Study oi Energy Problcms, TNO, Apeldoorn, The Netherlands, Tel. 0557733 44, Telex No. 49095 TNO AP. 


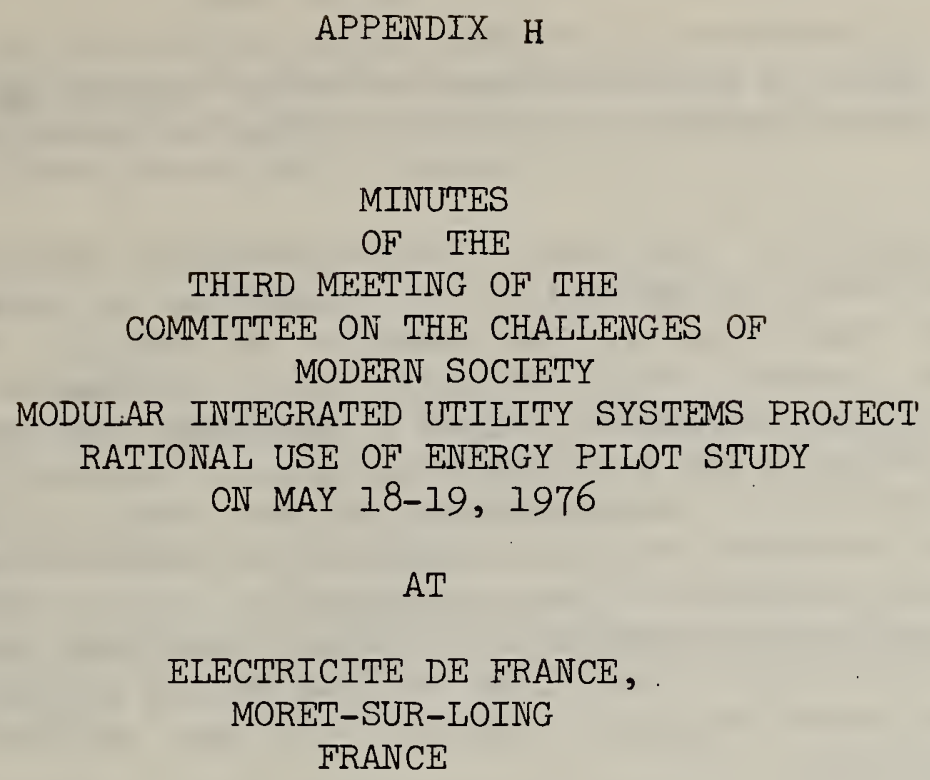


PLEASE NOTE: In addition to the semi-detailed minutes included herein, there is a set of Summary Minutes available for those who do not require a detailed account of the meeting.

The detailed account of the third CCMS-MIUS* Project meeting described herein hopefully will be helpful to the committees in their work as well as document the results and action items of the meeting. The minutes as written are not a word by word transcription of the tapes. In many cases, however, the minutes are very detailed. I believe that the most important points are highlighted and that the minutes are reasonably accurate. In view of the difficulty of understanding voices from a tape, particularly from a distance and when extraneous noises block out or distort some words, there may be some statements misinterpreted or misunderstood. Some statements may be missing that those who made them felt important. I may also have incorrectly identifled persons making statements. I apologize for any material which may have inadvertently been omitted, or interpreted or stated incorrectly.

Morris Nimmo - Editor

*CCMS-MIUS is Committee on the Challenges of Modern Society - Modular Integrated Utility Systems 
The third meeting of the CCMS-MIUS Project was called to order at 9:00 am May 18, 1976 by Mr. Clinton W. Phillips, Project Chairman at Electricite de France (EDF) at Moret-sur-Loing, France.

The following countries attended:

Austria (P.V.Gilli)

Belgium (R.Genin, J.Michel)

France (M.Simon, Host, T. Grjebine, H.Michel, A.Pfohl, J.Zyss)

Germany (W.Piller)

Italy (M.Mangialajo)

Netherlands (J.Van den Bergh, J.Knobbout)

Sweden (U.Rengholt)

U.S.A. (J.Rothenberg, S.Cavros, F.Harris*, M.Nimmo, C.Phillips)

Also in attendance were:

C.Sanders - CCMS Officer, U.S. and J.Sampas - CCMS Projects Office, NATO Brussels

\section{CALL TO ORDER AND INTRODUCTIONS}

Mr. Phillips welcomed those in attendance and explained the concept of Integrated Utility Systems and their productive application. He made several announcements concerning the purpose and arrangements for the meeting, the tour of the EDF laboratories, and the host's invitation to a dinner for those in attendance

\section{WELCOME TO ELECTRICITE DE FRANCE}

Mr. Phillips introduced Mr. Henri Miche1, Chief Department of Applications de l'Electricite, EDF who welcomed the attendees to EDF. He explained that their main concern is centralized power stations; however, they are also interested in the idea of modular integrated systems and work being conducted on modular integrated utility systems.

*Address - Mr. F.Harris, U.S. CCMS Coordinator, Environmental Protection Agency, Room 1025A, East Tower A-110, 401 M Street SW, Washington, D. C. 20460 
Mr. Michel Simon, the meeting host, distributed several booklets describing EDF and the work being conducted there. Mr. Simon explained the dinner arrangements and discussed briefly the tour and the present EDF facilities. EDF has the biggest high voltage testing laboratory in the world as far as size is concerned. The second biggest is located in Montreal. EDF tests heat exchangers, high voltage lines, circuit breakers, high power apparatus, etc. They also have laboratories dealing with mechanical properties, corrosion, wastewater resources and computers.

Mr. Phillips expressed his and the Committee's appreciation to EDF and Mr. Simon for hosting the meeting. He asked the other committee members to consider the possibility that one of them could host the next meeting. Mr. Phillips explained that there will be two speakers on the general subject of CCMS and the CCMS-MIUS Project. The CCMS-MIUS Project has a definite time target for completion, which will be addressed. The CCMS-MIUS project will probably involve not more than two more meetings and we should be aware of the targets for completing the CCMS-MIUS Project.

We have present, Mr. Cameron Sanders, CCMS officer U.S. in the NATO* Headquarters and Mr. F. Allen (Tex) Harris, the U.S. Coordinator for the CCMS-Project in an administrative capacity.

\section{UPDATE OF CCMS ACTIVITIES}

Report by Tex Harris - At the last two meetings of CCMS, three new pilot studies were adopted. The first one lead by Canada is on Nutrition and Health. This study will deal with the problem of nutritional education, the problem of eating too much of the wrong foods and too little of the right foods. Many countries are interested in this problem. Italy is very interested in trying to change the country's concerns from agriculture to agricultural nutrition. Under France's leadership we have an interesting new proposal which deal with remote sensing in the control of the pollution of the seas. This project will be limited to ground and airborne fixed wing and helicopter platforms for remote sensing of the marine environment, (not including use of satellites). These platforms will be used to investigate the question of protection from waste and oil spills in the sea and to look at the fall out over the sea and the pollution that comes from the land. These remote sensing techniques will be used to gain information that can be used in computer models of the coastal zone in order to manage more efficiently the costal zone. The U.S. is leading a new project that is relevant to the environmental energy interface that deals with flue gas and sulfurization systems. It is hoped that within a year or two a document can be published that would pull together in one book the operating experience on the test results and economics of as many systems as can possibly test for oil and for coal.

* North Atlantic Treaty Organization 
There are three speciffc c.MS energy programs: solar energy, geothermal energy and rational use of energy. The solar energy pilot study, the heating and cooling of buildings, will hold 1 ts annual meeting in Copenhagen in mid September hosted by Prof. Vagn Korsgaard of the technical university at Lyngby. The program there will parallel somewhat the work of the Modular Integrated Utility Systems in developing a data format to report on the performance of solar heating and cooling units as applied to buildings. This project will not look at the thermal application. We are looking at the use of solar components in heating and cooling of buildings including seasonal storage, heat pumps and every possible type of application which can increase the efficiency of a solar system. About 22 projects in 7 or 8 countries will be placed in a data format developed by the project. Presentations on these projects will be made at the Copenhagen meeting and the problems that people have in using the data format to convey information effectively will be discussed.

The second part of the solar program deals with the exchange of information. This is essentially to circulate on a timely basis, published information regarding solar heating and cooling applications in the original language in which it was published.

The development of several specialized working groups dealing with particular problems is being pursued. One working group which is lead by Denmark is studying the "zero energy"house. The Federal Republic of Germany and the United Kingdom are participating and the United States and Netherlands are interested in the study. The "zero energy" house is examining the development of an efficient experimental housing design incorporating solar collectors, seasonal storage and systems for capturing waste heat from the air and waste water.

France is interested in exploring the possibility of a Mediterranean group to look at the design of experimental prototype houses in this particular latitude. Also under discussion is a tropical group that would deal with and design solar houses to maximize heating and cooling of buildings located in the tropics. Thus, there probably will be three specialized subgroups.

Ten countries have signed a Memorandum of Understanding and are participating in a formal way in the information exchange program on solar heating and cooling.

The next CCMS pilot study on energy is geothermal energy. The United States and Italy CNR have developed a computer based information system which will collect data on all geothermal reservoirs, wells, and end-purpose uses, world-wide. The information will be available to all countries who contributed information.

The next project led by France, deals with non-electrical use of geothermal resources. This project is focusing at the present time on the economics of utilizing geothermal energy resources for heating buildings. This project is also looking at the French work on heat pumps. The Icelanders who have a lot of experience are providing data. Italy has a lot of information and experience with geothermal resources although not so much on non-electrical uses. Some new lower temperature findings in Italy quite close to Rome and other cities makes the application of non-electrical future use of geothermal resources in Italy imminent. We are looking primarily at the costs of transporting this energy to these cities. 
There is a project led by the U.S. dealing with reservoir assessment. This project deals with computer modeling of reservoirs for maximization and optimization of the resources and also the effect of the production of the spent water if pumped back into the reservoir. There is a program in Mexico in which the U.S. shares a common basin in the Imperial Valley which is being examined. New Zealand is also participating in terms of the field project. A five nation team has developed a small geothermal power station model blueprint. We now hope that this will be built, perhaps through joint funding. Italy and Mexico have expressed interest. Turkey has expressed interest in having a remote well tied into this small power plant.

The last project which is led by the U.S. is tied in with research work which the U.S. is doing in Los Alamos. This is the use of underground dry hot rocks. The rocks are factured and the water is inserted. Steam or superheated water is recovered. This project has succeeded in terms of having two wells and connecting the wells. There is an experimental heat exchanger at the top. The flow is not as large as we would like so we are examining ways of doing work in granite. We have had engineers from many countries outside the U.S. working with the U.S. team on rocks.

In the Rational Use of Energy pilot study there is an industrial data base project which has four parts. The first part is steel which is led by Italy. Basic data has been gathered for the energy consumed in the process of making steel. There are still some methodological problems in terms of the energy content which is given to scrap steel. There is a project on cement which is now completed. The final report has been approved, and is now being edited. It should be published within a few weeks in the U.S. The report has a very detailed analysis of the nature of the cement making processes from the energy standpoint and also addresses future energy research and development needed in the process of manufacturing cement.

There is another project dealing with plastics which is led by Italy. This project is just beginning. We have had one working group on the energy process data. There is a methodology group which encompasses all of these data bases and is addressing and developing a common methodology which allows effective international comparison of energy utilization in each of the industries.

One project is the aluminum industry and another covers some aspects of the food processing industry. There will be a meeting in Brussels at the end of June at which these subjects will be discussed. In terms of food processing we would like to take one or two types of industries which would serve as a methodological basis for examining the energy content in the fond industry. The next subproject is electric utility load management. The next meeting on this project will be held in Brussels in November. The project on Development of the Test Reference Year which is led by Denmark has been completed and the final report is being edited at this time. Four nations have agreed to perform tests on the Test Reference Year. This is a fitting project for those people dealing with the concern of weather and with building performance. They are developing a system on a test basis for extrapolating building performance from one climatic area to another climatic area. 
Participants who wish specific reports that have been completed or are being edited, please transmit your request to Tex Harris. (Refer to Page 1 of these minutes for Mr. Harris' address).

\section{OTHER INTRODUCTIONS}

Cameron Sanders as the U.S. CCMS Officer discussed briefly his responsibility, interests and viewpoints on the CCMS energy activities.

James Sampas, CCMS Projects Officer, NATO, discussed briefly his role in the CCMS activities.

Mr. Phillips joined Mr. Sanders in welcoming the participation of non-NATO countries in CCMS Projects. Mr. Phillips stated that Mexico, Spain, and Sweden had indicated that their participation would be continued through the remainder of the technical program. In behalf of the committee, Mr. Phillips expressed the committee's pleasure that non-NATO representatives were present. He emphasized that the technology goes beyond the NATO role.

The other nature of CCMS is that it definitely programs an effort to fill a need but with a definite time target to stimulate interests and if there is a continuing interest to identify some mechanism to carry the work on beyond the role played by the project identification capabilities of CCMS.

\section{UPDATE OF CCMS-MIUS PROJECT ACTIVITIES}

Mr. Phillips next introduced Mr. Jerome H. Rothenberg, Program Manager of the HUD*/MIUS Program, who provided an update of the CCMS-MIUS Project activities and described its targets and goals (Refer to Attachment 1). Mr. Rothenberg is also leader of the U.S. delegation which is serving as the lead country for this project. Mr. Rothenberg expressed his appreciation and congratulations to $\mathrm{Mr}$. Michel, Mr. Simon and EDF for hosting the meeting and thanked those attending for their participation.

\section{DATA FORMAT COMMITTEE RESPONSIBILITIES}

Mr. Phillips - The purpose of the committee work sessions is to present as many ideas as possible that will aid the committees in their tasks. All are invited to participate whether designated members of the committee or not.

We need to move this project work to a definite point of completion in about one year. We will probably have a fall ('76) meeting and a spring ('77) meeting. The purpose of the spring meeting should be to conclude and approve the products of this particular CCMS-MIUS Program. As we see it now, there are two primary products. One is a catalog which describes on-going projects that bear a technical relationship to the idea of integrated utility systems anywhere and certainly within the participating countries. If a project includes

* HUD is Department of Housing and Urban Development 
electric power generation, recovery of energy, transmission of energy for the purpose of providing utilities to a community of buildings and services, if it treats the wastewater and solid waste problem in such a way that there are benefits by an integration process with other needs of a community, then these subsystems are candidates for project identification. The development of a better boiler would be beyond the scope of the catalog or the development of a better generator or a better solar collector. However, the application of an improved technology which supplies the energy needs of a community as well as satisfies the minimum services to a community in an integrated fashion, even though it may only be two of these elements that are integrated, not necessarily five or six elements, is the thrust of the project identification. The principal product of the Data Format Committee is the catalog and in order for that to be a reality we have a great many questions which have to be answered. How can we best describe each project in a uniform fashion so we can compare projects with each other? What type of classification would make it easier to tell where certain kinds of projects are being conducted? We must know how big the projects are, what is their time schedule, what is their relative progress to date? To accomplish this we need the mechanism for that kind of reporting.

Much time will be spent on the detail. First, how do we describe the project, and second, the important part, how do we incorporate the follow-on as a part of the catalog for those projects which have moved into some degree of completion. Some projects will be at the point of planning, others under construction and others completed.

In addition to identifying the project there is a need for a progress report which will provide a means to compare projects and their results. The minimum product of the Data Format Committee would be the catalog, including the progress reports for those projects that are on-going by Spring 1977.

I believe that the product of this Committee should set an example for the continuation of the kind of activity that is represented by such a project. CCMS probably will not be the vehicle for the second revision of the catalog or 3 rd or $4 \mathrm{th}$, etc. This comittee work will be complete once we have estatlished the catalog. A mechanism for its continuation by others under a different procedure will be decided by others.

\section{CCMS-MIUS PROJECT CONTINUATION}

Tex Harris - After the project has begun and the functions and tasks have been established, CCMS will work toward placing it in another international organization. For example, Mr. Harris stated that we have different models for this. One of the more recent cases is the pilot study on Road Safety which had six projects. The Identification of Road Hazards, led by France, and the Development of an Experimental Safety Vehicle Testing procedure, led by the U.S., were placed in the International Organization for Automotive Safety in the OECD after CCMS had completed work to a particular point. The purpose of CCMS is to pilot and begin a project, see it to a definite product conclusion on a line of activity (usually a two year period) and place it in another committee, international scope, if there are needs for its continuation. Mr. Harris pointed out that after the project has been concluded and placed in another organization CCMS will follow it for about 2 years. Mr. Harris stated that at the next meeting the 
question of how the work of the CCMS-MIUS Project can best be continued should be addressed.

\section{SUMMARY OF PRODUCTS}

Mr. Phillips summed up the CCMS role by stating that he believed the CCMSMIUS project product would be the catalog and the establishing of a mechanism for continuing the catalog and establishing a progress/evaluation reporting system and standard methodology for collecting and reporting data. The continuation would be to update the catalog and collect and disseminate progress/evaluation reports and performance data.

Mr. Phillips next identified the companion task of the catalog as that of developing guidelines or a handbook that identifies the elements in an integrated utility system that should be addressed when reporting performance and standard procedures for making these measurements. This will be discussed in more detail this afternoon by the Measurement Technology Committee.

\section{DATA FORMAT COMMITTEE}

\section{Catalog Alternatives}

Mr. Phillips, Chairman of the Data Format Committee, led a discussion on the questions and proposed decisions on the catalog (Refer to Attachment 2). Concerning item a, guidelines for the type of projects to be included, Mr. Phillips extended the idea of keeping the criteria rather broad at first, i.e., the development of a criteria could best be accomplished after knowing the degree of response to Project Summarv Forms. Also after we progress to the point of having completed Project Summary Forms, the question of guidelines becomes a little less critical. Mr. Phillips offered as an example of one organization's approach to cataloging projects, the selected printout of energy projects cataloged by ORNL* in the U.S. (Attachment 3, a typical ORNL project summary).

What should be the cut off or the lower level below which we would not identify projects? Steve Cavros responding stated that everything and anything that can be combined and integrated to take advantage of energy exchange, or recovery of waste heat should be included. A minimum of two systems would also be an appropriate guideline. Mr. Phillips indicated that this was the type of guideline he was seeking. He further raised the following questions.

Should we limit projects to those being conducted by the country itself or one funded by national funds and should we include those being conducted by a commercial enterprise from which data could be obtained? Is there any reason to restrict this from commercial enterprises? C.W.Phillips further suggested that we not limit any project at this time that meets the basic idea of integrating one or more subsystems, regardless of sponsorship or size because we might learn a great deal from a small project that also had all the technical problems with which we must deal. Mr. Grejebine next asked if district heating systems should be included. He further asked the 
meaning of modular. Mr. Phillips replied that district heating systems should be included and that the word modular means different things to many people. One of the interpretations that modular has in the U.S. concept is that integrated systems would grow with the demands of the community that they serve. For example, if a community grew in segments over a 25 year period, then the utilities likewise would grow in segments, elements or modules. Also the idea that any two or more subsystems that are integrated makes an integrated system with two or more modules is another interpretation.

C.W.Phillips - Item b. We need a number to identify projects that are more than a simple sequential number and would show classification types. We will develop in the next draft a recommendation for an identification number based on types of projects such that a cross index may be utilized to aid in locating projects on heat recovery, distribution systems, incineration systems, etc.

Item c - This item is rather straight forward. Any catalog needs an introduction describing what it is and its purpose and how to use it. The major topics we belleve this front section should include are listed. The next draft will provide some of this information.

Item $d$ - Concerning the organization of the catalog, it has been established that we need to classify the kinds of projects in some manner. Thus, we should likely be considering elther item 2 or 3 . The question of whether the catalog will consist of multiple volumes will depend upon some later decision.

It should take no more than two pages to identify a project, front and back of one sheet. We will discuss later the contents of the Project Summary Form, the form that will aid you in deciding whether you would like to have additional information (Project Progress/Evaluation Report) from the project engineer.

Item e - Responding to a question, Mr. Phillips explained that random (e.1) no classification, i.e, no regard to type of project, county, size, etc. Perhaps before a classification system can be designed and accepted, a look at the types and number of projects being reported should be made. A classification system of course would eliminate any random arrangement of projects. A more specific breakdown would be, should we classify by country (e.2) within a different type of project?

The type of utility service (e.3) is important as well as the type of community it services such as residential, commercial, light industry, etc. This particular item is one in which we can use help. Items $(e .5, .6, .7$, .8 , and .9) indicate the further breakdown of the kinds of classification that can be considered. 
Referring to item e.7, Mr. Cavros raised a question by suggesting that major analytical work be included but not a paper study or calculations, from a project. Mr. Phillips provided an example in this case, by citing a particular project collecting data to establish a data base for part load performance of certain major plant components. Mr. Phillips stated that a program listing of this data base would be of great interest to people who are concerned with synthetizing programs and that he believes the committee understands this idea and will include it in the next write up. There should be more interest in knowing what kind of tools to use for establishing feasibility instead of a feasibility study itself.

Mr. J.Michel stated that it would also be interesting to know the kind of tools used for establishing the feasibility of simulations, etc.

Item $\mathrm{f}$ - Type of Graphics, Printing, Binder - Mr. Phillips asked if there is any reason why the catalog needs to be other than an easily reproduced form such as looseleaf as opposed to a hardback cover. Since the time frame for the catalog is tight, a typewritten looseleaf book would permit changes up to the last minute prior to printing. Mr. Simon replied that he was agreeable to this, others agreed by concensus.

Mr. Phillips asked Mr. Harris how CCMS material was published. Mr. Harris replied by describing the precedent for CCMS publications.

Publications are open. 200 copies or so are given to the NATO Secretariat and they are distributed to technical libraries, universities, and to whomever requests them. The cost of doing the printing is generally picked up by the lead country. Some of the CCMS publications have been copyrighted. This committee must address this question. We have generally in the U.S. put the information which has been gathered into the National Technical Information Service (NTIS) and in the case of energy information, it has been put into the ERDA* Energy Data Base as well. In this case, it will probably be placed in the HUD Data Base also.

In response to a question by Mr. Rothenberg, Mr. Harris replied that the advantage of a copyright is that it would protect a document from commercial venture. It could prevent a person from recopying a document possibly changing it and selling it for a profit.

Mr. Harris agreed to investigate the legal details of publishing a document within CCMS and will furnish Mr. Phillips the details.

A further discussion arose (among Mr. Van den Bergh, Mr. Grjebine, Mr. Harris and Mr. Phillips) about obtaining a copyright for the book. Mr. Harris pointed out that even should CCMS acquire a copyright for a particular document a limited number of coples could be supplied the representative of each country who could duplicate it for distribution to experts within their country with CCMS approva1. The copyright for example would protect the catalog from being published by someone who would take improper credit for the catalog.

*ERDA is U.S. Energy Research and Development Administration 
Looking at items $j, k$ and 1, Mr. Phillips asked Mr. Harris whether the catalog should be distributed on the basis of national participation, for example, an individual in a country would act as the agent and he would decide whether to give the catalog to a commercial industry. Mr. Harris replied that present CCMS policy is that CCMS in Brussels will make the publications available to experts performing research, technical institutes, universities, engineering firms, etc. upon request. In the case where a book distributor is seeking the catalog for a client, CCMS would simply tell the book distributor to inform his client that he must make the request direct to CCMS in Brussels. Mr. Phillips further raised the question concerning item $k$, how does the copy read when CCMS advertises or identifies the availability of the catalog in a technical journal, newsletter, etc.? Would we not have to identify who is eligible for a project catalog?

The placement of the catalog in GPO*, NTIS**and the number of copies that should be printed was discussed. It was agreed that the catalog should be made available to as many people as are interested in the catalog.

Item 1 - The number of copies of the catalog required was discussed which can be summarized as follows: Each country will be provided several initial copies. The expected number of countries receiving copies would be about 23, 10-15 copies would be provided each country. Thus about 500-1000 copies would be required.

\section{Project Summary Form Review}

Mr. Nimmo distributed two working drafts, Proposed Project Summary Form and proposed Project Progress/Evalution Report forms. Also distributed was a summary of comments received from members of the Data Format Committee and a revised form reflecting the Secretariat's interpretation of the comments. Mr. Phillips discussed briefly the purpose of the Project Summary Form and the Project Progress/Evaluation Report Form. As the committee reviewed the Project Summary Form, the following comments were noted:

Box 8 - "Research" may be too restrictive a word. A commercial project, not research in nature, may be willing to supply data. Change "Purpose of Research" to "Purpose of Project".

Box 6 - Change "Duration of Research" to "Duration of Investigation". It was pointed out that the instructions on how to complete the form, which is provided with the March 10,1976 version will be updated and supplied with a11 forms sent to participants for completion. Also words in italics, to aid in describing the desired information will be included in the next revised form.

Mr. Phillips summarized by saying that the next step would be to revise the Project Summary Form to include all of the comments received from the committee, transmit it very quickly to the Data Format Committee for review allowing a quick turn around, then upon finalizing, transmit to all participants for completin the form.

*GPO is U.S. Government Printing office

** NTIS is National Technical Information Service, U.S.A. 
Mr. Phillips stated that the Project Progress/Evaluation Report Form requires a great deal more work and that he would like as many ideas as possible. If you as an engineer consult the catalog and see a project that interests you, for example, the Julich thermal storage project, you might determine that you would like to know more about the project. In this case what additional information would you like to see in a progress report. That's what the Project Progress/Evaluation Report format is about. It is not the format for the final report. Mr. Knobbout's committee will cover that.

Obviously, this report cannot contain all of the engineering data one might wish to have. Assume that in your organization you have an engineer who can review this report, reporting back to management, and who can assess whether the project would be worthwhile pursuing and learning more about. This report would serve to provide enough information for one to understand and define the project and judge its worth to his organization or himself.

In view of the need for more work on this report form and help from you, the committee, we will have at least two more iterations of this report form that we will mail to everyone participating in the program. Any comments that you make now and in the next few weeks will be incorporated into this document. This report is a very important adjunct to the project catalog.

Mr. Phillips asked Mr. Harris where the progress/evaluation report might fit into the publication status. Obviously, a project that has not begun or has only begun would have very little information to provide. Suppose you have a project that ran for a year or two and you have some data, what is the publieation limitation for that kind of data. Mr. Harris responded that preliminary data would require one to go to a loose-leaf format in order that it could be updated. Mr. Phillips, as an example, mentioned the preliminary data from the Jersey City Total Energy Plant which was handed out at the 2nd CCMS-MIUS Project Meeting in Apeldoorn. Mr. Phillips pointed out that the U.S. has received some very useful criticism on the data. Some have pointed out errors in the data. It was distributed as preliminary data, not published data. As a result of this distribution some very valuable comments have been received and the published data will benefit from this critique.

Mr. Cavros questioned the check-off part of the report as opposed to narrative type suggesting that perhaps a narrative would be better and also questioned the nature of the progress/evaluation report.

Mr. Phillips replied that this was a first pass, an attempt to identify the kind of information that should be in a report and that we were trying to arrive at a format that wasn't totally random, the type of progress reports that would come from many different organizations. The format shown here doesn't mean that you would have to use this particular document and check-off each item. It does mean that these are the things needed to assess the value and nature of a particular project.

Mr. Van den Bergh stated that this format should be limited to the statement of the function of the requirements of the system and the basic design data. 
At this point Mr. Phillips pointed out that should an organization already have a progress report that includes the information called for in the Project Progress/Evaluation Report form, that all that would be required would be for it to submit the progress report. Perhaps the organization's progress report includes more information than is required. The main purpose of the CCMS report form is to identify the minimum requirements to assess a Total Energy or MIUS type project for its value or use to the inquiring organization and to compare projects. If an organization has a progress report that covers these minimum requirements, then no additional report or form needs to be prepared or furnished. Of course, a consiscent format from project to project is very helpful from an inquirer's viewpoint.

Mr. Knobbout's Committee will also explore this same rather sensitive question this afternoon. Do you dictate to an author on how to write a report? The answer is no. But you do have a right as an engineer to say that if you write a final report about a project, would you please cover all these elements and would you tell me about accuracy, the true nature of the data. He would also like to know where did you get the information, how good was the instrumentation, etc.? This report form should be a base. We would not want to restrict receiving more information.

Question about publication of Progress Reports - Mr. Phillips addressed Tex Harris as follows: For example, let's say a progress report was 3 inches $(7.5 \mathrm{~cm})$ thick and $2 / 3$ of it were computer printouts. Suppose the U.S. as the lead country has said that it will make reports avallable to anyone that wants them. The U.S. would need to be very careful in its commitments until it saw the variety and quantity of information that flows. If the U.S. agreed to assume the cost of printing or reproducing these reports, it might elect to drop all the appendices and instruct the inquirer to write the author for the appendices.

The Project Progress/Evaluation Report will also make the Project Summary Form more useful. There may be projects that never result in the completion of a Project Progress/Evaluation Report. However, the Project Summary Form should indicate the probability that the Project Progress/Evaluation Report will be available. That is one of the boxes on the form.

Mr. Simon suggested that prior to the next meeting that the Project Progress/ Evaluation Report form be circulated among CCMS-MIUS project participants for completion or compliance on one of their projects for testing. This would also permit each participant more time in examining and commenting on the report form. As Chairman of the Data Format Committee, Mr. Phillips agreed that he would proceed with this suggestion. 
A discussion followed concerning the approval and circulation of the Project Summary Form. There was some concern that the review and completion of the Project Summary Forms might be delayed due to summer vacations, etc.

(At this point the meeting was adjourned for lunch).

Mr. Phillips reconvened the meeting after lunch and summarized the Project Summary Form action items.

The immediate task is to get the comments assembled into a draft of the Project Summary Form. NBS will get the revised draft to each participant for review. We will give you a reasonable time, 2 to 3 weeks, to provide us with your comments. If you have no comments, then we will make multiple copies of it available to each of you and ask that you begin to complete the form for those projects in your country that you consider candidates for the catalog. If you can have them completed by the time of our fall meeting we can begin assembling the catalog.

There has been some confusion about the longer form (Project Progress/ Evaluation Report form). It does not have as high a priority time target as the Project Summary Form describing the projects. Between now and the time we complete the Committee's work next Spring, we would hope that some of these projects would have Project Progress/Evaluation Reports. In the interval between our Fall meeting and our Spring meeting the Data Format Committee will be concentrating on completing the format and the guidelines for preparing the Project Progress/Evaluation Reports.

A question arose if the forms have to be written in English. Mr. Phillips replied that it would be helpful to us as the Secretariat in expediting the forms, but that they do not have to be completed in English. If they are not prepared in English we will deal with the necessity for translating as the problem arises.

Mr. Simon commented on the second page of the draft Project Summary Form. He recommended changing "plant location" to "project location" and he questioned the base for heating degree days $(18,19$ or 20?) and stated that cooling degree days (hours above $267^{\circ} \mathrm{C}$ ) should be 25,26 , or 27 not $26.7^{\circ} \mathrm{C}$. He also commented on the other technical data. It was agreed that $\mathrm{Mr}$. Simon would provide written comments later. Mr. Phillips acknowledged the difficulty of the technical data.

Mr. Gilli stated that the instruction sheet distributed to the research workers should have a few sentences telling what CCMS is and what MIUS is. It should include a short definition and then start with the technicalities. 
He also suggested that a time limit be placed on how far back completed projects are considered, such as 2 years. He also suggested that this be clarified in the instructions.

In item 12, Mr. Cavros asked what is meant by "data available in a form applicable"? Mr. Phillips replied that many plants have information in the records, but nothing for distribution. Will there be documentation with test data available reflecting the results of their project?

Mr. Rothenberg stated that if there is no data then the Project Summary Form should not be completed. Mr. Phillips pointed out that defining data (what constitutes data) is in question. Estimates or design data could be acceptable.

In item 13, Mr. J. Michel recommended that we specify the mean expected heat power ratio for total energy systems on which an estimate has been made, peak and average.

Mr. Zyss recommended that the source of energy used, coal or gas be included in the technical data. Also suggested was the payback period. Mr. Van den Bergh indicated that he had sent comments in the form of a revised form.

Mr. Phillips concluded the Data Format Committee meeting by thanking the participants and briefly sumarizing the action items (Refer to previous portion of minutes).

\section{TASK 2 MEASUREMENT TECHNOLOGY COMMITTEE}

Mr. Phillips introduced Mr. J.A.Knobbout of the Netherlands, and Chairman of the Measurement Technology Committee. Mr. Knobbout explained the scope and goals of this activity.

He distributed a draft of a measurement technology chart which described the reporting requirements (Refer to Attachment 4). He stated that it is the first draft and that he wishes inputs from the group with the hope of improving the document. What do we want to know? The approach will be to arrive at a document which will guide project investigators in preparing their final report in order that sufficient data is provided for comparing projects and evaluting results.

Referring to the Introduction, Mr. Knobbout read through items 1-5 outlining the measurement technology phasing. We are trying to follow the systems approach looking at MIUS as a whole system, what's coming in, and what's going out of it, then observing the interactions of the subsystems. Referring. to Figure 2, Mr. Knobbout went through the inputs and outputs. He next described Figure 1 a more detailed diagram (abstracted MIUS) explaining that the interconnecting lines are whatever the actual output - input might be. In the case of the incinerator some fuel may be necessary to ignite the solid waste and to keep it burning, etc. This is now shown in Figure 1 . It was pointed out that one of the inputs on the left side of the diagram could be electricity for a MIUS that was a grid connected system. Mr. Gilli made a point that one input could be solar energy. Mr. Mangialiajo made a point about noise being an input, that it should be measured. Mr. Phillips then described the noise experience the U.S. has had with the Jersey City 
Total Energy plant. Mr. Pillar poisted out the difficulty they have had in Germany measuring noise. There was agreement that regardless, noise has to be measured. Mr. Van den Bergh pointed out the necessity of including engine vibration as well as noise.

There were questions concerning the incinerator output. It can be steam, hot water (completely open). There was a question as to whether we actually anticipate an incinerator in MIUS as opposed to pyrolysis or methane gas. Mr. Phillips replied that the incinerators are generic and that pyrolysis or methane gas could be possible in a more sophisticated system. There was a question of whether MIUS was limited to present technology or whether we go with a system of future technology (solar, etc.). A discussion ensued on the question of whether or not instrumentation should stay within the boundary of known systems and their performance. Mr. Rothenberg pointed out that HUD has been very careful not to apply anything to the public sector which is not completely reliable and available off the shelf (tried and tested hardware).

Mr. Zyss asked if the diagram is an actual system and does it include everything. Mr. Knobbout replied that it is only hypothetical and that the diagram hopefully would include most cases. There are so many schemes and possibilities that it is difficult to cover all in this type of document. It should be what we should measure and in what way. Mr. Rothenberg pointed out the diagram is a typical conventional MIUS.

Mr. Zyss pointed out that we should possibly add heat storage and heat extraction such as by heat pumps.

Mr. Phillips then raised the question, where does the utility system stop and the end-use begin. Are we talking about things inside of the building that use these utilities? For example, take a typical building to be tied into MIUS with a fired-bofler and electricity for mechanical cooling there clearly must be some conversion device in place of the boiler. When bringing in chilled water for cooling versus electrical cooling you have actually affected what is inside the building. The MIUS "black box" may depict the point of conversion. Perhaps you have a heat exchanger instead of a boiler. Buildings already in existence may not be a candidate for tie-in with a MIUS because extensive equipment conversion or retrofit might be necessary. Mr. Cavros raised the question that instrumenting the end-user or building for load monitoring might be a difficult problem.

Mr. Rothenberg pointed out that the degree to which one instruments the supply to the load and the return from the load depends on the particular application and what you call a load, its configuration and at what point is the delivery. If you have a large distribution system you would probably measure outside each building. The distribution losses would be considered part of the load. You also might have to reconsider where you instrument, and what you penalize with the losses the MIUS or the building. 
Mr. Phillips stated that part of the purpose of the committee's work is to look at those systems which will lend themselves to research feedback. A commercial application of a MIUS would be interested in different measurements, etc.

Mr. Rothenberg pointed out that we are trying to avoid extrapolations and certain assumptions when comparing systems. We need systematized comparison rather than customized information.

Mr. Phillips stated that if one is concerned about the economics of a TE plant then the annual seasonal efficiency should be at least 65 percent. If one plant has an annual seasonal efficiency of 40 percent and another 70 percent then one would want to know what the components are doing and what is different. Component efficiencies etc. can make considerable difference. Annual seasonal efficiency is the ratio of usable (delivered) energy out to the point of use to total energy into the system over the period of a year.

A prime mover may be low in electrical efficiency and high in waste heat recovery. For example a turbine produces a relatively low electrical efficiency and a high waste heat recovery potential when compared with a diesel. Also important in the choice of a prime mover would be whether your load demanded a high thermal output and a relatively low electrical output or vice versa.

A discussion followed on the effect of the building efficiencies, and the line losses when distributing chilled and hot water (in the case of a MIUS) as opposed to distributing air in the case of a conventional system. Losses may be different.

Mr. Cavros stated that in designing a system you have to optimize, but for the purposes of instrumentation you must take a physical plant which someone has designed and determine how you will instrument it. Mr. Rothenberg said that from the practical point of view in the U.S. it is characteristic to predict an optimum building system designed for the private sector in comparison with a maximum efficiency MIUS. Our approach for a building system will be controlled by traditional thinking unless the building owner hires a planner knowledgeable enough to consider future systems. For 90 percent of construction you have to design a system that will fit the traditional concept of a building design.

A discussion followed with Mr. Simon and Mr. Zyss pointing out the necessity of considering the efficiency of the housing units and the impact the users have on performance when comparing MIUS's. Because of these impacts Mr. Knobbout and Mr. Cavros felt that it was a matter of appropriate instrumenting of the energy flow into the housing units whether by steam, hot water, chilled water, electricity, etc. 
Mr. Knobbout continued his discussion of Figure 1 (Attachment 4) describing each subsystem and its relationship to the overall system. Also refer to "Description Subsystem" Page 3 of Attachment 4. During the presentation on item 8, air cooler/cooling tower, Mr. Phillips pointed out that the New Jersey Total Energy Plant has an emergency heat dump, which is part of the primary hot water loop (part of primary subsystem). Should the air coolers and/or cooling tower fail, hot water is discharged to a drain through a heat exchanger which extracts the heat. This should be considered. Mr. Knobbout asked if an aerobic wastewater treatment should be left in and Mr. Phillips replied that it should as the potential is available with MIUS.

Mr. Knobbout stated that drying, burning, and use of effluent was not considered in his description of sewage/waste water treatment. Mr. Rothenberg suggested that the use of effluent be included under the functions as it could be used for lawn sprinkling and in case of fire. Mr. Knobbout added an ANNEXE (Appendix) for consideration by the committee on the type of measurements to be made and accuracy of specific measurements. During this presentation the following comments were noted: Mr. Rothenberg suggested including the lubrication oil temperature. $\mathrm{Mr}$. Phillips pointed out that there possibly should be two circuits, one for the water jacket and another for the muffler. Mr. J.Michel suggested that the PCI (heat value) of the fuel be measured in addition to the flow and temperature in and out. Mr. Van den Bergh asked if the electricity out was the net power of the prime mover. Mr. Knobbout replied that it was the net power out of the generator. Mr. Piller suggested an analysis of the exhaust gases as there is $\mathrm{CO}$ being discharged.

In response to a question by $\mathrm{Mr}$. Van den Bergh about where do you intend to measure the power out. Mr. Phillips stated that you must measure power out of the generator and/or, preferably both, the parasitic losses and useful output to the load. Under generator performance, Mr. Knobbout pointed out that we are not measuring mechanical energy out of the prime mover, but electricity out of the generator.

A discussion followed on the measurement of mechanical energy, heat, etc. from heat pumps. Mr. Phillips pointed out the difficulty of measuring shaft power from a prime mover delivering shaft power to a heat pump, etc. Usually machine efficiencies are accepted.

Mr. Knobbout moved on to the heating system discussion, Page 6 of Attachment 4 .

Mr. Van den Bergh pointed out, under "performance", that since it is agreed that it is difficult to measure mechanical shaft power can you use "fuel used" to produce mechanical power? Mr. Knobbout pointed out the fact that the measurement as identified is theoretical and crucial and should be dealt with as practically as possible.

Mr. Knobbout proceeded to discuss hot water production, boilers, artificial coolers, chillers and wastewater and sewage. Mr. Phillips pointed out, that in the case of the wastewater sewage, some systems may use heat in and this should be measured. 
There were several comments on various known experiments where there is heat input. Mr. Piller indicated that Dr. Shaefer would probably have some experiences to share with the measurement technology task regarding wastewater and sewage processing.

Next Mr. Knobbout proceeded to incinerator performance, pointing out the uncertainty of measuring solid waste composition as it is constantly changing. He felt that one would need to know about the composition. Sampling in this case would seem important. Mr. Phillips pointed out that the U.S. is looking at using a calorimeter to measure heat value of solid waste at intervals (burned in sealed container and measured).

Mr. Knobbout proceeded with the Interface from the complex to the MIUS (the last item listed in Attachment 4 for measurements) and thus completed his overview of what he believed were the required measurements.

He then asked the committee to comment on the following questions?

a) Are these measurements as outlined difficult or not difficult to take?

b) Is this approach realistic?

c) Is this the way we should go to get the best performance data?

d) Should we approach the question of measurement technology for MIUS differently?

e) In what way should we proceed?

Mr. Piller pointed out that there will be difficulty in finding projects that have the means to instrument a plant to the degree outlined. Mr. Cavros stated that these measurement requirements presented could be considered guidelines for pilot plants.

Mr. Phillips commented that the requirements being discussed would lend themselves to research projects rather than commercial plants or facilities. Mr. Cavros stated that we should also consider the minimum measurements that an operating plant should conduct.

Mr. Phillips pointed out the necessity of many measurements by giving an example at the New Jersey Total Energy Plant (NJTE). It was discovered that about $35 \%$ of the recovered waste heat from the engines was being lost due to a malfunctioning heat exchanger. The extensive instrumentation made it possible to diagnose and correct the problem.

Mr. Rothenberg affirmed the idea of minimum instrumentation versus full instrumentation indicating that the determining factor would be the purpose or need for instrumentation? Are you conducting a full research plant or operating a commercial venture in which you must perform some minimum checks? 
Mr. Phillips pointed out that the extensive part of instrumenting a plant is the data collection system which, when automated, can be tied into a computer to take periodic readings and store the data for instant recall. The sensors are considerably less expensive and are the same instruments from which an operator might manually acquire readings. The sensors need not be any more accurate for the simple system as opposed to the sophisticated one.

One of the things that should also be addressed in the measurement requirements is how do you take the data? Do you have a technician with a clip board recording readings at intervals or do you have an automated system recording readings at frequent intervals?

Mr. Van den Bergh pointed out the importance of calling attention to the location of instruments in the measurement requirements. Instruments used in the operating process could be located such that they could serve a dual role, both for process and for experimentation.

In conjunction with this idea Mr. Phillips pointed out that NASA in the U.S., one of the U.S. agencies in the HUD-MIUS Program, has a strong feeling that process control should be upgraded and experimental control reduced and that both should be served by the same sensors integrating the process control with that of experimental control.

Mr. Van den Bergh also pointed out that experimental control could be important and of interest to the operators and to the owners. Mr. Phillips added that at the NJTE plant data showed a situation where the boilers were operating when they shouldn't have been operating; investigation showed that the temperature controls were set such that the operation of the dry cooler emergency dump and the minimum temperature of the water 1oop were not coordinated with each other. Thus the dry cooler would come on and then the boiler would come on to satisfy the temperature control demand. Why was the boiler on when the dry cooler was on? This further raises the question, what do you do with data when you have it. How do you analyze it and use it, in order to prevent the plant from becoming counterproductive particularly where you have integrated systems?

Mr. Cavros stated that the minimum requirements could require extensive study and wondered if there was any experience with the HUD-MIUS on this subject. Mr. Phillips then identified a forthcoming report on the MIST (a test bed at NASA for the MIUS which can be used to produce insights to MIUS performance and instrumentation).

Mr. Simon pointed out that so far as the measurement requirements stated in Mr. Knobbout's paper are concerned, he knows of no plant in France or Europe that could provide all of the measurements. He suggests that for these plants that performance be based on a scaled down version of Mr. Knobbout's paper such that essentially fuel-in, power-out and thermal energy out over a period of time (such as a year) would be used. Mr. Phillips replied that he believed once the project begins to comply with the measurement requirements guidelines that more data could be supplied than one might believe at this time. 
A discussion followed on the importance of two levels of measurement, a level of measurement which is practical to evaluate an operating plant and another level of measurement for a detailed evaluation. If one builds a plant on the basis of a feasibility study, then once the plant has been built and is operating there must be measurements to test, confirm, or justify the feasibility studies. These measurements would be the minimum level of measurements. Maybe what is needed is two columns, one for minimum operating measurements and another for minimum research or experimental measurements. A short discussion by Mr. Simon, Mr. Van den Bergh, Mr. Cavros, Mr. Knobbout, and Mr. Phillips followed on the method of determining fuelinput (deliveries, metering, etc.).

Mr. Knobbout at this point summarized the discussion concerning two levels of requirements. Mr. Simon then stated that the aid is, first of all, to get data, then make the comparison.

Mr. Phillips stated that in view of the discussion the question is what are the minimum things that can be measured without which you cannot compare one system with another and what are the techniques for doing that in terms of the least expensive.

Another thing, one should look at the trend as one tries to combine a more sophisticated operating control system with the kinds of instruments that would also satisfy an analysis system.

Mr. Rothenberg asked, how do you (Mr. Simon and others in Europe who must measure fuel) certify bulk delivery data? For example, you need the amount of fuel flowing, how much is consumed, its temperature and BTU value. The amount of bulk deliveries must be compared and confirmed with the actual fuel flowing from the day tanks (usually by metering). Mr. Simon agreed with Mr. Rothenberg but said that plants in France do not presently have means to accomplish fuel measurements and are not operating in such a manner. Mr. Rothenberg then said that this may be the case, aside from the HUD-MIUS, but if we want data then fuel measurements must as a minimum be conducted.

Mr. Simon replied that he does not believe all metering as described could be afforded by those plants in Europe. Mr. Simon then characterized fuel measurement in European plants. He was of the opinion that the plants, however, do know their fuel inputs without the extensive metering Mr. Rothenberg was describing.

Mr. Grjebine presented an example by stating that they have one set of data which is at the producing center and another set of data from the user. (Output from one and the input from another). When dealing with figures that are just rough energy figures there is insufficient data. He further discussed the difficulty that would exist in comparing different European systems without sufficient data, geographical data and the importance of user parameters. 
Mr. Harris then described a computer model associated with another CCMS project, the transmission of heat through water systems. A computer model is being developed at Battelle Northwestern that is applicable to district heating. The computer has some district heating data collected and stored. Data is being collected from 4 plants, data from the U.S. and Iceland. Mr. Harris at this point offered to have a paper delivered to the CCMS-MIUS Project Committee if they so chose. The chairman requested that he do so.

Mr. Grjebine discussed briefly the importance of the economic feasibility study having sufficient data and being conducted with consideration for all influencing factors. Economic studies may fall short of this. Inflation, discount rates, etc. can possibly over drive the performance data.

The Chairman closed the meeting at 5:00 pm

ECOND DAY, May 19, 1976

The meeting was reconvened May 19, 1976 at 9:25 am by the Chairman, who changed the agenda slightly, by distributing the May 19, 1976 Glossary of Special Terms unique to MIUS in English, French, and German. Mr. Phillips assured the committee that changes can be made if errors are present, and $\mathrm{Mr}$. Harris will advise the Project Chairman what is the mechanism for publishing the Glossary, as it is viewed a potential CCMS publication.

No additional action was required, the Glossary having been approved at the last CCMS-MIUS Project meeting.

The next item of business was the report of the Data Format Committee and the Measurement Technology Committee.

\section{Report of the Data Format Committee}

Mr. Phillips as Chairman of the Data Format Committee summarized the previous day's activities concerning the Project Summary Catalog and placed a tentative schedule on the blackboard for overall committee consideration, as follows:

Revised Summary Form

Out for Review

Comments received and coordinated

Final Form Distributed to Participants

Participants to review and complete

forms for their projects and send to

U.S. (Secretariat)

Secretariat to Prepare Final Forms

Assemble Catalog

Final Catalog approved for distribution
June 1976

July 1976

August 1976

Sept.-Dec. 1976

January 1977

Feb. - March, 1977

April - May 1977 
The U.S. Will prepare and distribute the revised summary form. During August we will send out to you working copies so that you can distribute to your research workers as you see feasible.

Early February we will coordinate, translate and assemble a catalog in draft form and get it to you in time that you can review it prior to the meeting time to be set in April or May 1977 (time to be set at the December CCMS-MIUS Project Meeting). At that time we hope to get the group's approval of the catalog in a form that could subsequently be printed and distributed.

In parallel we will continue to redefine with your help a recommended format for the Project Progress/Evaluation Reports to go with the catalog and hopefully would have this recommended format and guidelines in your hands at the time the catalog is completed. The mechanism for collecting and disseminating these reports should be decided at the December 1976 meeting. Also we must decide how one would use the reports and who would collect them. In that same time frame we will be looking for an organization to carry-on any follow-on activity necessary for the project catalog in the next few years. The Project Progress/Evaluation Report would not impact on the project catalog and would simply augment the project catalog.

In order to identify these dates and each step and the rationale for each step a complete set of minutes will be provided to our CCMS-MIUS projects' mailing list. Distribution of the minutes will be to the participants and to those who have identified interest in the CCMS-MIUS project (about 114 individuals from 23 countries).

Mr. Knobbout then provided the schedule for the Measurement Technology Comittee's work.

\author{
Prepare Second Draft \\ Distribute Second Draft to \\ Participants \\ Comments Rec'd and Revised Draft Comp'd \\ Final Revised Work \\ Final Draft Approved
}

$$
\begin{aligned}
& \text { June } 1976 \\
& \text { July-Aug., } 1976 \\
& \text { Nov.-Dec., } 1976 \\
& \text { Jan. } 1977 \\
& \text { April - May } 1977
\end{aligned}
$$

Mr. Phillips agreed to coordinate with Mr. Knobbout on an updated mailing list (names of participants).

In response to a question by Mr. Harris, Mr. Knobbout replied that there would be two levels (minimum and maximum package) of measurements defined, as had been discussed the previous day.

Mr. Mangialajo asked would it be possible to discuss the Jersey City Total Energy plant at the next CCMS-MIUS Project meeting in some depth. Mr. Rothenberg replied that it could be done and the Chairman was requested to schedule a presentation. 
Mr. Simon, in regard to the Measurement Technology Committee's task of developing a standard methodology for measuring the performance of a MIUS, suggested that a task force from the European members be formed to work on the tasks between CCMS-MIUS project meetings. This met with approval of those in attendance.

Moving on to the next agenda item, Mr. Phillips asked if there were any new project tasks that the committee should address? Mr. Harris, referring to the agenda item concerned with research needs, suggested that the group consider the research and development areas which are important to the continuation and development of a MIUS. The comittee should tell the CCMS how this area should be pursued either by the various governments or corporations. The Chairman said that he would consider setting-up a task group, preferably with European leadership to coordinate the European interests. There were no additional tasks recommended.

Mr. Phillips then asked for help in recommending effective dates and places for the fall meeting. Mr. Phillips replied that the U.S. would like very much to hold the next meeting in the U.S. but would not like to propose a location that would jeopardize any one's attendance. The committee responded that to hold the meeting in the U.S. (mostly European attendees) would pose a problem due to the cost. Mr. Harris stated that the meeting could always return to Brussels if necessary.

Mr. Phillips stated that Dr. Klein had previously indicated FRG's willingness to host a future meeting at an appropriate time and asked the attendees if that would be a suitable meeting place. The reply was affirmative. Mr. Phillips then asked if Great Britain would be an acceptable alternate location for the meeting? The reply was affirmative. Then Mr. Phillips stated that he would pursue with $\mathrm{Dr}$. Klein and Mr. O'Neil, if necessary, these possibilities.

Mr. Rothenberg suggested that Brussels be kept open as a third alternative if either Germany or Great Britain could not host the meeting. Mr. Phillips discussed the meeting date, and it was agreed that November 30 to December 2 : 1976 would be the first choice and December 7 to 9, 1976 would be the 2nd choice. The Netherlands representatives also stated that the next meeting could be held there.

Mr. Van den Bergh and Mr. Gilli then amplified a point which also was made the previous day, that there should be a short description of a MIUS in front of the documents (Catalog and Project Progress/Evaluation Report) to be filled-in to help experts, participants and those completing the forms understand what CCMS-MIUS and the project are, and their purpose.

Mr. Gilli further stated that he had given written comments to the Chairman including this and other information and recommended that they be included. 
Mr. Rothenberg stated that Mr. Phillips and Mr. Nimmo had prepared two guldance documents whlch actually cover the points made by Mr. Van den Bergh and Mr. Gill1. As a result, Mr. Phillips and Mr. Harris agreed that these two documents could be handed out as privileged information to the participants. Mr.Phillips pointed out that these two documents were written from the U.S. Role and Secretarlat viewpoint to guide the U.S. in their responsibility.

Mr. Phlllips then stated that minutes of this meeting will be sent out and will contaln a confirmation of the date and place of the next meeting.

\section{PROJECT DESCRIPTIONS}

The Chairman stated that at this time one of the most useful exercises of our meetings has been the opportunity to hear from each of the participants some comment on projects in their current state of activities that they feel are of interest to the MIUS project group. The discussions started around the table ( 1 imit to 5 to 10 minutes).

U.S. (Mr. Rothenberg - HUD)

The current activity in HUD with NBS support is the HUD-MIUS Program. Also supporting HUD are other agencies such as ERDA, Oak Ridge National Laboratory. now part of ERDA, NASA, HEW, etc.

The HUD-MIUS Program is basically a 3 phase program. Phase I is Technology Development; Phase II, MIUS Demonstration and Evaluation; and Phase III Technology Transfer.

Phase I should be completed this year with the preparation of the final documentation about 10-15 additional publications. We have prepared a list of HUD-MIUS publications including abstracts. We will provide you with a copy. (Copies were passed around to attendees). We will endeavor to provide copies of these documents upon request as they are available. Please glve your request to Mr. Phillips.

Mr. Rothenberg displayed several HUD-MIUS publications. One pertained to the development of candidate concepts, several on the coal-fired MIUS concept which is being sponsored jointly by HUD and ERDA, another on water supply and treatment, and another on a closed-cycled turbine associated with the coal-fired MIUS concept.

The HUD-MIUS Program is trying to address most of the concerns of Technology Assessment, not only what the technology is, but what the long term impact will be. It will be more than an impact statement on the country and energy use. We will be receiving more model studies from Oak Ridge and NASA on actual communities. NBS is responsible for the performance specification, which is the basis of the MIUS performance, and against which it will be evaluated.

Two documents were prepared on the CCMS-MIUS, one describing the U.S. role in the CCMS-MIUS and the other role of CCMS-MIUS as viewed by the CCMS-MIUS Secretariat (Copies of these two documents were provided to attendees earlier). 
Mr. Rothenberg described the status of the T.E. Project at Jersey City, New Jersey. The hook-up of the buildings (instrumentation sensors, etc.) has been completed. Data has been collected over the past several months. The month of April showed a savings of about $13-14 \mathrm{~K}$ gallons of fuel. Typical data from the plant reveals about 25-35 percent savings of fuel as compared with typical conventional system. If you will recall, a data package of the New Jersey $\mathrm{TE}$ data was made available at the last meeting. Data acquisition and processing has generally been excellent except for several critical areas such as fuel measurements. In the case of fuel measurements, new instrumentation is being installed to improve the accuracy of measurements.

The start of a grid-connected total energy study is underway with a contract to be signed with the San Diego Gas and Electric Company which supplies an industrial community. Help in planning this study was received from Commonwealth Edison of Chicago and the Edison Electric Institute.

On April 8, HUD issued a grant to the Interstate Land Development Corp. to prepare the preliminary design concept and costing for a MIUS Demonstration plant at St. Charles, Md. (copies of several newspaper clippings were made available to attendees). The MIUS Demonstration plant will be designed, constructed and operated by the developer. HUD with NBS support will instrument, acquire data, and evaluate the plant. The objectives of the demonstration are to: demonstrate the technical performance of the MIUS, the public benefits involved, the viability of private sector ownership and operation of a MIUS, and to provide a data base for the evaluation and analysis of MIUS. This particular MIUS is dedicated to serving a portion of a new town at St. Charles, Maryland, near Washington, D. C.

Mr. Rothenberg showed a set of slides on the new community at St. Charles, site of the HUD-MIUS Demonstration plant. The new community of about 8000 acres is located in a beautifully wooded area of virgin forest, 25 miles from Washington, D. C. The MIUS will be built to serve one of the villages consisting of about 800 dwelling units on a tract of land about 130 acres in size. The units served by the MIUS will include: high, middle and low-rise apartments; garden apartments, a village shopping center, a school, a medical building, senior citizen dwelling units and recreation facilities such as a golf course, swimming pools and tennis courts. There will be several villages in St. Charles; the MIUS will serve one of them. The MIUS will be located adjacent to the shopping center or in a wooded area nearby.

Sweden (Mr. Renghold)

Scandinavia as yet does not have so many applications for a MIUS. There are some questions about the work (concerning integration) especially the situations common to Scandinavia. Sweden has MIUS systems that are very open ("not rigidly defined" - editors interpretation) and that are being developed more and more in relation to big district heating systems connected to or combined with big power stations. These stations are usually 100-600 Megawatts and fueled by oil. There are no nuclear plants at present. These stations may be considered as some type of MIUS, not the closed MIUS as we know it (Sweden's plants are not strictly MIUS, but together could be viewed as approaching the MIUS concept - editors interpretation). They_contain some of the MIUS combinations such as heating, water heating, wastewater and solid waste processing, and power generation. The question is can you combine all of these systems and turn them into a MIUS? 
Mr. Phillips replied that the MIUS system is a totally open system, and that no size limits have been placed on the concept. Generally the restriction is the economics of the integration. Mr. Philips could see no reason why 20,000 homes could not be served by a MIUS. In the U.S. there are some who believe there should be a MIUS in every home. A MIUS is not restricted to a new town, old town or the suburbs. It can be an area surrounded by many communities. A grid-connected MIUS (several MIUS's connected together, and they in turn connected to the commercial grid) can reduce the need for redundant spare engines thus reducing the initial capital investment of a MIUS. Mr. Phillips indicated that the U.S. viewed Europe and Scandinavia as having already utilized the MIUS concept. In the HUD-MIUS visit to Europe, 1974, we found the MIUS concept in practice.

Mr. Renghold further explained that power and district heating stations in Sweden are usually locally owned but have not been moved into the MIUS concept. However, it appears that it is convenient and possible to do so.

\section{Austria (Mr. Gilli)}

Mr. Gilli provided to each attendee a copy of a list of projects in Austria related to MIUS. (Refer to Enclosure 5). The ones listed were modular in nature rather than projects where utilities were being integrated. $\mathrm{Mr}$. Gilli pointed out that he would not discuss the modular projects, but would discuss the plans underway for integrated utilities. Austria is much in the same situation as Sweden except Austrian plants are much smaller, about 10-100 megawatts generating capacity. To some extent the idea of having a large network was begun several years ago and discontinued in 1970. Now there is renewed thought of starting the network again. Plants started in the 1950's and 1960's largely provided electric power and heating by steam.

There are some utilities which process solid waste, several of which incinerate the trash and produce steam for power generation heat. These would fall under the broad definition of MIUS. In the late $60^{\prime} \mathrm{s}$ these installations were successful on a large scale in cities, but were less successful in small villages and towns. These towns believed it cheaper to simply dispose of their solid waste. There are about 10-15 plants in Austria on a municipal scale.

Austria has one nuclear power plant coming on-line in one year and another to be ordered. Waste heat will be recovered for heating purposes.

\section{The Netherlands (Mr. Knobbout)}

Mr. Knobbout distributed to each attendee a copy of a performance summary of a total energy installation in the Netherlands (Refer to Enclosure 6). The summary provided an overview of one of the several total energy plants in the Netherlands. This particular one has been instrumented in order to acquire and evaluate its data. The data for 1975 demonstrated that the plant efficiency, electrical efficiency, and engine efficiency have improved since 1974. The load factor for 1974 and 1975 were about the same. The economic calculations showed a substantial increase in savings from 
1974 to 1975. The savings increased by a factor of 2.1 to 1 . The expectations appear good for continued improvement. Based upon the data taken thus far a total energy plant looks very good.

Italy (Mr. Mangialajo)

Mr. Mangialajo accounted for three experiences with total energy in Italy, the Quartiere COMASINA in Milan, Telenscaldamento in Brescia, and the FIAT experiment. The first one was a thermo-electric power plant designed by the "istitutio Antonomo per le Case Popolari" for a housing development of 12,000 inhabitants in the District of Comasina. In 1968 the system which was based on heavy fuel oil was dismantled for economic reasons.

This installation was to be able to generate electricity utilizing the steam enthalpy drop resulting from the pressure differences between the boilers and the heat exchangers serving the district heating system; and the boilers and condenser discharge (serving the power plant).

In order to enable evaluation of the power generation linked with central heating plant and to compile cost data usable for future urban applications, A.E.M. (the utility company) assumed financial and managerial responsibilities of the heating plant by receiving electric energy produced from November 1st to March 31 st amounting to $18,500 \mathrm{KW}$. This represents approximately 40-50 million $\mathrm{KWH}$ annually.

In 1958 A.E.M. contributed to the Institute 6.90 lira per KWH. (This consisted of the electrical generation and transformation losses of $9 / 23 \mathrm{KV}$ ). A breakdown of the above costs is as follows:

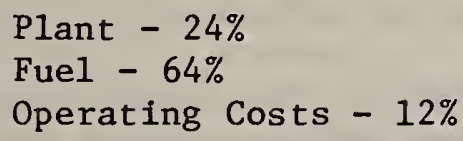

For energy produced and received in excess of 47 million KWH, the Institute allowed an additional discount of $0.51 \mathrm{ira} / \mathrm{KWH}$.

1968 - The plant discontinued power generation for the following reasons:

The plant was designed and built for continuous usage of its total steam capacity (70-75 tons from 3 boilers), increasing power generation whenever heat load requirements are reduced and vice versa. This method of operation generally results in economical operation of the Thermoelectric Power Plant.

Since the operation of the Thermoelectric Power Plant proved economically unsound, it was decided to discontinue generation of electricity because:

A. The heat supplied was less than anticipated (reduced by about 20\%), resulting from fewer consumers than originally anticipated. 
B. Electrical generation was at least $37 \%$ lower than anticipated, of which $22 \%$ was attributable to the boilers and $15 \%$ to a deficiency in cooling water supply to the condensers.

C. Particularly high labor costs due to the high cost of plant maintenance.

The second is a project being pursued by the Azienda Servizi Municipalizzati (ASM) of Brescla (a town 60 miles east of Milan of about 150,000 inhabitants). The municipality is pushing towards connecting every house of the town with a district heating system (teleriscaldamento). At the beginning of 1976, ASM ordered an 18 megawatt boller-turbine system in order to produce electric and thermal power. There are no plans to expand to the full MIUS concept, however, ASM is open to the potential of MIUS technology.

The third is the FIAT experiment. In Turin, FIAT has designed and is beginning a Total Energy System for the cafeteria of its Research Center at Sangone. After construction and testing, FIAT anticipates that they will be able to transfer the plant technology - and perhaps even the plant itself - to an apartment complex for FIAT workers. A copy of the initial project summary form is enclosed. Refer to Enclosure 7.

FRG (Mr. P111er)

In the Federal Republic of Germany, there are a number of energy related projects, several of which are MIUS related. FRG has instrumented a total energy plant which is now being tested and evaluated. There is a study into the possibility of district heating from thermal power plants in the Federal Republic and a planning study for district heating from thermal power plants in the Mannheim - Ludwigs-haten-Herdelbing area.

EDITOR'S NOTE: Mr. Plller described in some detail the total energy instrumented plant, however due to difficulties in transcribing the tape that portion is not included. Mr. Plller will be consulted for help; and the additional material will be provided with minutes of the next CCMS-MIUS Project meeting.

Belgium - (Mr. Michel)

In Belgium they have district heating systems. Only two are working on the MIUS principle. There is a nuclear plant being studied on two basis. One considers using load level temperatures by using (heat peak heat pumps?). The first calculations in this case pointed out that the town with 20,000 people was too small and not dense enough for district heating. Another application in connection with green houses is the use of load low temperature water from the nuclear plant for tropical fruits. Results have been good. 
In the last meeting I discussed two heat recovery systems in Brussels. One is a large office building 100,000 square meters now under development. Another is a center 5000 square meters which was completed in January 1976. A third project is a swimming pool using solar energy combined with heat pumps. We have a National Program of Research covering a wide range of projects such as solar collectors, heat pumps and total energy.

France - (Mr. Simon)

In France there are four big projects. One in northern France will convert a plant to the T.E. Idea. Another is supposed to be built which will employ a gas turbine to supply electricity and heat. In Paris there are two projects, one is to take in old network in northern Paris and surrounding suburbs and provide central or district heating along with electricity; another idea is to use a compound reactor for generating electricity. Another project involves the generation of electricity by compound nuclear reactor with a study of heat pump use.

The last project involves the distribution of hot water from nuclear plants producing 60,000 cubic meters/hour of hot water. Generally, the work in France is directed toward a more efficient use of electricity and investigation of processes that can more efficiently and conveniently use electricity than other forms of energy; expansion of district heating; expansion of nuclear power plants; exploration of the advantages of smaller power plants (such as modular size) as opposed to larger power plants.

United States - (Mr. Steve Cavros, ERDA)

The expanded concept of MIUS that is developing here today covers more and more the scope of our program at the Energy Research and Development Administration (ERDA) that deals with Community Energy Systems particularly integrated utility systems. It lays a foundation for a later and more complete coverage in various programs. I will speak primarily about the scope of our programs. The Community Systems Program is made up of the scope of three basic elements, the central one being Integrated Energy System. Next is a companion one that in a technical sense is community design and urban systems. Dext is institutional problems which we identify as "commercialization". We have some goals. We are primarily concerned with testing the institutional problems of today. This is very similar to what HUD is doing. We are working with other U.S. agencies and institutions such as Universities to get integrated utilities considered. Concerning integrated community energy systems - we are developing a feasibility study of a grid connected integrated total energy system at the city of Pasadena, California. Here we have the cooperation of the mayor, local government, local redevelopment agency of the downtown area and the municipally-owned water and power company. What is interesting institutionally about this arrangement is that this system is based on the following. 
The power company, the utility company will be grid-connected and municipallyowned, the output will go into the grid, and the plant will be thermally loaded to achieve optimum efficiency. The power company will be accepting electrical output from the project and giving the project credit for the power recelved. In this case, you have the system paying the project for standby use instead of the other way around. This arrangement was arrived at primarily becuase the municipality has a need for supply. This arrangement may make the system economically feasible because the feasibility studies show a small heat load in California. The final report will soon be available and by the next CCMS-MIUS project meeting I will be able to report on its progress and if we have gone ahead.

ERDA is also conducting a feasibility study on such unusual things as using cold sea water (there are cold layers of sea water out a few kilometers) in such municipal areas in Florida, Calfornia and Hawaii where there are heavy concentrations of hotels and motels.

We have an effort to move away from scarce fuels, primarily oil and gas. The initiative has already been taken by HUD in the aase of the coal-fired MIUS study. We are looking at the coal-using integrated community energy system and attempting to work out the software program, the analytical tools which will look at all of the possible conversions of the secondary energy form of the gas and direct combustion. We are also studying patterns for the secondary energy form and looking at the community services required, taking advantage of research already complete or being performed by other agencies.

We have a proposal from a university which if accepted and funded will result in an actual fluidized-bed, coal-fired facility.

ERDA has a major long range program, the Advanced Technology Mixed-Energy Systems (ATMES) at the Argonne National Laboratory to be conducted on a multi-year basis. We hope this program will be the central development of future energy systems for integrated communities. This will produce more programmatic information instead of technical information. ATMES is the novel synthesis of existing, emerging and future technologies. Technology outputs of various factions of ERDA will be compiled and synthesized, as we go into the future, and fed back into ERDA with modifications and adaption which will make a subsystem technology perform better.

In two years ERDA hopes to have any analytical tool which will allow us to look at any city or community of any size and be able to simulate with reasonable accuracy the energy consumption of that city. This tool would be used for design as well as for analyzing utility loads, not in terms of peak or average loads but in terms of real time energy consumption, starting with service demands. We hope to place this tool in the hands of the urban designers so they can evaluate their designs.

There is an interest in developing a methodology for combining the science of "oekistics" (human settlements and science) urban design in a demonstration project and the possibility of working with the ATHENS Center of OEKISTICS. 
An analytical matrix will be used to combine the design of settlements, neighborhoods, buildings, community with an energy component to improve energy utilization.

ERDA is also developing mechanisms to reduce institutional and financial barriers associated with integrated utility systems. This will be helpful to municipalities and financial institutions.

\section{GENERAL DISCUSSION}

Mr. Simon further described projects related to MIUS in France particularly at EDF. He stated that EDF has about 100 projects that are concerned with economizing on energy consumption.

Mr. Grjebine commented that in the catalog we should include an economic analysis of the project as a whole and the project broken down into its constituent parts.

Referring to the earlier request for identification of research needs, Mr. Phillips announced that $\mathrm{Mr}$. Michel of Belgium will head a committee composed of Mr. Michel, Mr. Piller of Germany (who will consult Dr. Klein for a designated individual to represent Germany) and Mr. Cavros of the U.S. They will identify research needs in integrated utility systems and identify the priorities. Mr. Michel has agredd to coordinate the activity and prepare a brief report for the December meeting. The U.S., acting as Secretariat, will provide Mr. Michel with a mailing list and the administrative support required to provide this report.

Mr. Phillips and Mr. Harris emphasized the importance of each attendee expressing his ideas on research needs. All attendees should transmit their ideas to Mr. Michel.

Mr. Phillips closed the session on the research needs and turned the meeting over to Mr. Simon to explain and conduct the shceduled tour of EDF laboratories. Mr. Phillips on behalf of the group expressed their appreciation to EDF for hosting the meeting.

$\underline{\text { TOUR }}$

The tour included projects performing research in the following areas:

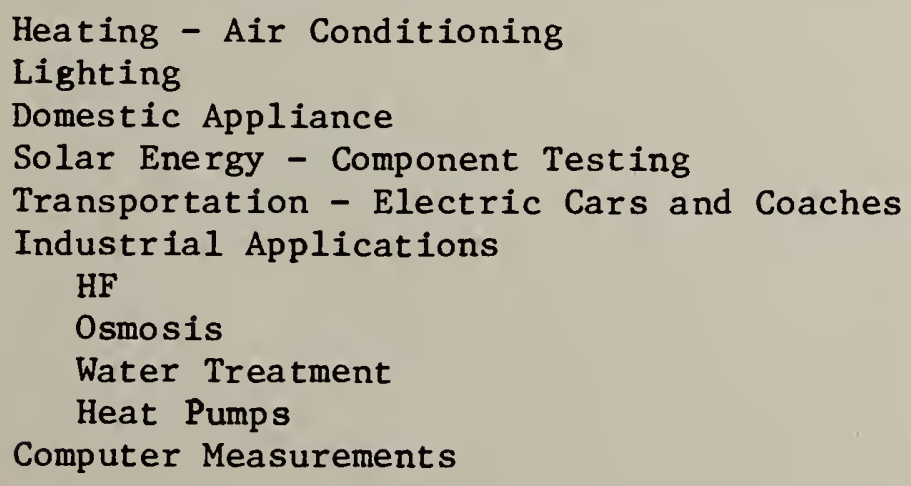



Tasks :

1. Develop a glossary of terms related to integrated utility systems in order to expedite the transfer of information.

2. Develop a "catalog" of MIUS type of projects planned or in progress.

3. Develop a summary report system to highlight quickly research activities and reports. (Integral part of "catalog")

4. Develop a uniform reporting system for reporting progress and evaluating performance of CCMS-MIUS related projects in order that they may be compared with each other.

5. Develop a uniform methodology for the measurement of performance and the taking of and reporting of data related to CCMS-MIUS Projects.

Goals :

1. To provide all participating countries with a current and viable Glossary of Special Terms for the CCMS-MIUS Project by May 18-19, 1976.

2. To assemble and distribute a catalog of project descriptions to all participating countries by January 1977 .

3. To establish a file of Project Progress/Evaluation reports by April 1977 on those CCMS-MIUS related projects for which the sponsors and investigators have agreed to provide data. Information from this file to be available for dissemination to participating countries upon request.

4. To help bring about the development of a standard methodology for the measurement of performance, and taking of and reporting of data resulting from testing of and demonstrations of CCMS-MIUS related projects. 

The following decisions are necessary for implementation of the Catalog of Project Descriptions. Below are suggested alternatives:

a. Guidelines for type of projects to be included.

b. Design of identification number for each form.

1. Sequential as they appear in catalog.

2. A multiple part number.

(a) Section-Country-Sequence

(b) Country-Section-Sequence

(c) Section-Type of Project-Country-Sequence

(d) Section-Type of Project-Sequence

(e) Etc.

c. Contents of the Catalog Front Matter (Introduction)

1. Purpose

2. Scope

3. History and Description of CCMS

4. Participating Countries

5. Instructions How to Use Manual and Organization of Manual

6. Discussion of Project Summary Form and Use

7. Discussion of Three Level Reporting System

8. How to Acquire Additional Copies

9. Preface

10. Cross-Index

11. Others

d. Organization of Catalog

1. Projects sequentially

2. Projects by classification (See e. below)

3. Sections by Classification (See e. below)

4. Multiple Volume (page limit, etc.)

e. Classification System

1. Random

2. Country

3. Utility Service

4. Scale (cost, community served, etc.) 
5. Type of Project
(a) Total Energy
(b) Integrated Utility System
(c) Thermal Storage
(d) Solar

6. Scope of Project
(a) System
(b) Subsystem
(c) Component

7. Purpose of Project
(a) A demonstration
(b) Verification of a technical design
(c) Pilot Plant
(d) A technical laboratory
(e) An operational system

8. Nature of Project
(a) Harware Development
(b) Evaluation of Exdsting System
(c) Feasibility Study

9. Status
(a) Planned
(b) On-going
(c) Completed

f. Type of Graphics, Printing, Binder, etc.

1. Photos of Demonstrations (selected)

2. Photos of Operating Plant (selected)

3. Photos of Laboratory Facilities (selected)

4. Cover Illustration

5. Type written, Typeset, etc.

6. Looseleaf (3-ring, multi-ring) bound (soft cover, hardback)

g. Who will Publish

1. COMS

2. COMS-MIUS Project

3. U.S .
(a) NBS
(b) HUD
(c) EPA
(d) DOS

4. Other Participating Country

h. Should the Catalog be published with copyrights?

1. Methods of Financing the Printing and Distribution of the Catalog?

1. CCMS-MIUS Project (Contributions by Participating Countries)

2. Secretarial

3. Price per copy 
j. Should the catalog be made avallable upon request to recipients outside the COMS-MUS Project?

k. Should avallability of the Catalog.be publicized or announced outside the CCMS-MIUS Project? If so, to whom?

1. The number of coples of the catalog required. 

Comments received on Proposed Project Summary Form:

1. Comments from the Netherlands

During the last meeting it was assumed that also MIUS related projects dealing with some special features incorporated in MIUS projects were also of interest.

Therefore I would suggest the following comments on the project Summary Form.

- CCMS-MIUS PROJECT SUMMARY FORM to be read as CCMS-MIUS AND MIUS RELATED SUMMARY FORM

- Add one box in which is indicated which utilities are provided for as:

- electric supply

o heating

o cooling

- solid waste treatment

- sewage treatment etc.

\section{Comments from Italy}

(a) I think the Summary Form should also be aimed at making the selection of MIUS-like projects easier, in order to facilitate preliminary comparisons prior to the consulting the Reporting Formats.

But even such a rough selection can be made only if some essential technical data can be excerpted from the Summary Form itself.

Otherwise one would have to have recourse to the Reporting Format for every MIUS project.

In view of the foregoing, I think it will be necessary to provide the Summary Form with some technical data, such as e.g.: 1. Plant location

2. Degrees-day at the site

3. Maximum available (thermal and electric) power of the plant

4. Type and size of users residential ... dwelling units commercial $\ldots \mathrm{m}^{2}$ industrial .... Mw (th. + elec.)

5. Services supplied

i) Electric power

ii) Residential heating

iii) Residential cooling

iv) Sanitary hot water

v) Waste Treatment 
vi) Water Treatment

vii) Commercial and/or Industrial heating

v11) Commercial and/or Industrial cooling

With this kind of data available on the Summary Form I think a preliminary screening is indeed feasible.

(b) In order to introduce the above data into the Summary Form $1 t$ will be necessary to modify the selection of and the space allocation for the different items in the form. For example, it seems to me that the space allotted for items 8) and 9) should be reduced, with more detalls devoted to the Reporting Format, without-however-impairing the quality and the amount of information required for a Sumary form-based preliminary screening.

Comments on the Project Progress/Evaluation Report form are represented by the attached revision. 


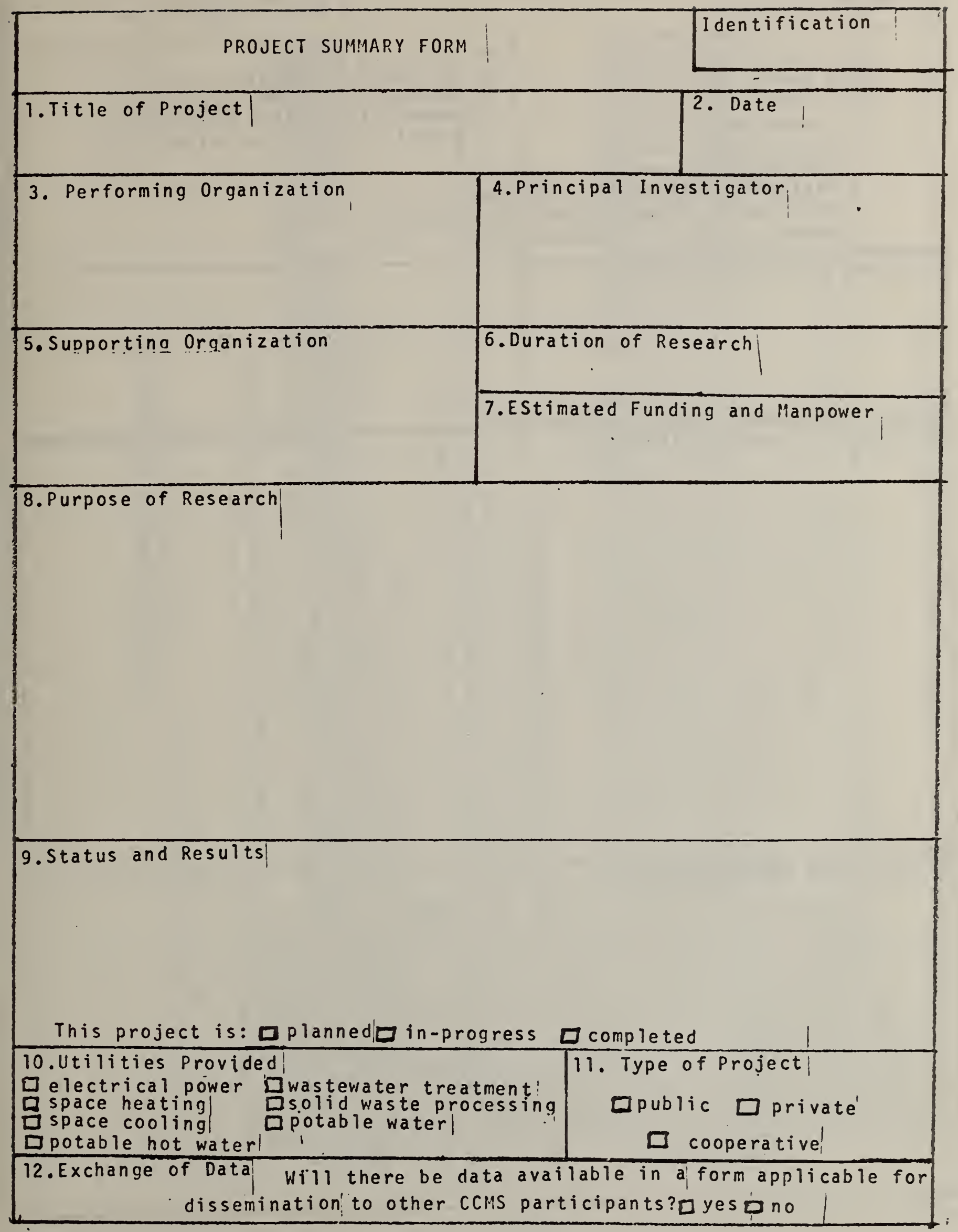




\section{Technical Data}

plant locationi- - degree-days (at site) hours above $26.7 \mathrm{C}-\cdots$ plant capacity

a. power(HW) $-\ldots$

b. heating $(M W)--\ldots$

c. cooling (MW) - - -

d. Wastewater treatment-liters/day $-{ }_{-}-{ }_{-}$

e. solid waste processing-kilograms/day--

f. potable water-liters/day - $\ldots+\ldots$

\section{Identification, no.}

Type and size of user

a. residential (dwelling units)---

b. residential square area-m? - -

c. commericial square area-m $m^{2},-\ldots$

d. industrial (thermal+elec.-MW)--

14.0ther Related Projects

8. Purpose of Research(cont.)

9. Status and Resuits(cont.)! 
$\stackrel{4}{2}$
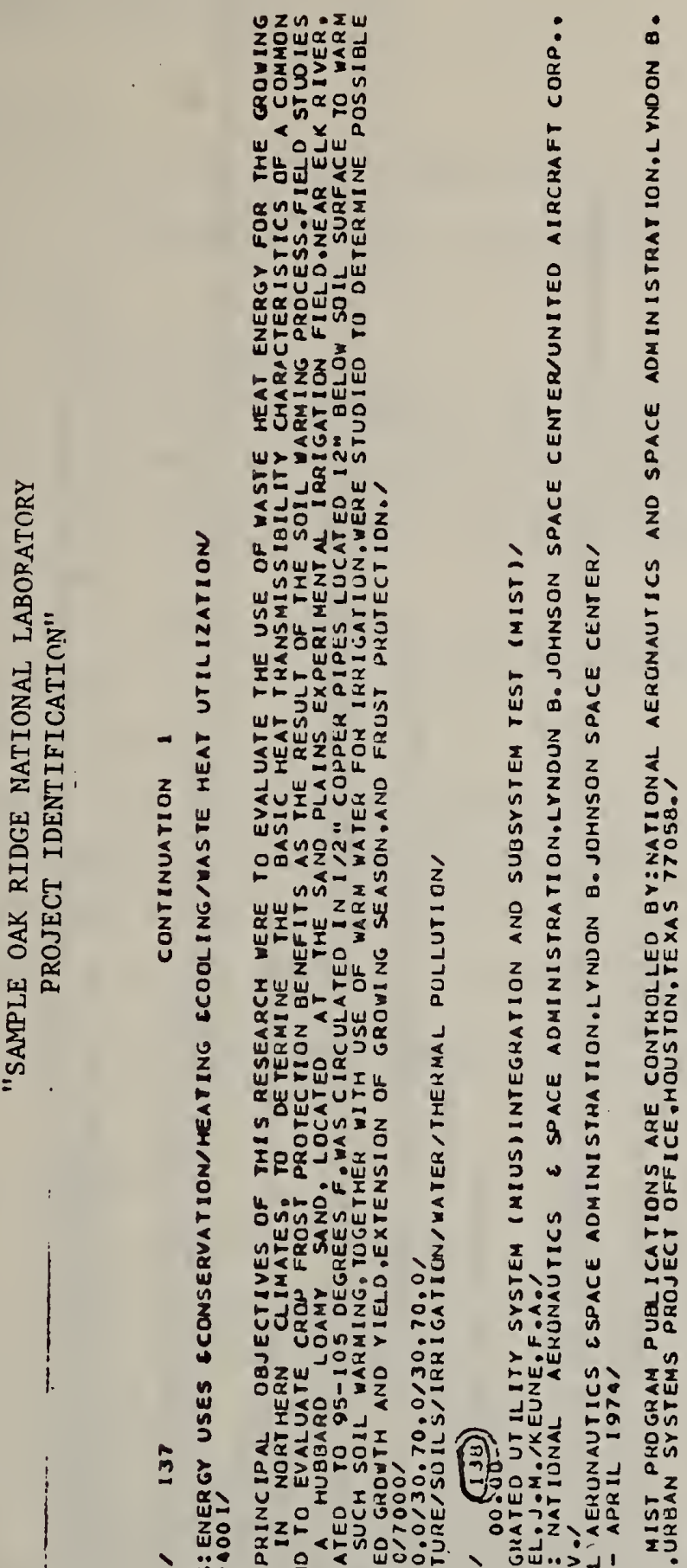

แ山山<யnznO nuz

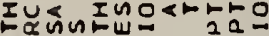

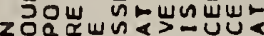

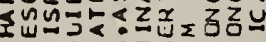
-

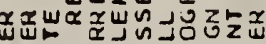

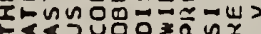

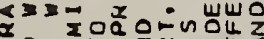
a

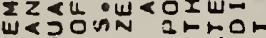

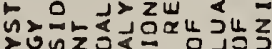

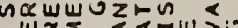

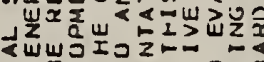

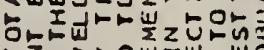
-

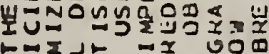
- I I J

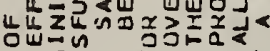
山以

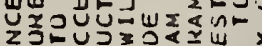

iे

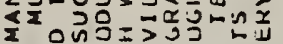

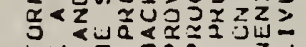

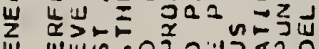

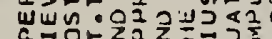

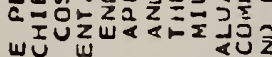

a

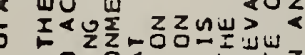

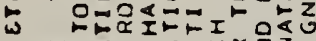

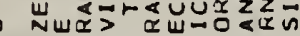

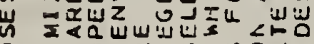

$\supset$

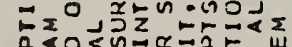

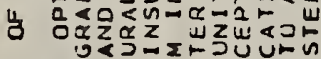

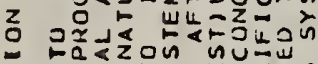

$\bar{F}$

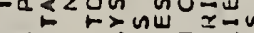

$\underline{2}$

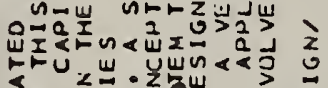

类

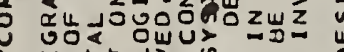

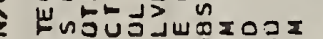
年

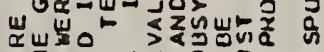

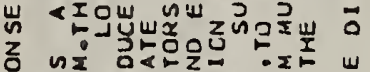

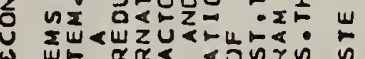

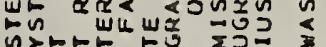

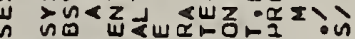

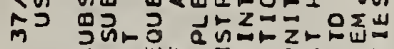

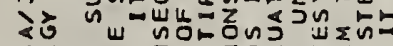

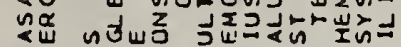

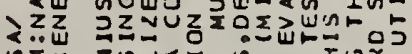
咲出 in:

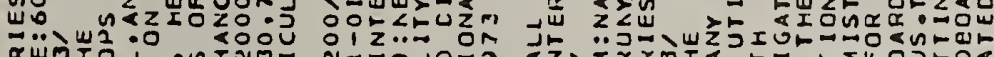

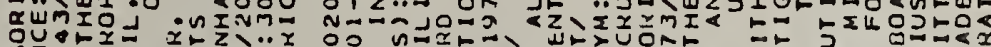
忌:..

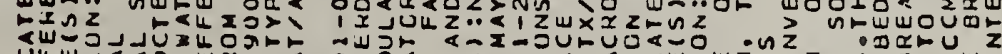
Uu

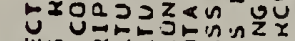

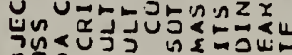

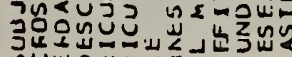

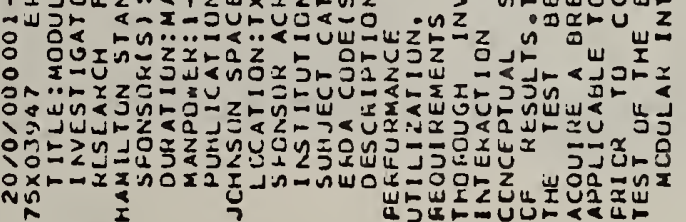




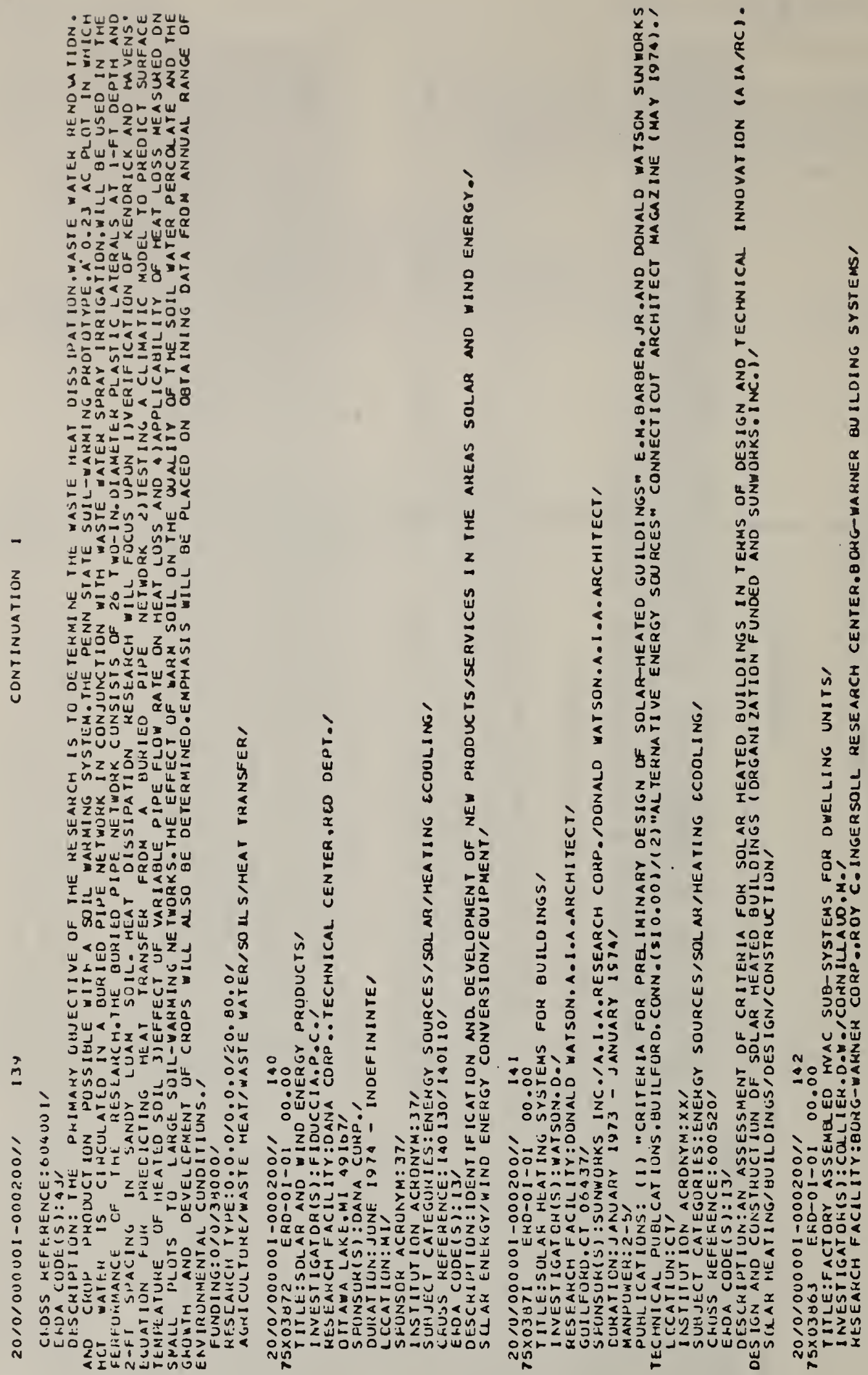


Measurement Technology

\section{Introduction}

The CCMS-MIUS project has a number of objectives, one of which is the streamlining of the exchange of data concerning tine layout of the MIUS and its performance.

The main documents are:

- Reporting format for community total energy systems

- Reporting format for MIUS and total energy systems.

The underlying document covers the measurement technology and its phasing is as follows:

1. evaluation of the conditions to be measured for calculation of the system's performance

2. interface data

3. evaluation of the required specification of the sensors

4. assessing the crucial measurements from a comparison of the rcquired specification and the state of the art

5. evaluation of the field for further development of measurement technology.

Remark: This draft document contains only the phases 1 and 2.

\section{Ceneral Remarks}

There are many rules and standards concerning the moasurement of the pertormance, both static and dynamic, of the elements in a MIls system. This applies to the national and international rules and itandards. The rulcs and standards can be applied under more or less ideal laboratory conditions. The aim of this dorument is to present a basis of practical rules or codes to ensure thit the measurements are executed in such a way that comparison of different HIUS systents is possible.

This means that the accuracy of the neasurenents should be acceptabla (this vill, in general, be lower than can be reached under lahoratory conditions). The fact that the measurements are executou under practical conlitions means:

- the conditions are not constant

- the conditions cannot be controlled. 
The aim of this document is to present the basic ideas that are applicable to a large number of MIUS systems. This means that for unusual or complicated MIUS systems the basis developed here is sufficiently broad to be applied in the sense of the objective of this project.

Figure 1 presents an abstracted MIUS system. The MIUS system consists of a number of subsystems, which each have a certain function (it is thus not important in what technical way this function is realised).

The lines between the subsystems give the interrelation between the subsystems rather than the piping system as such. No indications are given as to how the subsystem is connected to the main system (for instance the air cooler and the emergency water cooler).

Not only the MIUS system is essential, but also the buildings as a syster are equally important, like the static and dynamic response to changing conditions. In the attached scheme a dynamic approach is envisaged.

In this document no attention is paid to the data acquisition system and the processing of the data, one of the reasons being that the processing highly depends on the layout of the project, the objective of the project and the geographical conditions. 
1. Heat/power installation

Function: to convert fuel to electricity and heat in the form of:

- hot water for heating

- hot water for domestic hot water

- steam

The elements of the subsystem are the prime mover, the heat exchangers, the exhaust gas heater or steamboiler, oil cooler etc. with their controls.

In this.definition the type of prime mover is not relevant and the definition applies to a gas engine as well as a steam or gasturbine as prime mover.

The electrical generator, with the cooling and controls are elements of the subsystem.

2. Boiler

Function: to convert fuel to heat in the form of hot water or steam. The pre-heating of the fuel (if required) or water treatment is part of the subsystem.

This subsystem is incorporated in the total system and the feedwater comes from the steam or hot water circuit.

3. The hot water production for heating

Function: to produce hot water at the desired temperature and flow for the heating of the building.

As the hot water from the subsystem 1 is directly used the subsystem contains only the circulation pump as element. Other elements can be: a heat exchanger or a heat pump to elevate the temperature of the water. The heat pump is driven by an electric motor and generates the possibilities to balance optimally between heat and power production.

4. The domestic hot water production

Function: to produce hot domestic water.

Elements: heat exchanger with transport pump or heat pump if the -temperature is too low and there is an excess of power. 
5. The cold water production (chiller)

Function: the production of chilled water for the A.C. installation. Elements of the subsystem: The chiller can be or a mechanical driven compressor system or a heat driven absorption refrigeration installation, or a combination.

It is supposed that an electric motor is used to drive the compressor. The pumps are also electrical driven (for large installations a direct driven (gas engine or turbine) refrigeration installation is appropriate)

6. Solid waste incenerator

Function: to convert solid waste to ash, under production of heat. Depending on the caloric value of the solid waste extra fuel has to be added or not.

The main elements of this subsystem are:

- a solid waste burner and boiler

- ash storage and transport.

7. Storage dryer solid waste

Function: to store the solid waste and eventually to dry the solid waste.

Elements: - storage bunker

- drying section

- air ventilator, etc.

It is supposed that the dryer is heated with the hot water or steam.

8. Air cooler/cooling tower

Function: under conditions that there is an excess heat production the release of the excess heat to the environment.

This situntion can arise in a number of conditions and also of a view point of control: and or reliability one ore more coolers has to be incorporated in the system.

For instance:

- condensor chiller

- emergency watercooler for the prime mover

- release of excess heat. 


$$
\begin{aligned}
\text { Elements: } & \text { - air cooler } \\
& \text { - cooling tower } \\
& \text { - water cooler, cooled by ground water, or tap water. }
\end{aligned}
$$

9. Sewage/waste water treatment

Function: to digest the sewage and waste water in such a way that the effluent can be discarded

(criteria: environmental rules)

and the sludge can be also discarded.

In principal this subsystem can be an anaerobic or aerobic digester.

Elements are:

- pretreatment (mechanical separation of water and large objects)

- digester with air circulation (aerobic) or with methane production (relevant seems the aerobic digester)

- often treatment installation (if necessary) (dephosphating or denitrification)

- separation effluent - sludge installation (sludge decanter)

\section{ANNEXE}

The best accuracy of the measured performance of some installations under practical conditions.

Remarks: the accuracy is given for the nominal conditions and installations of medium capacity.

1. Heat/porver installation, performance $5 \%$

- produced electricity $0,1 \%$

- efficient heat production

2. Boiler

- overall performance medium

- small boilers

3. Hot water production for heat in

- overall performance

4. Domestic hot water production

- overall performance

5. The cold water production

- overall performance 
- fuel input

- heat value

- electricity output

- in and out watertemperature and flow

- idem from the stack

\section{Generator}

Per.

included in prime mover

System for heating

(heat exchangers or heat pump)

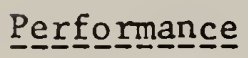

- electricity or mechanical power

- temperature water in and out

- flow of water

- temperature heat source in and out

- flow water from source

Hot water production

as water for heating

\section{Inte- $\underline{\text { rffasce }}$ \\ - flow hot water \\ - temperature water}

\section{Boilers}

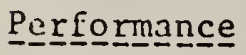

- fuel flow (and quality)

- outlet gas . flow

$$
\text { - temperature }
$$

- steam flow and conditions

- water temperature in and out

- water flow

\section{Int트트므ㅁㅗㅡㄹ}

- electricity

- temperature water and flow to:

- heat pump

- heat exchangers

- chiller

- air cooler

- solid waste dryer

\section{Intㅡㅡ르므믈}

- distribution of electricity

\section{Intㅡㅡ로므믈}

- flow hot water

- temperature water 


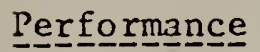

- water flow

- temperature water in and out

- electricity consumption

- water consumption

- inlet air temperature and humidity

- idem outlet air and flow

- cooling water temperature in and out

- flow of cooling water

\section{Chiller (electrical and/or absorption type)}

Per fó

- power consumption

- temperature cold water in and out

- flow cold water

- hot water temperature in and out

- flow hot water (steam flow and conditions)

- condensor water temperature in and out

- Elnw condensing water

Waste water and sewage

(no recuperation of heat from waste water)

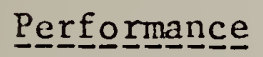

- temperature and flow of water inlet

- composition (BOD and COD)

- power consurption

- temperature and flow water outlet

- composition (BOD and COD)

- sludge flow and dry material

\section{Intㅡㅡ르므ㅁㅗㅡ}

- water flow

- temperature of outlet water

\section{Inte- eㅡ므믈}

- flow and temperature of chilled water

- outlet temperature of condensate and flow

- temperature and flow of cooling water 
$A=$ drying section

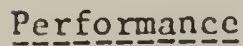

- hot water temperature in and out

- flow hot water

- temperature in and out of air (and humidity)

- flow of drying air

- power consumption

- flow of solid waste

- composition solid waste

- overflow solid waste

B

\section{Perffoormance}

- power consumption

- solid waste flow and composition

- temperature air in and out (and quality)

- temperature water in and out and flow

- ash; composition and flow

\section{Interface from the Complex to the MIUS}

1. heating

- temperature water and flow

2. hot water (domestic)

- nothing.

3. cooling

- temperature cold water

- flow cold water

4. sewage water

- flow water

- tempcrature water

- composition

5. solid waste

- quantity

- composition (more special humidity and heat value).

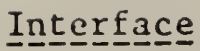

- outflow solid waste

- composition solid waste.

\section{Inㅡㅡ토드므믈}

- temperature and flow of the heated water 


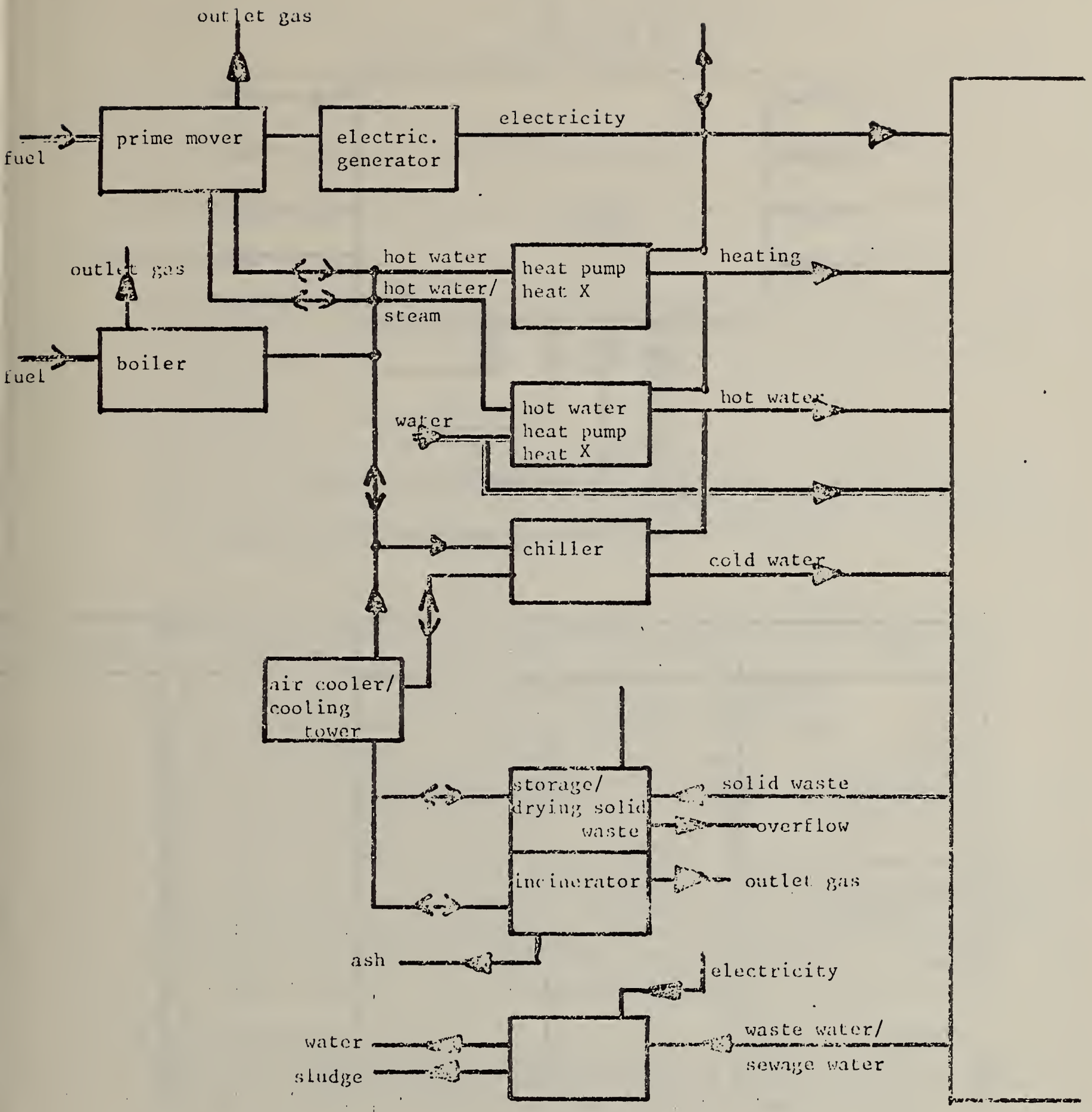

Figure 1. Abstracted MUUS. 


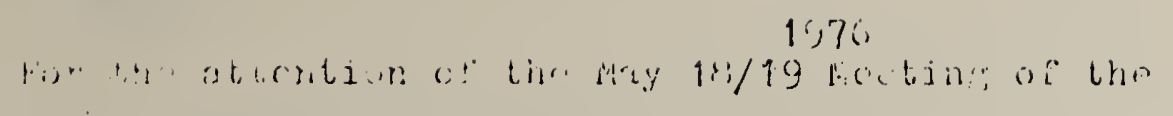

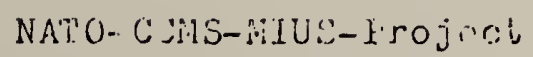

\section{Sone Aidsirjian MIUS-irojects}

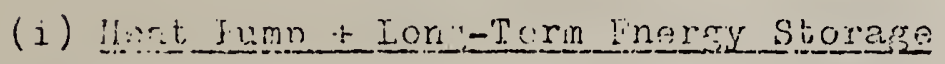

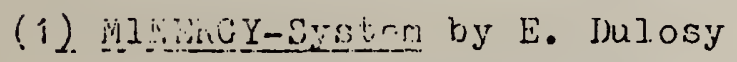

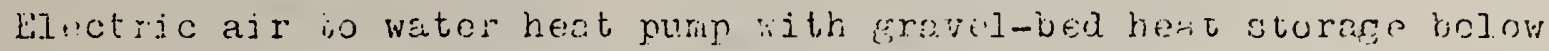

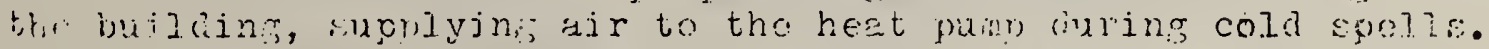

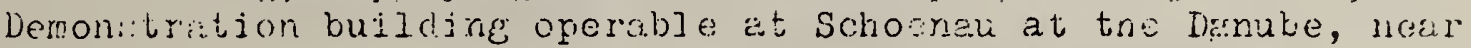
Vinnizis.

(2) Ien stornes

sup lying hout to heut purap by freezing watcr, vithout pinsur in the storage tank. Inborntory-scale prototype, demon-tratin-r tha:

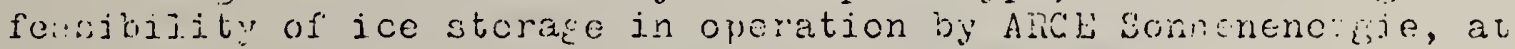
Inititute oi fh rwal lower and Nuclesr Enginsering, Graz Univerejty of liechnolory.

(ii) Ifote inter ient Becovery

(3) Domorsiration plant for ari apartment buliding (planned)

(jij) Sol: rever.y for doneatic hot water and heating

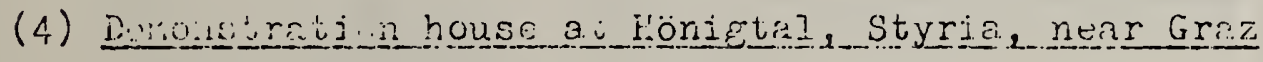

by hiue Sonfrenersie, sponsored by the Austrich linistry of Builcinäard Techrology, in oyeration since sumper 1975

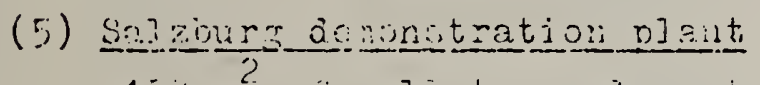

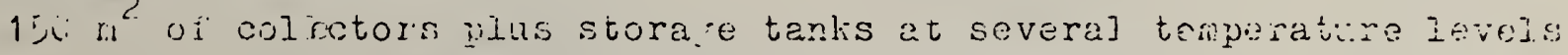

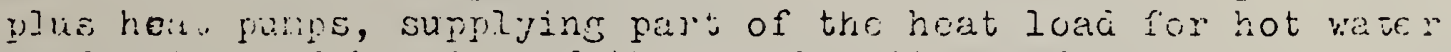

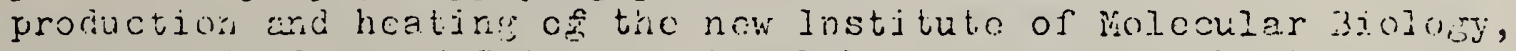

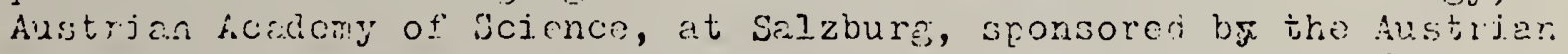

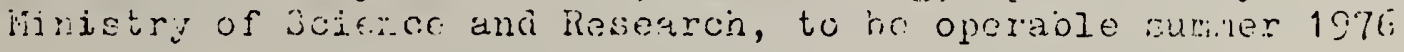

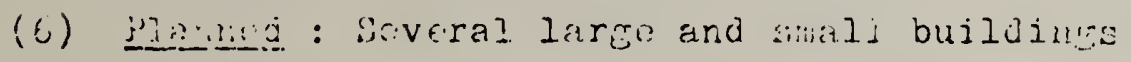

(iv) Esor bentrion Iover

Planici : Vory small ( 10 to $50 \mathrm{kj}$ ) solar thernil eloctric power nlant, nainly for devclopinz; countrifs of low latituac.

J. V. Gj].1j

Griz, Har 14, 1976 


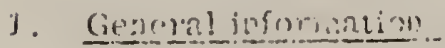

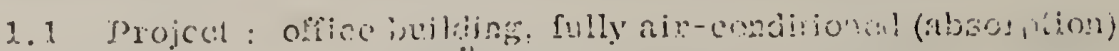

1. 2 Caipacity : $6 \mathrm{l}, 2) 0 \mathrm{n}^{3}$

1. $\therefore$ Emplovecs: 1,100 persoms

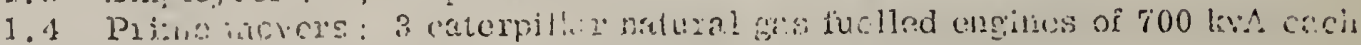

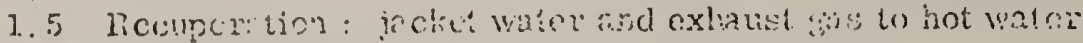

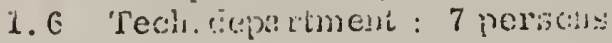

2. Pereorinacio data

2.1. Tinancial

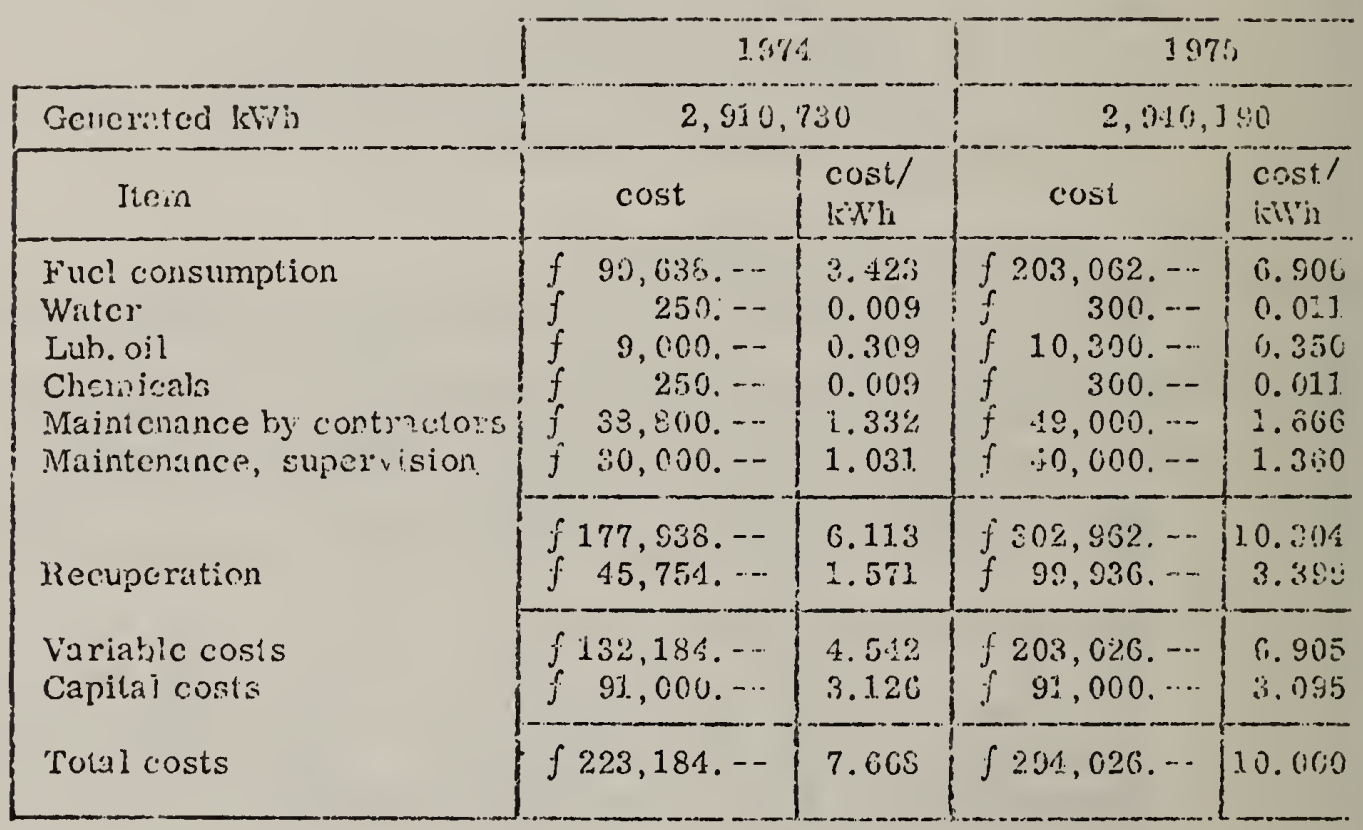

\section{2 linergy}

$-137.4$

$-1975$

$-1974$

$-1975$

- 1974

- 1975

$-1974 !$

- 1975

$-107 ! 1$

- 1975

$-\quad 197 \div$

$-1.975$

- $199^{\prime} \cdot 1$

$-197 ;$
Energs to ergines: $1,315,167 \times 7,560=9,912,81.4 \mathrm{Mcri}$ Sncigy 10 engires: $1,313,000 \times 7,560=-9,926,280 \mathrm{Mcal}$ Energy to hoilers: $\quad 250,200 \times 7,500=1,847,512 . \mathrm{Mc}: 1$ Energy to boilcrs: $\quad 280,461 \times 7,500=2,150,285 \mathrm{Mic:}$ i

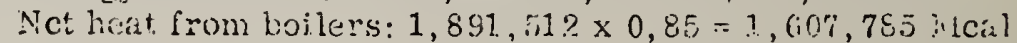

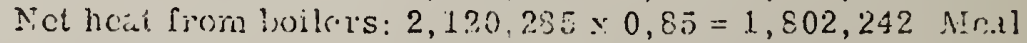
kWh to Mcal: $2,910,730: \because 860=2,503,228$ Mral

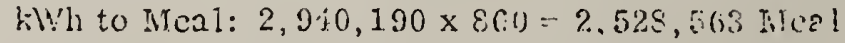
Gross het recovered from engines: $4,447,900 \mathrm{Mical}$ Gross heat recovered from engines: $4,0.30,300$ hical Not beat recorered: $4,417,500 \cdots 386,500=4,061,400$ Nical

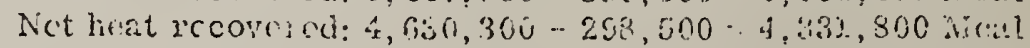

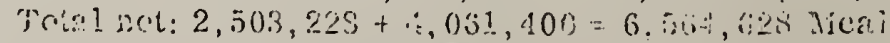

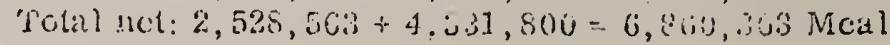




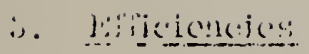

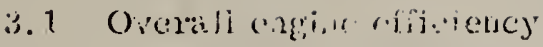

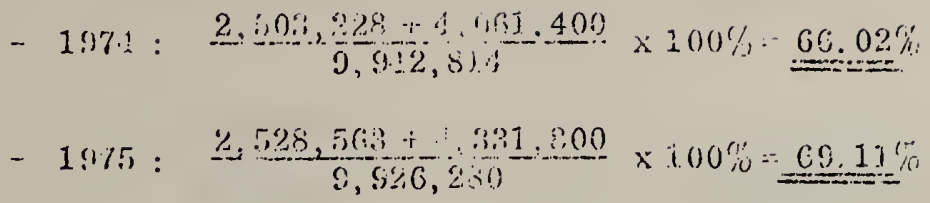

3.2 Decirical off cicncy

- $10,74: \frac{2,501,228}{0,012,814} \times 1.00 \%=25.18 \%$

$-19^{\prime} 15: \frac{2,528,500}{5,326,280} \times 100 \%=25.47 \%$

3.3 Installation efficieney

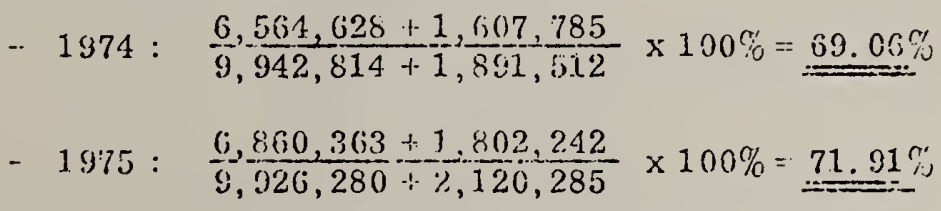

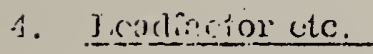

\subsection{Loadfactor:}

$-1974: \frac{2,910,730}{600 \times 8,700}=0.3699 \quad(900=2 \times 450 \mathrm{~kW}$ max cuso atmon;

$-1975: \frac{210,190}{900 \times 8,760}=0.373$

4.2 Average load:

- 1974: $\frac{2.910,739}{14,501} \cdot 200.73 \mathrm{lW} \quad(14,501$ hours/a)

and $\frac{200.73}{540} \times 100^{\prime \prime}: 2 \% .17 \%$ of max. output per unit

$-1975: \frac{40.1900}{13,234} \quad 22 \%, 10 \mathrm{~kW} \quad(13,238 \mathrm{~h} / \mathrm{a})$

and $\frac{2010}{510} \times 3.00 \%=\frac{4.15 \%}{=}$ of max. outiout per unit 
1.: Max. inoll hosus/s

$-197 x: \frac{2910,530}{900}=3,204$ hours

$-1975: \frac{2,940,190}{900}=3,267$ hours:

\section{Recuperation}

The savings accouding 2.1 are $f 45,754,--$ and $f 99,936 .--$ for 1974 resp. 1975.

Calculated as follows:

$-1974: \frac{4,061}{7,560 \times 0.85} \times \frac{400 \times 1}{2000} \times 0,07239=f 45,751 .$.

$-1975: \frac{4,331,800 \times 1,000}{7,560 \times 0.85} \times 0,1.4825=f 99,936 .--$

CV/IA (hr. Jongrelijh)

d.d. .11 mei 1976 


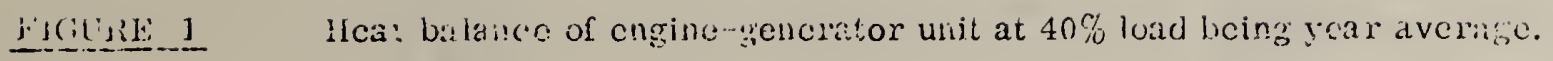

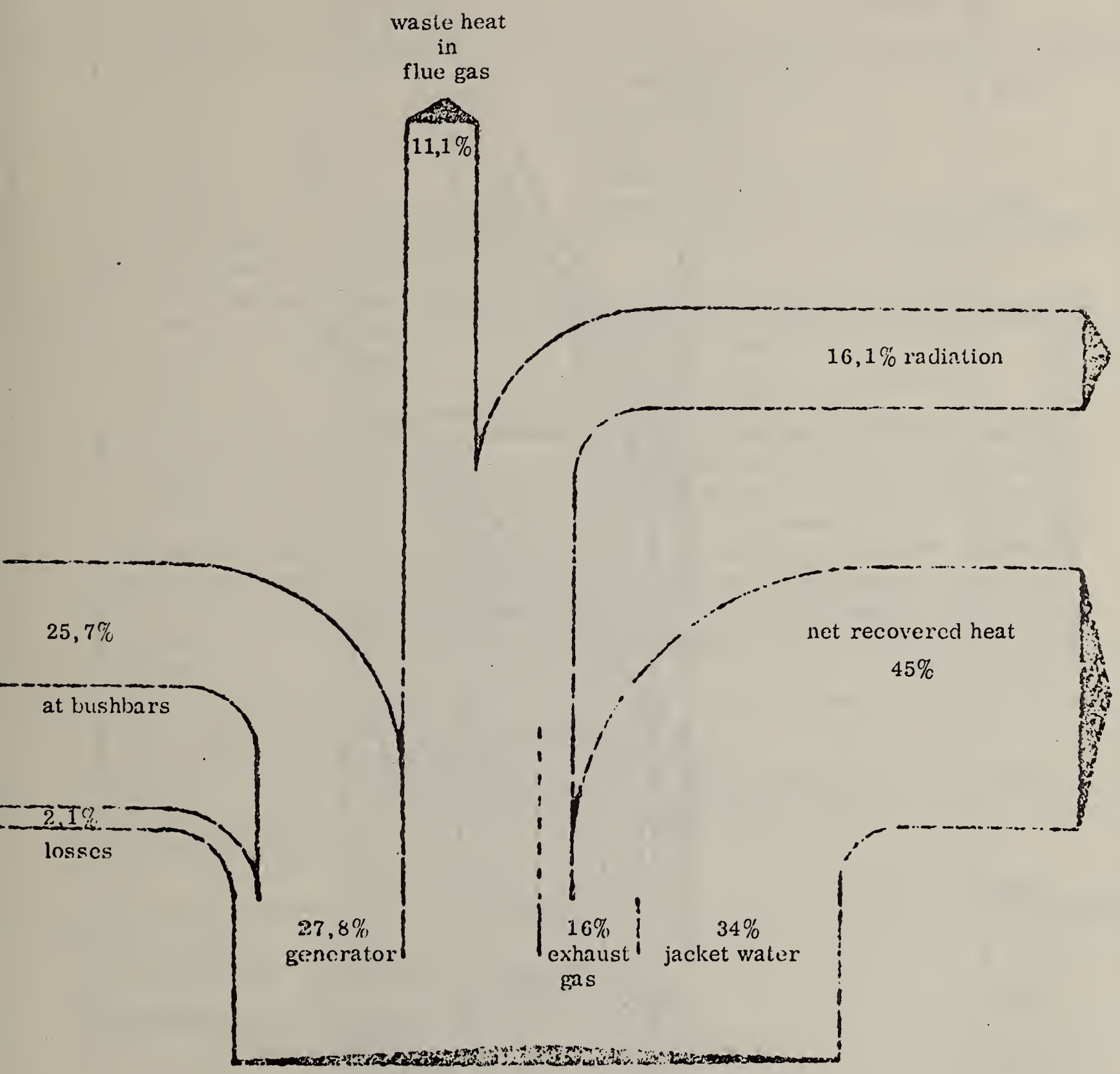

$100 \%$ supplied energy 
1. Title of Project (Official title)

:'cat pump for air conditioning of buildings driven by Diesel enrine

2. Date (rivir compleze:

27 April 1976

3. Perforining organization (Compleie maizing 4. Princinal Investigator (ivame crid compleze: audress)

iThT - C.R.T.

Strada del Drosso, 145

10135 TORTI:O mailing audress)

In

FIAT - C.R.F.

Strada del Drosso, 145

10135 TO:2 I 110

5. Supporting Organization (Compiete mailing address and name of contact)

Comission des Communautes Luropeennes-CDi

Programme Economic de l Iinercie

Rue de la Loi 200 - 1049 Bruxclles

lir. II. Enringer

6. Iruration of Research(Beginnirg and eris; Irarch 1975 - Dec. 1973

8. Purpose of Rescarch (Objectives, motivations, approach, plans and expected resuits) Consiruction and comparative operation of a pilot plant powered by a Diesel engine litil an output of about $50 \mathrm{KP}$, for a peais iseut requirement of about $140,000 \mathrm{kcal} / \mathrm{h}$ for binter reatine (outdoor temperature of $-10^{\circ} \mathrm{C}$ ) and of about half tine above figu re for summer cooling (tris on account of the smaller heat differential recuired). The noveity, with respect to the conventional heat pumps (electrically driven) is reprcsented by the fact that the power is zupplied by a thermal engine which allows

- the possibility of recovering the exhaust gas and coolant heat which would other wise be lost.

T:Le program develops throurin the following main phases: preliminary studies, study and cicsign of the system, construction, terts.

fro inal product is a running system for cvaluating:

- Cocration of the system for a full season vith critical processing of the experimen tal results obtained ard comparison with the conventional system

- Tin defrostinc probiem.

Q. Siatus and Results

- Stuigy and project of the system: completed

- Construction: is no: starting

This nroject is: 口plannedinin-propress口conpleted 10. Other Related l'rojects ("itivies)

11. Type of Project

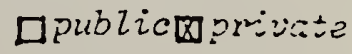

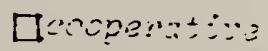

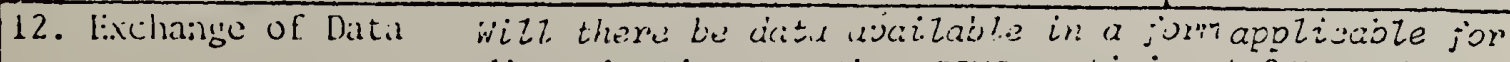
discemination to sther CCHs participants? $\square$ yesaro suvgcet to authorization of Ciì - li!? 


\title{
APPENDIX $¥$
}

\author{
MINUTES \\ OF THE \\ FOURTH MEETING OF THE \\ COMMITTEE ON THE CHALLENGES OF \\ MODERN SOCIETY \\ MODULAR INTEGRATED UTILITY SYSTEMS PROJECT \\ RATIONAL USE OF ENERGY PILOT STUDY \\ ON DECEMBER 7-9, 1976
}

AT

THE KERNSFORSCHUNGSANLAGE JUELICH

(Nuclear Research Center)

Juelich, Federal Republic of Germany 


\section{FORWARD TO MINUTES}

The minutes of the fourth CCMS-MIUS* Project meeting presented herein hopefully will be helpful to the committees in their work as well as to document the results and action items of the meeting.

The minutes are a summary of the meeting and have attached several significant documents that were distributed to participants during the meeting. I believe that the most important points are highlighted and that the minutes are reasonably accurate. I apologize for any material which inadvertently may have been omitted, misinterpreted, or stated incorrectly.

$$
\text { Morris Nimmo - Editor }
$$

* CCMS-MIUS is Committee on the Challenges of Modern Society - Modular Integrated Utility Systems 


\section{MINUTES OF THE FOURTH \\ CCMS-MIUS Project Meeting \\ December 7-9, 1976}

The fourth meeting of the CCMS-MIUS Project was called to order at 9:00 am December 7, 1976, by Mr. Clinton W. Phillips, Project Chairman at the Kernsforschungsanlage, Juelich (KFA), (Nuclear Research Center) Juelich, Federal Republic of Germany.

The following countries were represented and the attendees were:

\begin{tabular}{|c|c|c|c|c|}
\hline Country & Attendees & Dec. 7 & 8 & 9 \\
\hline Belgium & J.A. Michel & $\sqrt{ }$ & $\sqrt{ }$ & $\sqrt{ }$ \\
\hline \multirow[t]{5}{*}{$\begin{array}{l}\text { Federal Republic } \\
\text { of Germany }\end{array}$} & R. Jank & $\sqrt{ }$ & $\checkmark$ & $\checkmark$ \\
\hline & P. Kuppers & $\checkmark$ & $\sqrt{ }$ & $\sqrt{ }$ \\
\hline & U. Plantikow & $\sqrt{ }$ & $\sqrt{ }$ & $\sqrt{ }$ \\
\hline & 0. Renn & $\sqrt{ }$ & $\sqrt{ }$ & $\checkmark$ \\
\hline & J. Stocker & $\sqrt{ }$ & & $\checkmark$ \\
\hline France & T. Grjebine & $\sqrt{ }$ & $\sqrt{ }$ & $\sqrt{ }$ \\
\hline \multirow[t]{2}{*}{ Italy } & A. Campanile & & & $\sqrt{ }$ \\
\hline & M. Mangialajo & $\sqrt{ }$ & $\sqrt{ }$ & $\sqrt{ }$ \\
\hline \multirow[t]{4}{*}{ Netherlands } & W. Jongedijk & $\sqrt{ }$ & $\sqrt{ }$ & $\sqrt{ }$ \\
\hline & B.A. Kleinbloesm & $\sqrt{ }$ & $\sqrt{ }$ & \\
\hline & J.A. Knobbout & $\sqrt{ }$ & $\sqrt{ }$ & $\sqrt{ }$ \\
\hline & J.W.H. Van den Bergh & $\sqrt{ }$ & $\sqrt{ }$ & $\sqrt{ }$ \\
\hline \multirow[t]{2}{*}{ New Zealand } & P. Mears & $\sqrt{ }$ & & $\checkmark$ \\
\hline & D.E. Paulay & $\checkmark$ & $\sqrt{ }$ & $\sqrt{ }$ \\
\hline
\end{tabular}




\begin{tabular}{|c|c|c|c|c|}
\hline Country & Attendees & Dec. 7 & 8 & 9 \\
\hline Spain & J.A. Gonzalez & $\checkmark$ & $\checkmark$ & $\checkmark$ \\
\hline Sweden & U. Renghold & $\checkmark$ & $\sqrt{ }$ & $\sqrt{ }$ \\
\hline \multirow[t]{6}{*}{ U.S. } & S. Cavros & $\sqrt{ }$ & $\checkmark$ & \\
\hline & P. Folan & $\checkmark$ & $\checkmark$ & \\
\hline & F.A. Harris & $\checkmark$ & $\checkmark$ & \\
\hline & M. Nimmo & $\checkmark$ & $\checkmark$ & $\checkmark$ \\
\hline & C.W. Phillips & $\sqrt{ }$ & $\sqrt{ }$ & $\checkmark$ \\
\hline & J.H. Rothenberg & $\checkmark$ & $\checkmark$ & $\sqrt{ }$ \\
\hline $\begin{array}{l}\text { European } \\
\text { Communities }\end{array}$ & G Foherta & ( & 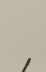 & \\
\hline
\end{tabular}

\section{CALL TO ORDER AND INTRODUCTION}

Mr. Phillips welcomed those in attendance and described briefly the work to be accomplished during the three day meeting (1) formalize the glossary (2) approve the structure of the International Project Catalog (3) review the measurement Technology Committee's work on a standard methodology for reporting performance of systems (4) review the research needs in integrated utility system technology (5) determine a termination day for the project and (6) arrive at a date and place for the next mecting. Refer to the agenda Attachment 1.

Mr. Phillips thanked KFA for their effort and work in: hosting the meeting and led the attendees in an introduction of themselves.

\section{WELCOME TO THE KERNSFORSCHUNGSANLAGE JUELICH (KFA)}

Mr. J. Stocker welcomed the CCMS-MIUS Project Meeting to the KFA and described some of the work of the KFA. Originally the KFA performed an important work, thersepar: tion of isotopes, because of its work on uranium enrichment it started at Juelich. Now this work has been taken over by industry.

Juelich has mostly new houses as the older ones were destroyed during the war. The region is noted for sugar beets and its large lignite mines. The biggest open 
pit mine in the world is within 10 miles of the KFA toward Aachen. Giant scrapers capable of 200,000 tons a day are now in use. Electricity production within 20 miles of Juelich is the highest density anywhere in the world, and supplies $25 \%$ of W. Germany's power needs.

Concerning the KFA, it has the highest high temperature electricity producing reactor. It is a gas tube reactor (helium) with $950^{\circ} \mathrm{C}$ temperature. Mr. Stocker explained the history of how W. Germany's research was organized and how it became centralized.

The nuclear energy research program has five parts: (1) coal utilization (2) mining technology (3) goe-physics and geo-chemistry (4) energy transformation and (5) rational use of energy.

Rational use of energy, headed by Dr. Plantikow, began in 1974, with $4 \%$ of the budget. In 1975 it rose to $11 \%$ of the work.

Mr. Renn discussed the arrangements for the day's meeting at the KFA, the tour to Diusberg and the Agrotherm. He announced a reception and buffet in the evening for participants.

\section{UPDATE OF CCMS ACTIVITIES}

Mr. F. Allen Harris reported. With respect to the Rational Use of Energy, the pilot study of which the MIUS is one project, work is at a completion stage for all the component projects. Final reports from the International Data Base Project, the Electric Utility Load Management Project, the Climatic Conditions and Test Reference Year Project, as well as the MIUS Project will be available at the October 1977 CCMS Plenary. The Climate Conditions and Test Reference Year Final Report has been prepared in draft. This work is being led by Professor von Korsgaard, who many of you know from the Technical University in Copenhagen. The computer program, which is the center core of the work for the Climatic Conditions and Test Reference Year is now undergoing actual tests in three or four of the participating countries. In a year 
or so participants will have actual experience based on climate data.

The cement report, a quite useful report, is the only thing like it in existence in which the energy efficiencies of cement industries internationally are compared. CCMS is very pleased with this work. The plastics report on polyvinylcloride also has been completed and $1 \mathrm{~s}$ now in the final editing phase. Both the steel and the plastics reports are to be published early in 1977, and will be avaflable at the next MIUS meeting. The new project which has been undertaken in the data base work deals with a demonstration project at a brewing facility to utilize the energy account ing methodology in a agricultural processing situation. By the early part of the summer four industries, steel, cement, plastics and brewing will have been covered.

The major work that is remaining in the International Data Base Project deals with the central core of the Project which is methodology. The methodology group prepared a draft report, which was revised extensively since it did not address the plant manager or the people who will actually be saving energy. The final meeting of this project, will probably be held in late April in Brussels.

There are many recommendations, from the steel, cement and plastics with respect to future research and development. One of these, which is certainly the.most ambitious calls for the establishment of an experimental blast furnace which could be dedicated $100 \%$ to experimental work in this technology. The problem is that if you have interesting ideas with respect to a blast furnace, it is very difficult to find someone who can test these on a real scale. Experts test these things in laboratories, but that is really not sufficiently indicative of what the total energy savings will be in the real world.

Additional ideas and recommendations will be discussed in the late January meeting in Stockholm by the IEA Energy Conservation Subgroup Committee. The Electric Utility Load Management is now in its final stages. This is primarily a cataloging and description of a number of techniques which have been used to level energy consumption from the utility standpoint. 
In terms of new projects we have one on flue gas disulfurization. This project 11 prepare a catalog similar to the catalog which you, the CCMS-MIUS Project Committee 11 put together, and it will include existing flue gas disulfurization projects.

Another new project will investigate the problem of carcinogentic agents in inking water by pooling present information. The project will also attempt to deterne the extent of the problem.

Mr. Harris, as requested by the Chairman, explained the nature of projects under MS. They are usually 2 year projects which are investigated to determine their intertional interest. Occassionally CCMS will continue a project beyond 2 years, but its in goal is to begin a project and have it transferred to other international organizaon within 2 years if the interest is there. CCMS will follow a project for 2 years ter it has been turned over to another organization.

\section{DATE OF CCMS-MIUS PROJECT ACTIVITIES}

Mr. Phillips discussed the beginning of the CCMS-MIUS Project and described iefly the accomplishments to date. The thrust of the committee's work falls into le catagory of, how do we communicate with each other in terms of uniform terminology, lere are the on-going projects of interest to MIUS, and what type of information do exchange. The order of business is to look at the first draft of the catalog, discuss outline of the standard methodology of reporting performance, and review the report of le research needs committee.

\section{DATE OF HUD-MIUS PROGRAM}

Mr. Rothenberg descirbed some of the history and factors which brought about he HUD-MIUS Program within the U.S. Dept. of Housing and Urban Development. HUD was eeking a new growth option in utility research. Out of this need to aid communities their growth and the New Communities Program came the 1dea and inputs for MIUS. sisted by other agencies HUD inaugurated a three phase HUD-MIUS Program to evaluate ad access the technology, develop a breadboard test facility at NASA, build a TE 
demonstration facility and a MIUS demonstration facility to assist in the implementatiun of the TE and MIUS concepts through the evaluation of test data, investigation and amelioration of institutional constraints, and the dissemination of data and information on the results of the demonstrations. The Total Energy facility at Jersey City, N.J., which is built on a Operation Breakthrough site, is the first total energy demonstration of the HUD-MIUS program. The MIUS demonstration at St. Charles, which is in its preliminary design stage, will be the first demonstration of the more comprehensive MIUS concept.

Mr. Rothenberg described the total energy plant at Jersey City using several slides to show the site and plant. One of the major publications of Phase I of the HUD-MIUS Program is entitled "Technology Assessment of MIUS". It is in publication at this time. Refer to Attachment 2 for preliminary data on the Jersey City Total Energy Plant.

For the MIUS demonstration, its objectives are, in addition to the measurement of performance, to look at the public benefits and the viability of the private sector designing, building and operating a MIUS, and to provide a data base to support and evaluation of its performance, environmental acceptability, and economical feasibility and to support policy decisions. It will further seek to examine the institutional barriers.

Mr. Rothenberg showed slides of the new community of St. Charles and the demonstration site while describing the size and characteristics of the area and possible configuration of the MIUS users.

\section{UPDATE OF MIUS TYPE OF PROJECTS}

Belgium (Mr. Miche1)

There are three centralized heat pump systems which I mentioned last time. Two of these systems are under development and the buildings effected are almost complete. One is finished, it is the control data center in Brussels and it is equipped with a heat pump system with recovery systems. It has been in operation since the first of January of this year. Unfortunately, there is no data on the first 
year of experience. Perhaps it will be available at the next meeting. The second project, a swimming pool equipped with a solar energy system, storage and heat pumps is almost completed near Brussels. The third project is a general study involving every important energy vector and is to be carried on in various universities. This study will be completed in two years, including solar energy, gasification etc. Our department is dealing with heating for cities, total energy systems, etc.

The Netherlands (Mr. Van den Bergh)

The Stichling Energy Foundation is gathering information which might be of interest to the MIUS group. The Foundation is gathering information on total energy projects at five or six hospitals. There are three projects for sewage treatment and three on dual fuel energy and total energy systems. There are on-going projects for greenhouses. A total energy installation at one of the hospitals was found to have an overal1 thermal efficiency of about $70.2 \%$ and an average load factor of $56.6 \%$. The thermal efficiency of the combined engine generator set was $44.8 \%$. An older installation had an efficiency of $60.6 \%$, and a load factor of about $50 \%$. Completed Project Summary Forms will be forwarded for inclusion in the catalog. The greenhouse is being used in the winter season to improve growth of the flowers, etc.

The energy consumption is about 500,000 kilowatt hours per year for lighting. If electric heat is considered it would consume an additional 100,000 cubic meters of natural gas using conventional means of power generation. If you supply this heat from a total energy installation, on 1 y 20,000 cubic meters of natural gas is consumed. A comparison between two total energy installations installed in hospitals is available. The net savings will be 120,000 guilders per year out of a total cost of 500,000 guilders by using a total energy system. 
France (Mr. Gjebine)

Mr. Grjebine raised the question whether the two project outputs (catalog and standard methodology) are fulfilling entirely the need of the participating countries. He stressed the importance of having the right type of information available in order that authorities at the state, regional and administrative levels could be convinced of the significance and importance of integrated energy systems (MIUS). He stressed the need for a catalog of component parts to identify the existing technology etc, within the various countries. Mr. Grjebine further suggested that we develop a CCMS relationship with the press because the resources that could be available to us through T.V., radio, newspapers, magazines etc. are not now available to us.

Mr. Grjebine further discussed the importance of acquiring appropriate experts to consult or have testify before parlimentary commissions etc. He described legislation, which he supported, which could obligate customers to hook-up to district heating where it is available if it is cheaper than conventional heating. Otherwise they would pay a penalty tax similar to that now in effect concerning sewage collection etc. The National Committee has recommended that all options be kept open for the future such as, nuclear plants be constructed with capability of using the waste heat for hot water heating networks, and that turbines be constructed that are capable of providing 70-90 degree heating when needed, and that electric houses have hot water systems in order that they can be converted to hot water system networks (district heating). The Commission has proposed that seven areas be studied for the application of programs, such as MIUS. The interparlimentary groups will launch studies on a more global scale. Mr. Grejbine next discussed some of the cost incentives of electricity and heating.

ERDA (Mr. Cavros)

Mr. Cavros discussed the need for institutional innovation and the importance of the energy industry, utilities, municipalities or any other public body accustom to long term write off of investments, adopting the MIUS concepts. For example, the 
builder may have certain burdens and operating rules of return on his investment which may not fit exactly the nature of utility systems such as the MIUS. He may want to recover his monety quickly, and it's not the nature of the system to do that. ERDA has one project, an international project with the National Energy Council of Greece, which is addressing the problem of how does a team of urban planners, city designers and energy specialists or engineers get together for the first time to design a energy efficient human settlement? A Greek island has been choosen as a test case site. Work is in progress to create the capability of analyzing and matching the end use of utility services with the conversion and delivery of services. The Integrated Community Energy Systems (ICES) program at ERDA, is investigating the use of coal. This program also includes a research and development program to foster the use of advancing technologies in integrated systems.

Using today's technology, ERDA has one project that will be conducting feasibility studies of six particular sites where MIUS type of integrated community energy systems can be built. The project does not necessarily include wastewater and water treatment. This of en has institutional constraints. Proposals from investorowned and municipally-owned utility systems and large private developers have been received. Not only will the design be evaluated, but also the potential for success by the sponsoring team. ERDA hopes to select three different kinds of teams in order to test the institutional problems peculiar to each. Another interest is the Community Annual Service Energy System which could use a commercially available ice making machine and large storage ponds or large storage areas of water which are converted to ice or very cold water by heat extraction in the winter and then in the summer melting the ice for cooling purposes. ERDA has a contract with the Swedes, who have a computer program to test the economic and technical feasibility of district heating. They will be evaluating a few sites in the U.S. approaching large utility companies to see how district heating on a large scale can best be demonstrated through a feasibility study. The community systems branch is cooperating with the ERDA's nuclear research activity to explore the waste heat potential from nuclear plants. 
There is another project which involves the retrofit or redesign of an existing power plant for district heating. We are looking for opportunities where district heating can become economically feasible immediately. We have another international project with the Federal Republic of Germany, an IEA Project, which involves a heating system for apartments using heat pumps for extracting heat from a nearby canal in Esslingen.

There is a standby oil heating system that will be compared with the heat pump system. ERDA in its community systems programs is pursuing the concept of energy master planning. The idea is to bring together the utility companies, the municipal consumers, the private developer i.e. all the players who supply and consume energy in a mutual effort to conserve energy instead of each serving his interest first. To address the problems of energy within each community is to assist these communities We are developing methodology for a comprehensive community energy management, hopefully enlisting local governments to work with the problem and at the same time prepare the market to accept the technologies being developed.

NOTE: Mr. Harris informed the committee that another sub-project of the CCMS work on thermal energy led by France is looking at the cost of heat transmission and expects to have a final draft in 3 to 4 months. This could be made available to the project. The computer program which is being worked out by Northest Batelle is being demonstrated at 3 sites on a western U.S. site, Iceland (where actual costs are known) and in France (several locations).

The update of projects by Dr. Plantikow (RFG), Mr. Renghold (Sweden), and Mr. Campanile (Italy) where deferred to the second day (Dec. 8).

\section{TASK 1 DATA FORMAT COMMITTEE}

(Refer to the agenda of the fourth meeting, Attachment 1, page 2, Work Material for Data Format Committee, Attachment 3, Summary of Project Summary Forms, Attachment 4 , and "Definition of MIUS Type of Project", Attachment 5). A paper containing work materia for the Data Format Committee, Attachment 3, the First Draft of completed Project Summary 
Forms for the International Project Catalog, and a paper entitled "Definitions of MIUS type of Projects", Attachment 5, were handed out.

As chairman of the Data Format Committee, Mr. Phillips urged that participants submit their completed Project Summary Forms for the catalog. As a matter of record, (Refer to Summary of Project Summary Forms, Attachment 4) 50 forms were received from the U.S. and 3 from other countries. Mr. Phillips asked that completed Project Summary For be submitted to the Data Format Committee via the Secretariat within three months and that the catalog be submitted at the next meeting in about 6 months or more for appoval.

A discussion followed on the guidelines for including projects in the catalog. Questions raised were: should projects be included on the basis of data available, what is the minimum amount of data from a project that would be of value, are items such as cost of operation, cost for installation, the kilowatt hours or pounds of steam produced sufficient information and how about cost of processing waste, and how much would it cost the city to process the waste without a MIUS?

From this discussion a consensus was achieved on the following: If the sponsor of a project stated that there would be no data, the project would not be included, if some data was available and this particular project was not similar to many other projects reporting data, then the project would be included. Obviously, projects with more than casual data would be included?

Also raised was the question of - should a project limited to a better generator, engine, or boiler, or other component be included. The consensus was only if the component is in fact integrated in some way and/or offers strong potential to effect the welfare of integrated systems.

Agenda Mr. Harris suggested that the Glossary of Special Terms and the Catalog It em a be an appendix of the final report. He reported that all CCMS publications are placed in the National Technical Information Service (NTIS), located in Springfield, Va., and thus are available to anyone. The publications on energy arc usually put into Oak Ridge systcm as well. as the NiIs systcm. 
The European mechanisms for getting CCMS reports is usually through NATO. Mr. Folan stated that final reports are distributed to each country's delegation. Concerning distribution of reports, Mr. Harris related that the audience should be recommended by the ciMS-MIUS committee. Initial distribution is usually 1000, with a second distribution also around 1000. Mr. Harris also stated that a final draft document should be submitted to th? plenary for approval in lieu of the final published document which of course should finlinw thereafter. Since the Fall plenary is Oct. 77, Mr. Folan and Mr. Harris recommended that the catalog and final report be submitted to the Plenary for approval about Sept. 1, 1977. This would necessitate approval of the catalog and component parts of the final report such as recommendations to CCMS, research needs, and standard methodology by the next meeting.

Mr. Harris suggested that Mr. Grjebine and Mr. Cavros draft a report on the difficulties and the opportunities with integrated utility systems face in participating countries entitled "Incentives and Barriers for the MIUS System". They both agreed. Mr. Cavros agreed to be the Chairman, Mr. Grjebine agreed to serve on the committee, and Mr. Mangialajo offered to also serve. It was agreed that this report should be distributed prior to the next meeting in order that participants could prepare for its review and approval at the next meeting.

Agenda Item b

Concerning approval of the Project Summary Form Mr. van den Bergh suggested that a box be added to identify the owner of the plant. It was decided that the instructions for completing the form would be changed to instruct one to use the box for the sponsoring organization for entering the owner also. Mr. Mangialajo asked if the catalog should include name of the industrial plants that were utilizing combined po and heat generation. Mr. Phillips agreed that if it could add to integrated systems technology, that they should be considered for 
inclusion in the catalog.

Agenda

It was agreed that the catalog would be furnished in loose-leaf

Item $c$ form.

Agenda

Item d

It was agreed that: (a) the catalog would not have copyrights,

(b) that persons contributing to the catalog would be advised

that their material was for publication, (c) the initial printing

would be about 1000 , and copies would be made available via NTIS

possibly GPO (U.S. Gov't Printing Office).

Agenda

Item e

In review of the first draft of the catalog, Mr. Phillips pointed out that a summary of the 53 projects was included in the

front of the draft. He also called the committee's attention to the paper "Definition of a MIUS Type of Project" - He also anticipated more than 30 European projects.

Item $f \& g$
Agenda

Project Progress/Evaluation Report. Mr. van den Bergh suggested that Item 12 include the type and thickness of insulation rather that indicating the gross heat rate. In Item 11 e expand to include types of wastewater treatment. For example in Part III both terms sewage and wastewater are used.

Agenda I tem h\&i
Concerning the Project Progress Evaluation Report, no specific recommendations were made. It was suggested, however, that this report would serve to update the catalog and that this should receive the committe's recommendatioi?. It was agreed that the future work on the Project Progress/Evaluation Report might possibility fall within IEA's energy cascading work which is looking at energy recovery and reuse. 
Sweden (Mr. Renghold)

Mr. Renghold explained that after understanding what MIUS (the concept) is he could now identify some projects in Sweden as being MIUS type of projects. There are a number of MIUS type activities such as the municipal heating systems with contemporary production of heat and power. Mr. Renghold pointed out that in Sweden there is little research on MIUS type of projects as they are a common technology in Sweden, (about 20-30 years). Thirty to Eurty large cities have MIUS type of projects. All of Sweden's big cit are heated with these municipal heating systems (District Heating). Vasteras with 80,000 inhabitants is almost totally heated by this method. Research, generally, is limited due to financial resources. The economics of MIUS types of systems (district heating, combined power and heating) are known and controlled. Although, Sweden and Scandinavia have MIUS type of systems, very few follow the complete MIUS concept.

Mr. Renghold submitted a Project Summary Form for the 12MW TE diesel plant serving Västeràs.

\section{Genera1 Discussion}

Mr. Harris pointed out that the CCMS-MIUS Project got much of its inspiration from Sweden's existing technology in utilities, which other countries would like to share. Mr. Cavros pointed out that Sweden had solved the institutional problems while other countries have not.

The idea of a catalog of component parts was again discussed in view of Sweden's technology such as the transportation of low grade heat up to 80 kilometers. Mr. Rothenberg pointed out that at JCTE risen-bonded fiber glass reinforced pipe saved $\$ 30,000$ over steel and this technology should be included in such a catalog. 
The meeting was convened Dec. 8, 1977, at 9:00 by the Chairman. He turned the meeting over to Mr. John Knobbout, Chairman of the Measurement Technology Committee.

\section{TASK 2 MEASUREMENT TECHNOLOGY COMMITTEE}

Mr. Knobbout handed out an outline of the methodology (layout of report: measuring systems for a MIUS) and reviewed the accomplishments and content of discussion at the last CCMS-MIUS Project meeting, where measurements were discussed extensively. Discussed were views on the possibility and usefulness of measurements, what should be included and what should not be included, a typical measurement system, a system approach to a measurement system, and borders of the system. It was agreed that performing measurements in practice is not simple and there are different.levels of measurement required. It was concluded at the last meeting that a new draft should be prepared. For, this discussion the chairman presented an outline of the report for discussion and comment. The significant comments and discussion are in the succeeding paragraphs.

In para 1, Project comparison with Different Goals, Mr. Phillips pointed out that care should be given to comparing real data with an idealized model as the real data is collected under operating constraints such as mechanical problems, breakdowns, outages, malfunctioning components, instrumentation which can not reach the ideal model's performance.

In para 2, several purposes of the report were highlighted such as, to serve as a basis for information exchange with a standardized format, identify minimum data necessary to support specific comparisons, serve as guidelines for how to measure and report the results, present general experience with the MIUS system, and to guide potential user's of a MIUS etc. It was agreed that the data acquisition system should be specified, not described, and that the various standards in different countries should not be included. 
In para 3, Approach of the Technical Problem, the discussion centered around the minimum measurement, levels of measurement, not the application of the measurement (included later in report). It was agreed that there should be a system oriented approach.

In para 4, Subsystem Approach, it was pointed out that optimization of subsystem performance requires subsystem measurements. It was suggested that the parameters to be monitored could be listed in a table.

In para 5, Measurements, Mr. Knobbout suggested that instrumentation is probably a better title. In the discussion of repeatability and reliability of the field measurements a concern was expressed that the requirements and accuracies specified be within the range of available instrumentation at an acceptable price when the measurement technique and specific type of measurement is being considered. For example, two quartz resistance thermometers on a high temperature line will cost about $\$ 2000$ ( $\$ 1000$ each) whereas a thermocouple wire with a proper instrument measurement the voltage differential will cost far less for equivalent precision.

In para 6A, Approach in Practice, a discussion developed on seasonal efficiency and how one factors or considers the COP in the overall efficiency. Mr. Cavros stated that ERDA is considering using a "fuel effectiveness ratio" that would be based on an input of one energy unit to an output of the same or equivalent energy unit. The consensus was that the methodology of taking and reporting data does not describe how to analyze plant performance, but merely what data is needed and generally how to acquir! it.

In para 6B - Subsystem Inputs and Outputs, the discussion centered around the difficul of assessing black box efficiency if the boundaries are unknown. Depending upon the user' needs and his building and equipment configuration greater user demand whether frugal or wasteful could result in higher plant efficiency. Thus energy conservation practiced by $t$ user could lower the plant efficiency and vice versa. There was a concensus that information is needed on the dynamics of the building and the user's habits. The end-use 
systems should be considered part of the comprehensive energy system. Thus idailly the user buildings and MIUS should be designed as an overall system. Institutionally this may prove difficult.

In para 7, Data Acquisition System (DAS) - it was agreed that there are many ways to acquire data from "clipboard and pencil" to sophisticated "computerized data acquisition systems" with various costs. This section should discuss the range of comple general benefits, general costs, a desirable degree of accuracy for system analysis, and methods of data reduction. DAS' can differ depending upon program objectives, measurement objectives, management practices and available funds.

The following schedule was set for the Measurement Technology Committee's standard methodology draft material:

1) Submit draft material to chairman Mid-March 1977 for inclusion in second draft.

2) Distribute second draft to participates Apri1 30, 1977 for review prior to July 77 meeting.

3) Approval of second draft of July 77 July 12-14, 77 meeting for inclusion is final report.

The following assignments were made to assist the committee in preparing the second draft of the standard methodology:

1) Introduction - Mr. Phillips, U.S.

2) Purpose - Mr. Rothenberg, U.S.

3) Approach of Technical Problems

4) Subsystem - Not assigned

5) Instrumentation (The measurements) - Mr. Knobbout, The Netherlands

6) Approach in Practice - Mr. Phillips, U.S. and Mr. Rothenberg, U.S.

7) Data Acquisition System - Mr. Phillips, U.S. (also Analysis Techniques)

8) Influence Objectives - Mr. Knobbout, The Netherlands 
Mr. Crjebine of France was asked by the Chairman to serve as a replacement for Mr. Simon on the Measurement Technology Committee. He agreed. Mr. Knobbout reviewed the schedule then closed his committee meeting.

\section{CONTINUATION OF UPDATE OF MIUS TYPE OF PROJECTS}

W. Germany (Mr. Jank)

Mr. Jank supplied participants with a copy of "Energy R\&D Program of the Government of the Federal Republic of Germany - Annual Report 1975". The book 1ncludes about 400 projects, 61 of which are in the field of energy conservation with which Dr. Plantikow is associated. Several district heating studies by different industries have been made. The project summaries are on pages 437 - 452. These studies were to assess the potential savings of such systems and cost about 12 million marks to perform. Four or flve of the studies are complete. The maln study is in progress. The study w1ll be completed in Jan 77 and w1ll cover technical and polftical (institutional) problem: The studies are mostly of real existing systems to examine the benefits of using rejected heat. The results indicate a savings of 200 million marks by 1990 by using these systems for the entire country. The payoff would be between 10-15 years.

Mr. Jank also described a project dealing with energy storage by use of a large lake. An experimental lake (p1lot lake) to study Insulation is underway. The hot water lake will be between 90-95 degrees Centigrade.

Perhaps the most important and interesting project is the Block Heat Power Station. It has a gas engine, produces $620 \mathrm{KW}$ of electrical power and produces heat for 260 dwelling units, possibly 300-400, in the area adjacent to the plant. It became operational in early 1976 and will continue until the end of 1978.

Another project is the Modern community with new energy and heating systems. The report is complete and available in the German language. The short version is available in English.

Another project is the Agrotherm where rejected heat from a nuclear plant is reclaimed and plped beneath an agricultural area. The warm soil is hoped to be a benefit to crop production. 
Mr. Michel, Chairman of the Research Needs Committee presented a general framework for combined production of heat and electricity by drawing a diagram on the blackboard (See Figure 1). Problems will be presented in three parts, production distribution and consumers. There are short term; medium and long term problems. These fall into categories such as fundamental research, technological research and development, component and system research, economics, institutional, and organizational.

In combined systems for heat and power, research is needed on turbines that can adapt to both power and heat production. It would be interesting to establish a dynamic model of this turbine using calculations to determine parameters and their transfer functions and also to analyze the possibility of partial oxidization. Also it would be interesting to gather data on the efficiency of part-loads for the classical boilers. There is a lack of knowledge about the use of plastic pipes for district heating. Obviously planners will use new technologies only if well tested and proven. There is a need for better control of systems which recognize instantaneous changes in electrical power demand. Reliability is another problem which may be studied on the basis of component failure probability.

It would be very important to develop a common methodology for evaluating large scale projects economically over a period of twenty years for example. It is important to consider the dynamic approach being able to answer questions concerning inflation and interest. We need dynamic programming as oppose to linear programming to provide a base for optimizing and analyzing systems in complex networks. It is important to work with the dynamics of the distribution networks to make coincident the peaks of electricity and heat.

END OF MEETING

THIRD DAY, DECEMBER 9, 1977

- Tour of KFA

- Trip to Duisberg and tour of August Thyssen Hutte 


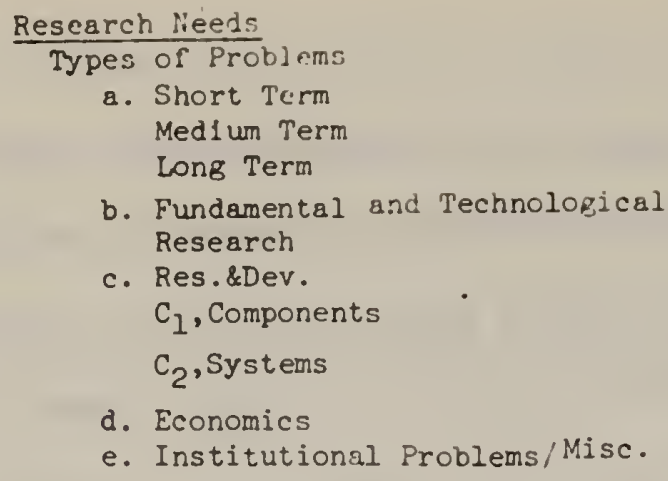

d. Economics

e. Institutional Problems/Misc.

A PROD

Al $\mathrm{Cb} E / Q$

'Steam

${ }^{\circ} \mathrm{Gas}$ plus second steam systen ${ }^{\circ}$ Diesel/gas engine

A2 $Q$ (heat Only)

${ }^{0}$ Classical steam

oNuclear (sm.bldg.)

'Heat Pumps ( $1 \mathrm{~g} . \& \mathrm{sm}$. )

B. Dist.System

Bl Transport

B2 Dist.

B3 Stor.

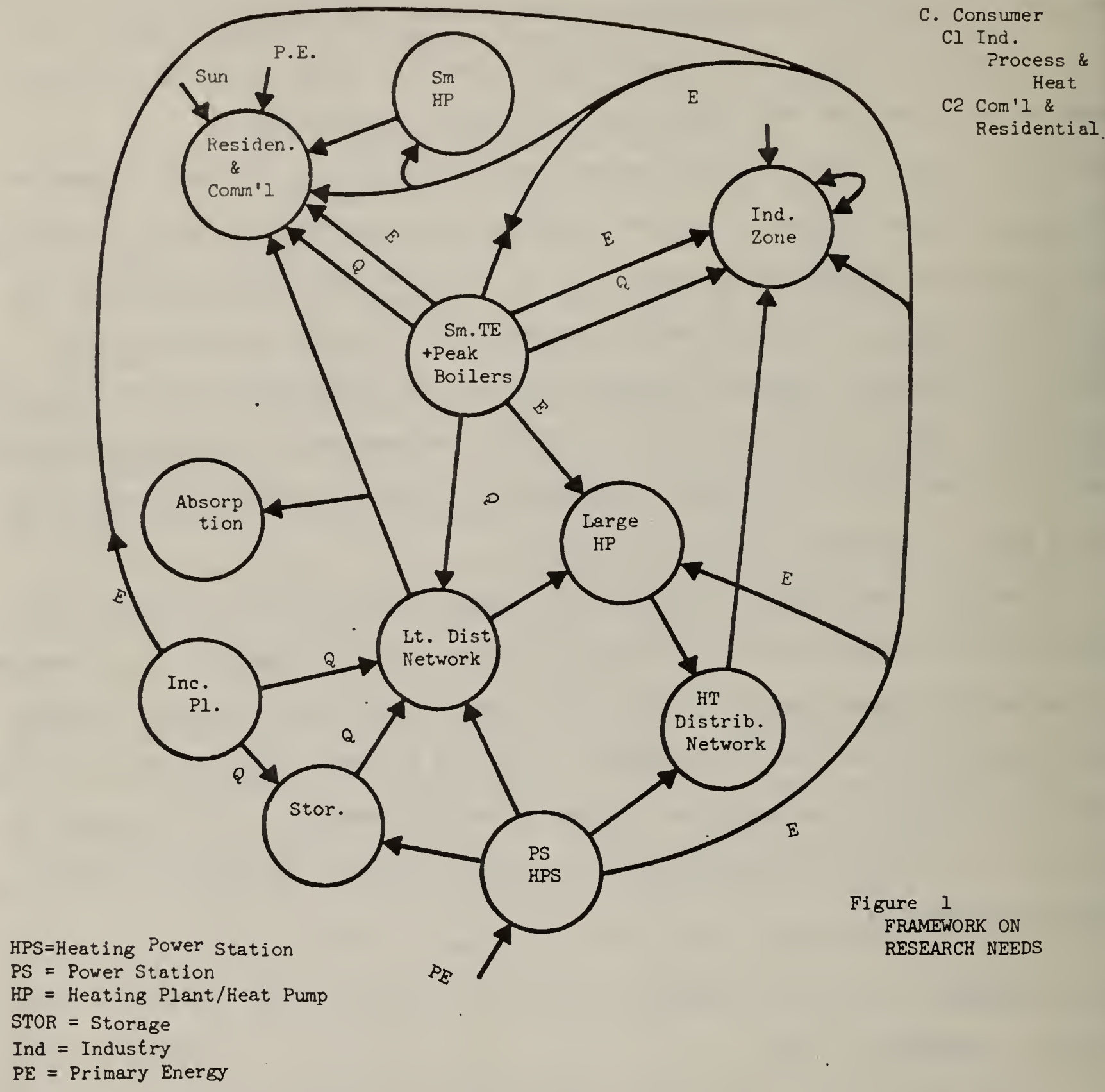


COMMLTES FUR THE CHALLEACFS OF MODERN SOCIETY

RATIONAL USE OF ENER.GY

MOIULAR INTEGRATED UTILITY SYSTCM (MIUS)

CONFIPRATION NOTICE OF

SCHEDLLLD MEETING

Date: Tuesday, Wednesday and Thursday

December 7-9, 1976

Place: Kernforschungsanlage, Juelich (KFA)

(Nuclear Research Center)

Juelich, Federal Republic of Germany

Host: Dr. U. Plantikow

Meeting Chairman: C.W.Phillips

\section{AGEND $\Lambda$}

TUESDAY, Decenber 7

0900

CALL TO ORDEP. AND INTRODLICTION

Welcome to Federal Republic of Germany and the Kerrforschunganlage Juclich (Nuclear Research Center), Dr. Prof, K.H. Beclurts, Scientific Director Kernforschungsanlage Juelich

Update of CCils Activities, Goals and Objectives, F.Allen Harris, Special Assistant, U,S, CCis Delegation

Update of CCMS-MIUS Project Activities, J.H.Rothenberg, Manager, U.S. HLD-MIUS Program (HUD is the U,S, Department of Housing and Urban Development)

Technical Presentation - U.S. HUD-MIUS Program.

Mr. J.ii.Rothenberg, Manager, U.S. HUD-HIUS Program, will describe the current status of the HUD-iIUS Program, including the lnial Energy plem at Jersey City, Ner Jersey. The Milus Demonstration at St. Cinarles, ind. and other related projects.

1043

UPDATE OF INTEGRATED UTILITY SYSTEIS PROJECTS

Experts in attendance are requested to present brief reports of on-going projects in their respective countries. (Notice to presentors: Written reports for distribution to attendees will be helpful). 
Discussion and review for approval

a. Presentation of CCiS Policy on Production of Documents and Recomnendations on Type of Document and Production for Catalog.

(1) Glossary of Special Tertis

(2) Catalog

(3) Final Report

b. Approval of Project Sumiary Form, assuciated instructions and CCMS General Information

c. Comittee Recomendation for system and structure of International Project Catalog

d. Committee Recommendations for catalog-on distribution. methods and audiences, for copyright, number of copies to be printed, etc.

e. Review of Catalog Progress

(1) Number of projects reported

(2) Countries responding

(3) Type of projects being reported

(4) Usefulness to MIUS related activities

(5) Appropriateness of response

(6) Completeness of response

(7) Recomnendations etc. (Projects to include or reject, any last minute changes to Project Summary Forms changes in timetable and milestones)

f. Report on Test results of Project Progress/Evaluation Report Form

g. Comittee Recommendations on Changes and Improvements to Project Progress/Evaluation Report

h. Recominendations on Methodology for supplying Project Progress/Evaluation Reports to participants

i. Milestones and Schedule for Conpleting Project Progress/ Evaluation Reporting System Task

All cois-ilus Project experts are requested to participate in the Dila Foriat Committee work session. 
$-3-$

ILISIDil, Necember 7 (Continued)

DATA FORHAT CORITTEE -

Canada (K.R.Solvason)

Iialy (M.Mangialajo)

Netherlands (J.W.H.Van den Bergh)

United Kingdom (P.J.O'Neill)

United States (C.W.Phillips)

1645

ADJOURN DATA FORIAT COMIITTEE SESSION

SOCIAL HOUR AND DINNER - Courtesy of the Kernforschungsanlage Juelich

WEDNESDAY, December 8, 1976

0500

TASK 2 :YFASURENENT TECHNOLOGY CONATTTEE

- J.A.Knobbout (The Netherlands

Chairman

Discussion and Review of:

a. General update of Committee goals and objectives

b. Report on Task Force Activity to Incorporate Comments

and Improve First Draft of Stanclard Methodology for

Reporting performance of systems and taking of and

reporting of data

(Task Force members are: France (M.Simon), Federal RepubIic

Germany (H.Klein or F.Richter), Netherlands (,$A_{2}$ Knobbout), and Sweden (U.Renghold).

c. Recommendations (presentation of second draft) on:

(1) MIUS subsystem functions

(2) Minimun data items for reporting performance of systems for both an operating system and a research/ experimental facilities being demonstrated

(3) Accuracy of data items desircd

(4) Measurement Nethodology Guidelines (procedures, techniques, measuring devices, new measurement technology, sampling requirenents, $ミ \pm c$.

d. Milestores and Schedule for Completing Standard Methodology

for reporting perfoimance of systems

A11 CCis-iflus project experts are requested to participate in the Heasurement Technology Comnitiee work session.

MEASUREYE:T TECHOLOGY COSEITTEE

France (I.Simon)

Federal Republic of Germany (H.klejn or F, Richter)

Netherlands (.J.A. Knobhout)

Sweden ( $u$. Renghold)

United States (c.h. Phillips) 
1215 LUNCH (COFFIE BRFAK at 1030 ista and $1500 \mathrm{pm}$ )

13] 5 Cont inuation of Task 2 MIASURE:TEN TECHNOLOGL CO:LIITEE

1430 TASK 3 RESEARCH ZLEDS COYMTTEEE

Discussion and Review of:

a. Commitlee lieport on the identification of needs for rescarch in support of Integrated Utility System lechnology

b. Additional Recommendations by participants.

(All participants are requested to assist the comittee in identifying areas of integrated utility systems technolog,y and processes which need basis or applied rescarch. The goal of this session is for the commitlee to prepare a prioritized list of research needs in integrated utility systcm technolozy for dissemination to CCMS-MIUS Project participants and to the CC..is Plenary in 1977.

c. Schedule renaining work for the completing report to the cCas Plenary in 1977.

All participants are requested to provide input to the Research lleeds Cuminice.

RESENRCH COILITTEE

Belgium (J.A.Michcl)

Federal Republic of Germany (W.Piller or Dr. H.Klein)

United States (S.Cavros)

1530 COREITTEE SURAARIES/ACTION

Data Format Comittee, Task 1

Measurement Technology Conmittce, Task 2

Rescarch ileeds Committee, Task 3

- Itens resulting from Task 1 (Dec.7) and Task 2 and 3 (Dec.8) requiring CCAS-MIUS Project liction

1630 OTHER EUSINESS

Future CC:is-ilitus Project Schedule

Date and Place for liext liceting

!Fịnal Arrancmenls for December 9 Technical Visits/Tours

1700 AD.JOURN FOR THE DAY 
TECHNICAL TOUR OF KERUFORSCHUNGSANLAGE JUELTCH (Nuclear Research Center)

The itinerary for visiting the KFA Laboratories will be determined on the first day of the project meeting. Tuesday, 9 December 1.976. Participants in attendance will be given an opportunity to recommend the types of projects they wish to visit.

\section{TECHNICAL TOUR TO DUISBERG (Bus Trip)}

Participants may journey to Europe's largest inland harbour in Duisberg (70 kilometers from Juelich) with LUiCll at the August Thyssen Hutte. The government-supported Agrotherm-project a project using a part of the waste heat of a 500 MJ power plant: for agricultural purposes will be visited.

NOTE: On the return trip to Juelich the bus can stop at the Cologne and Dusseldorf airports. Scheduled time for return to Juelich is approximately 1700 hours.

\section{ARRIVE BACK AT JUELICH /AACHEN - ENI OF MFFTTING}

Complete information on arrangements (reservations) for housing accomodations near the meeting place and transportation to the hotel and meeting place will be provided to you with an invitation from the Kernforschungsanlage Juelich which you should have received by this time. Accomodations will be at hotels in Aachen. Rooms can be rescrved by returning the Hotel Reservation Form attached to the invitation.

If you have not received the llotel Reservation Form, or if you nced any assistance with accommodations or transportation, you may contact Mr. Ortwin Renn, head of Tarungsburo, KFA, telephone 06/02461/614662. You may also contact Dr. Plantikow (telephone 06/02461/614621) or Dr. Reinhard Jank at KFA (telephone 06/02461/613269). The KFA te:lex: number is $833556 \mathrm{kfad}$.

If you have any questions concerning the CCis-MIUs Project, please got in touch with the Project Chairman, C.W.Phillips, Room A145, B1dg. 225, National bureau of Standards, Washington, D. C. 20234, U.S.A., telephone 202-921-3741. The NLS telex number is 89-3493. 

First Draft: JCTE Part of CCMS 12/1/76

FOR CCMS MIUS DISCUSSION PURPOSES ONLY NOT FOR PUBLICATION

OR REFERENCE

J.H.Rothenberg, December, 1976

\author{
HUD-MIUS PROGRAM \\ Jersey City Total Energy Demonstration
}

The Jersey City Total Energy Demonstration is a HUD-MIUS Project which has been discussed at previous CCMS meetings. The $61 / 2$ acre $(2.4$ hectare) site is located in Jersey City, New Jersey across the Hudson River from New York City. This site has four apartment buildings containing 485 apartments, a commercial building, a school, a swimming pool, and a central equipment building. The central equipment building houses an automatic total energy plant which supplies electric power, hot water, and chilled water required by the site.

The plant has been serving the site since January, 1974. In support of HUD, NBS** has instrumented this total energy plant so that its performance can be evaluated. Since April of 1975, plant data has been recorded, and beginning November 1975, utilities to the remaining buildings have been instrumented and preliminary data recorded as construction and calibration

\footnotetext{
* HUD-MIUS stands for U.S. Department of Housing and Urban DevelopmentModular Integrated Utility System

** U.S. National Bureau of Standards
} 
schedules permitted. Prior to May, 1976, fuel usage was determined by total delfvery to the site, with relative use between engines and boilers determined by calculation. Beginning with May, 1976, we now have six months of direct measured fuel data showing separate usage by engines and boilers. These data will be discussed later in my talk.

The Jersey City Total Energy Plant has five dlesel engine-generator sets with heat recovery. In operation, each of these units produce between 300 and 500 kflowatts (maximum $\mathrm{kw}$ output is 640 ). The peak site and plant loads can be handled at any time by three of these units, leaving one unft available for maintenance and one unit as a standy-by. Heat is recovered from the jackets and exhausts of each engine. The electrical efficiency of these engine-generators is $32 \%$ as determined by precise fuel and kwh measurement. The electrical-plus-heat-recovery efficlency is slightly above $60 \%$.

Figure 1 is a schematic of the plant. Thermal energy recovered from the engines is used to produce site hot water and to operate two 546 ton (1920 kw) absorption chillers. A primary hot water loop, which is 10 Inch pipe carrying 11,000 pounds $(5000 \mathrm{~kg})$ per minute of water at $180^{\circ}$ to $220^{\circ} \mathrm{F}\left(82\right.$ to $\left.104^{\circ} \mathrm{C}\right)$ transfers recovered engine heat to the site loop heat exchangers and chlllers. Two 400 horsepower ( $3920 \mathrm{kw}$ ) fire tube bollers are also in the primary loop to provide supplemental heat when needed. In the rare event that more recovered heat is produced than needed, dry coolers can release primary heat to the atmosphere. An emergency heat exchanger using raw city water provides redundant back up to the dry coolers to assure the primary loop can adequately cool 
the engines. Although these heat dumping units are rarely used in nomal operation, they allow portions of the secondary distribution systems to be turned off for maintenance without shutting down the primary system with resultant loss of the electrical power.

Figure 2 is a computer plot from site recorded data showing the seasonal output of electtical power from generators that is required for site power and for HVAC use. The graph shows that site demands have a $\pm 25 \%$ diurnal variation but mean levels are relatively constant year-round. Electrical power required by the HVAC equipment in the central equipment building varies considerably throughout the year. During the summer the HVAC system requires electrical power to run the accessories for the absorption chillers and the cooling tower fans and pumps.

Figure 3 shows the typical site thermal demand for hot water and chilled water during the four seasons. Site hot water is used both for space heating and for domestic hot water production, so that even in mid-summer'hot water from the CEB is required by the site. Note that the site thermal energy demands in mid-winter for hot water are about double the demands in mid-summer for chilled water.

The site thermal demands require heat from the primary loop. Hot water demands are met by site heat exchangers in the plant which transfer thermal energy from the primary loop to a secondary hot water loop for site distribuiton to the several buildings. Chilled water demands are met by two absorption chillers operated by primary loop thermal energy. Although mid-summer site chilled water thermal demands are approximately half of 


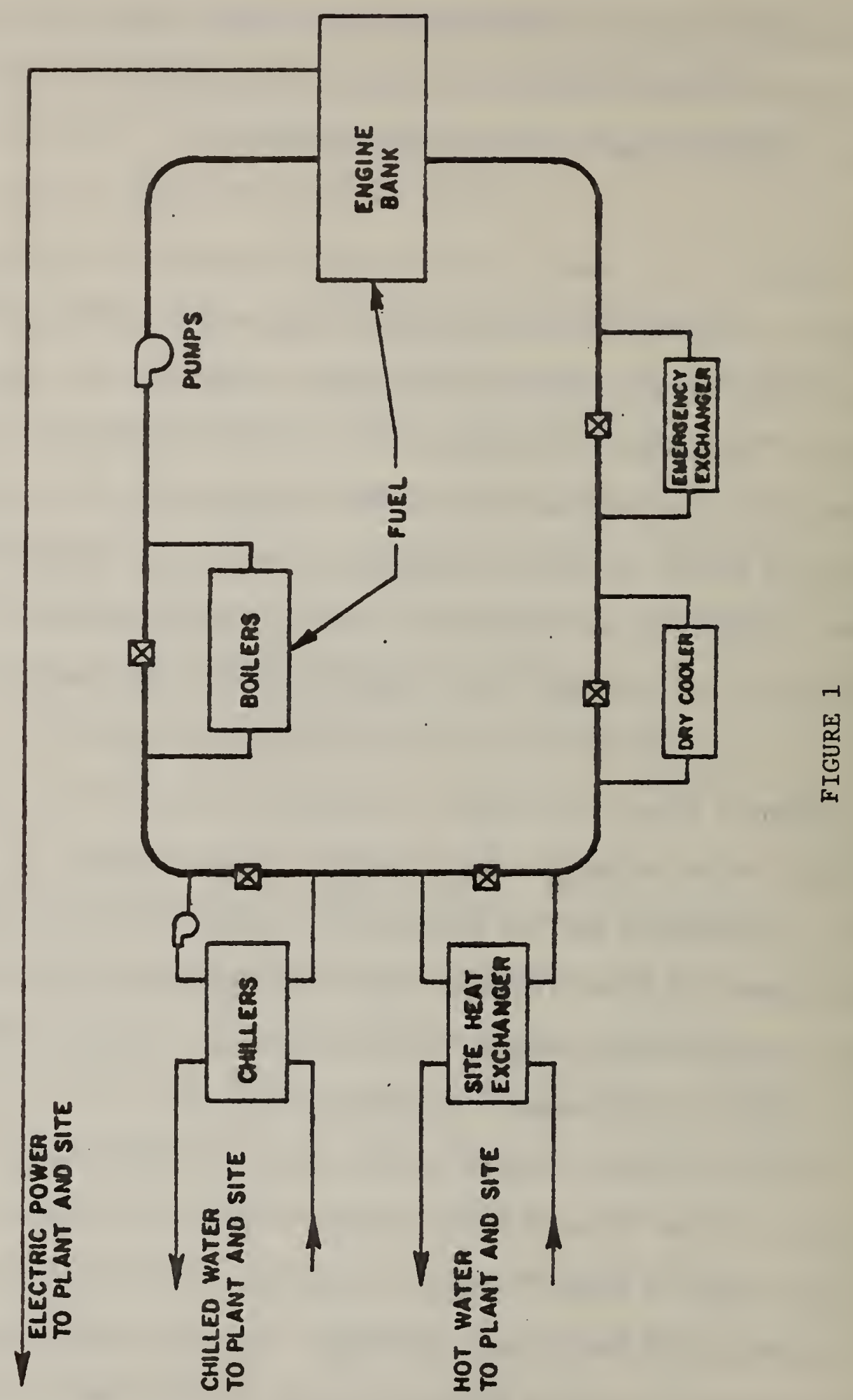




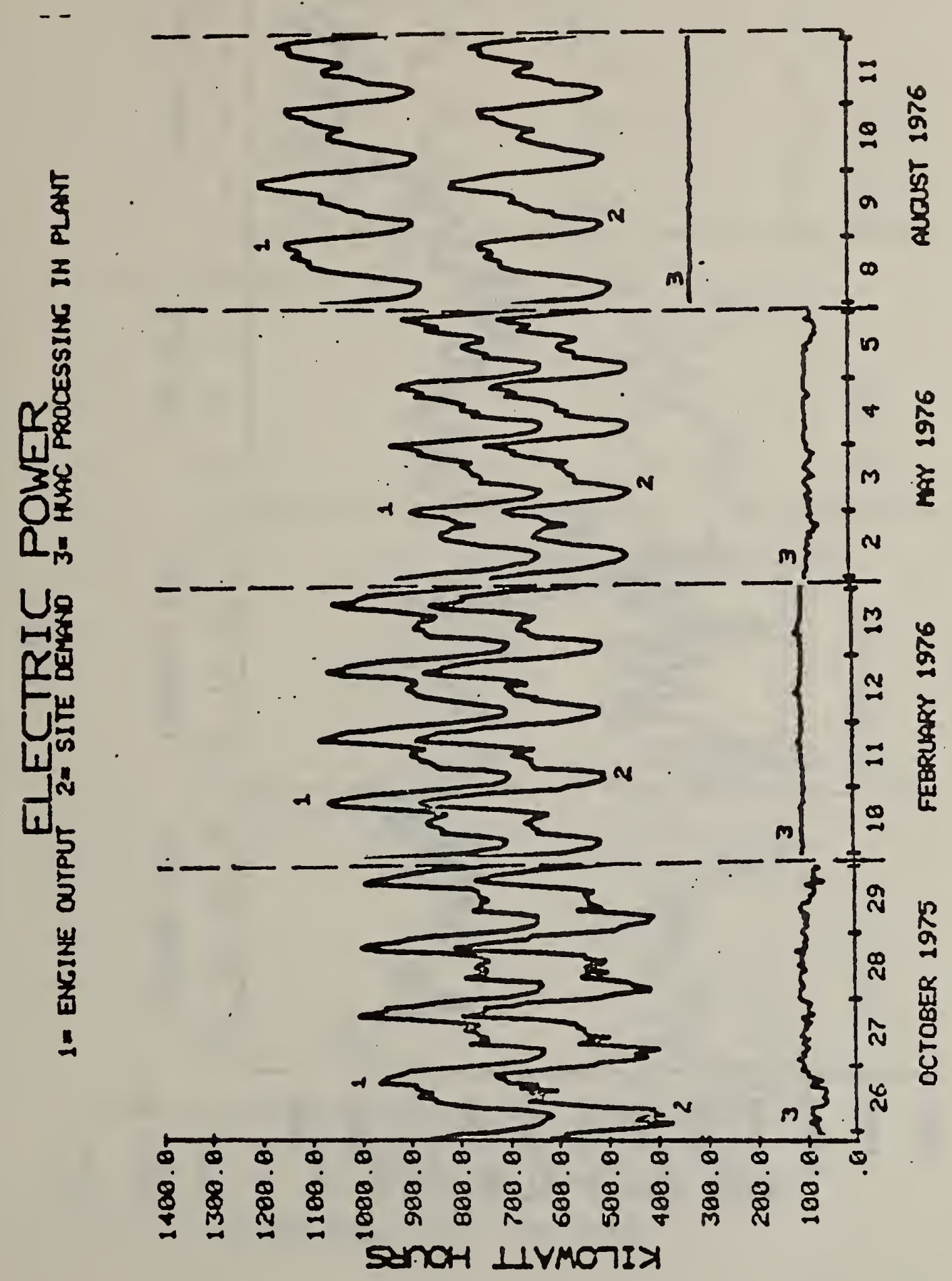

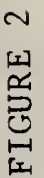



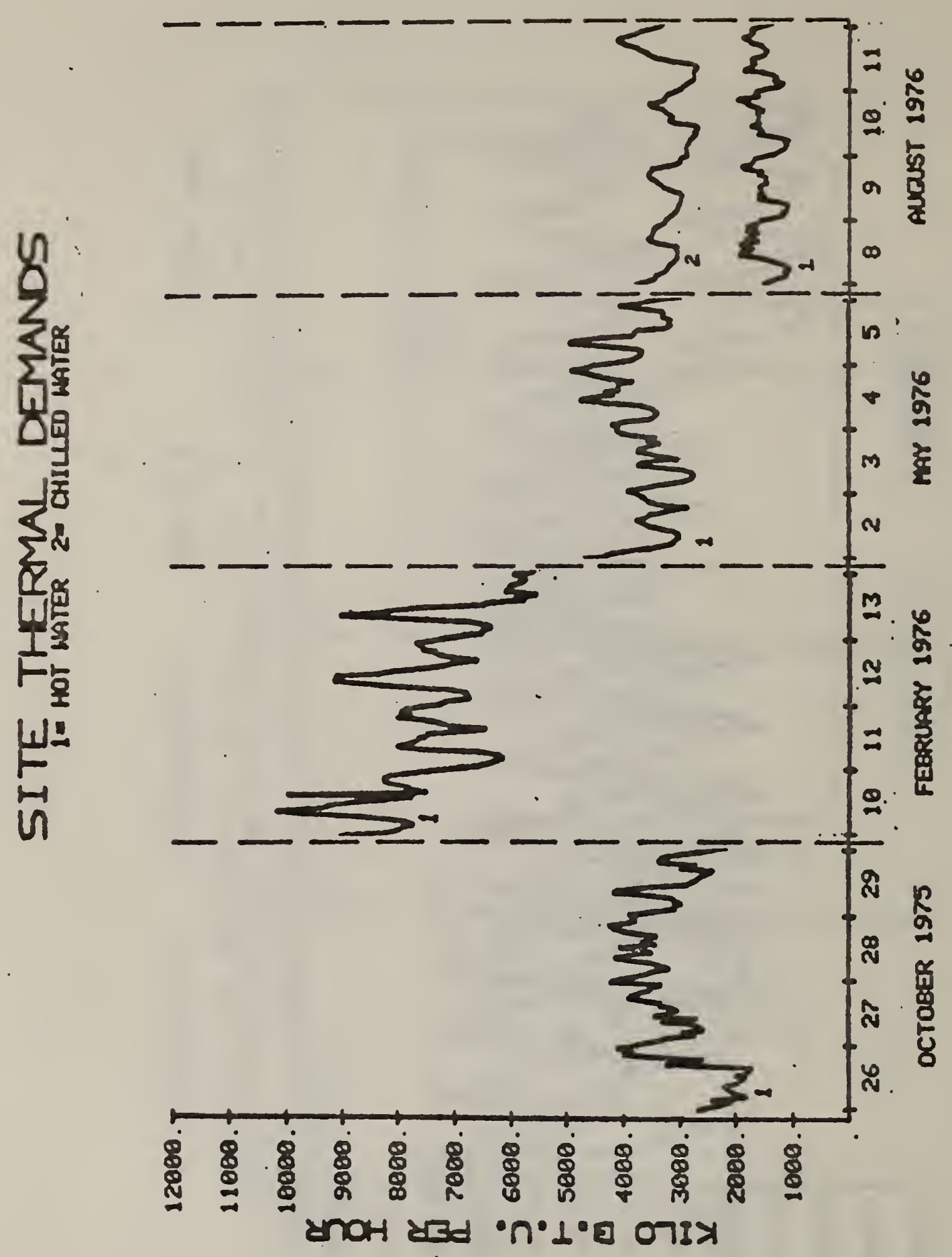
mid-winter site hot water thermal demands, more heat is required from the plant primary hot water loop in sumer than in winter to meet the demands of the chillers and primary site exchangers.

Heat is supplied to the primary loop to meet site exchanger and chiller demands from eaglne heat recovery and from the boilers. This graph in Figure 4 compares the thermal energy added in the primary loop by engine recovery and by the bollers. Heat recovered from the engfines is directly related to electrical loads on the engine-generators. Thus, 11ke electrical power production, engine heat recovery shows a diurnal variation but is relatively constant year-round with some increase in summer due to the increase in HWAC electrical loads. In summer and In winter the bollers supply about $2 / 3$ of the primary hot water loop energy. However, in the milder spring and fall months, the bollers supply less thermal energy than the enginss.

The relationship between recovered engine heat and the site and chiller Drimary hot water demands is shown in Flgure 5. In oumer and winter. englne heat recovery equals about $1 / 3$ of the site and chlller heat requirements. In the spring and fall englne heat recovery supplies almost all required heat. Note that on several of the days shown here, recovered englne heat exceeded the heat required by the site. If recovered heat is greater than the heat required by the site plus the primary loop losses then the dry coolers dispose of the excess heat. Presently the excess heat is a relatively small amount and does not fustify the addition of thermal storage components to the Jersey City Total Energy Plant.

Figure 6 reports the monthly performance of the Jersey City Total Energy Plant from May 1976 through October 1976. This chart also contains a 


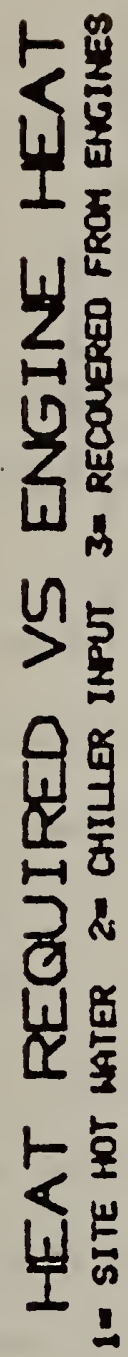

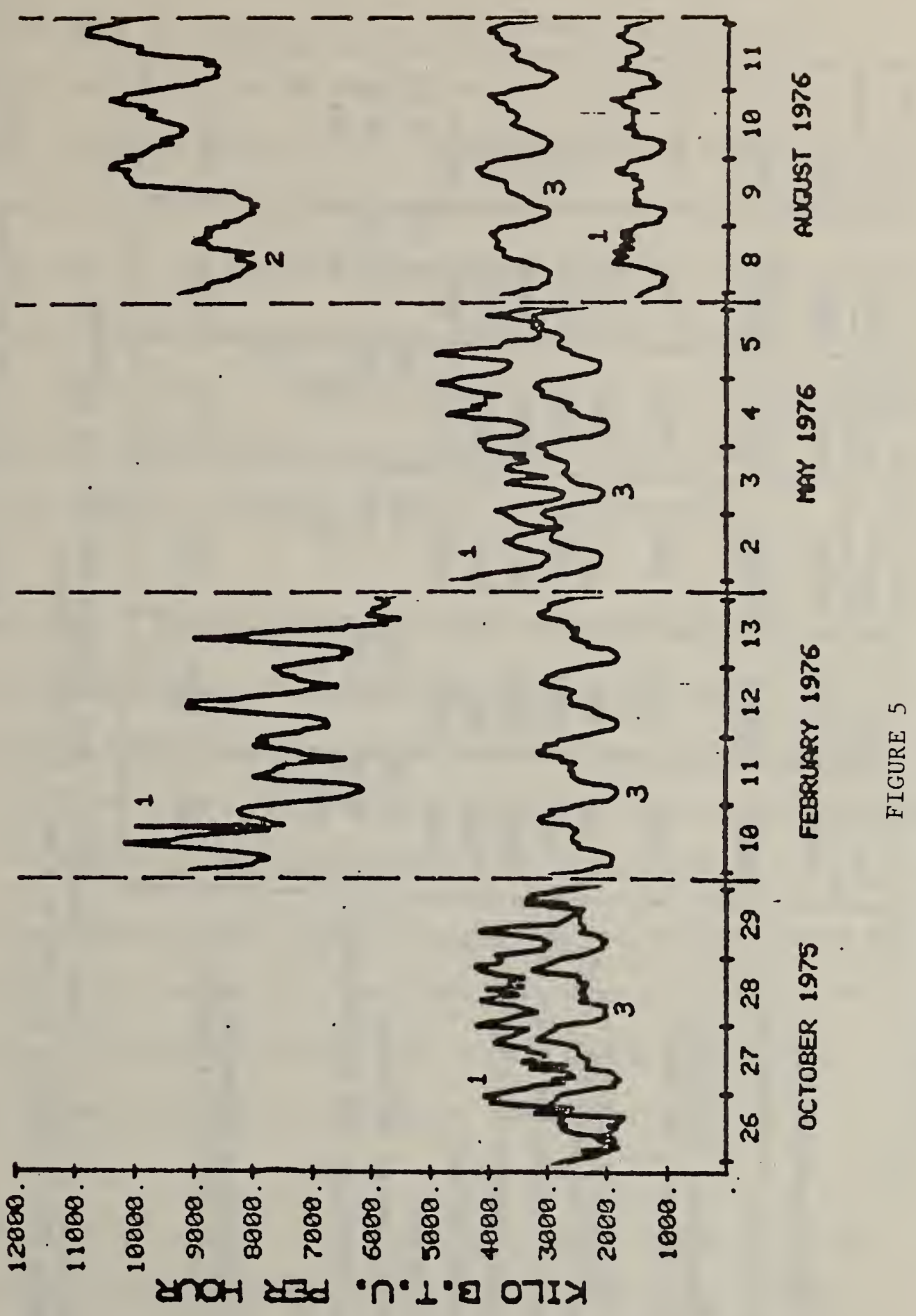




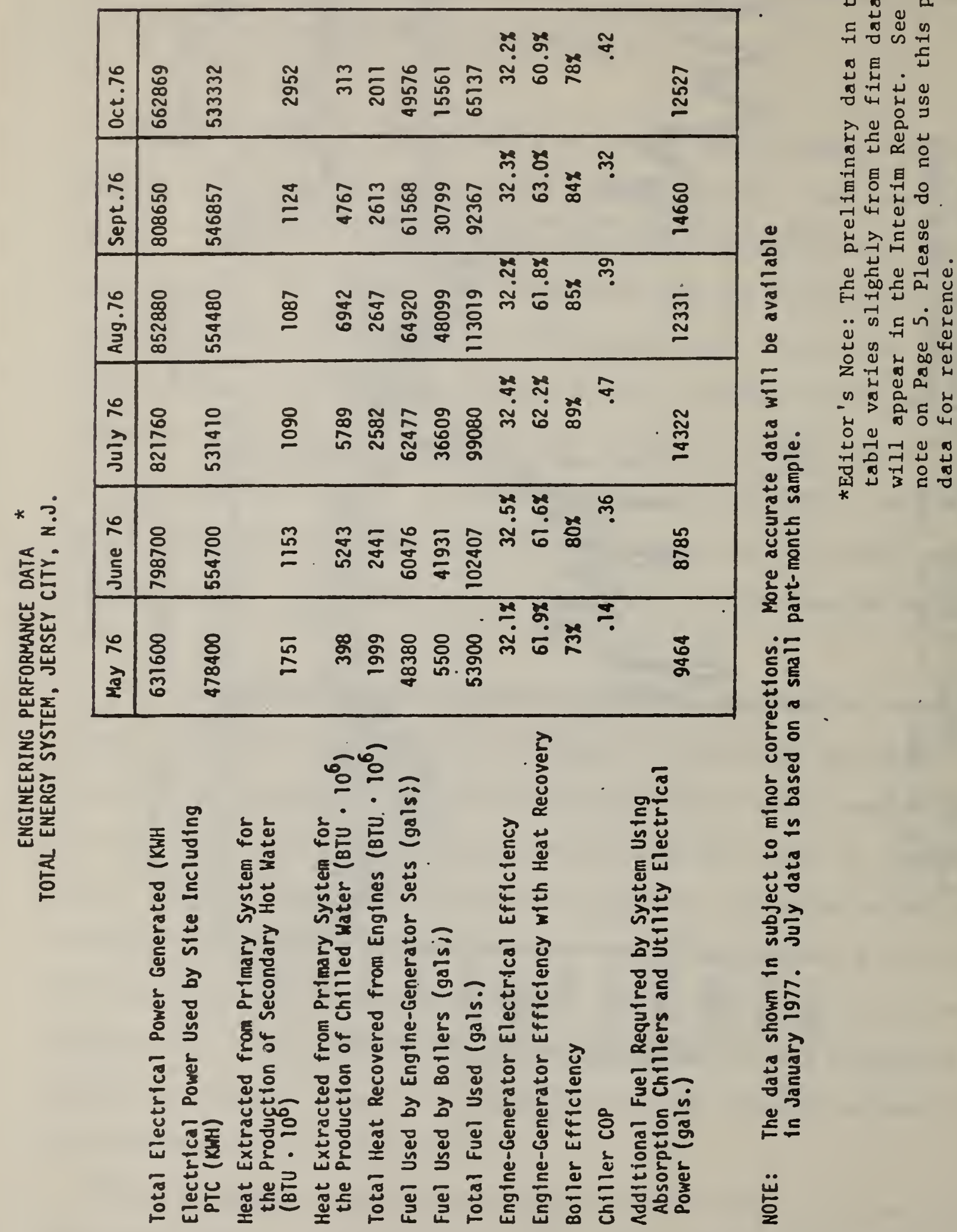

๒2 
comparison of the JCTE fuel consumption with the calculated energy consumption of the site if electricity were purchased from the local utility; hot water were supplied by absorption chillers in a central plant. The local utilities efficiency in converting fuel to delivered electric power is just under $30 \%$. The savings ranged from about 9000 to 15000 gals per month. It should be pointed out the total energy plant fuel savings will continue to improve as resolution of known problems in plant operation is achleved. These problems include correction of improper setting of the dry cooler controllers, isolating the standby boiler and possible reduction of plant air-conditioning.

Using the May 1976 to October 1976 fuel data for the Jersey City engines and bollers, models for the engine and boiler efficiencies have been developed. These models together with data describing engine and boiler outputs allow us to extrapolate the JCTE fuel usage from November 1975 through nctober 1976. See Figure 7. The extrapolated fuel data and the fuel required by a "conventional" system using purchased electric power and absorption chilling are plotted for a one year period on this chart. Note that the JCTE plant requires less fuel each m onth the described conventional utilities for the site throughout the entire year.

The first interim report containing performance and economic from the Jersey City Total Energy Demonstration will be published early in 1977. * EDITUR's NO'E: The interim report has been approved and will be published in June 1977. Copies will be available in July 1977. If you would like a copy please contact Mr. J.H.Rothenberg,U.S.Dept. of Housing \& Urban Dev., Washington,D.C.20410 Analysis of the data to date shows several ways in which the plant can

be further optimized for significant reduction of fuel requirement. As 


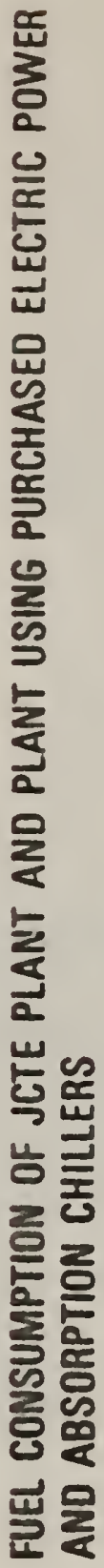

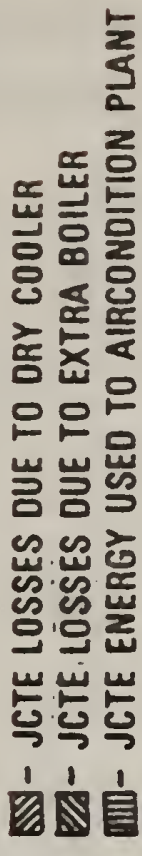
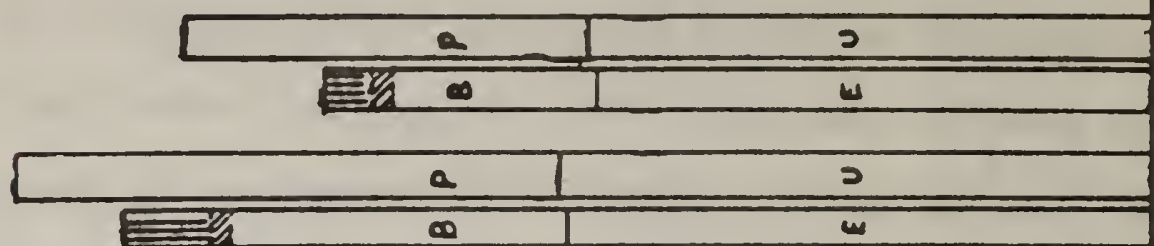

울

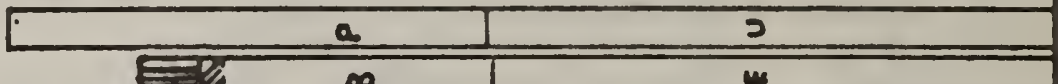

$\equiv$

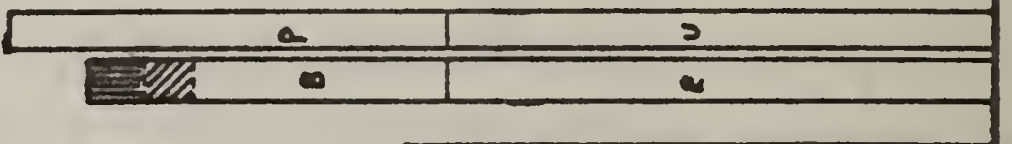

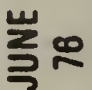

$\infty$

แ

$\sum \infty$

$\frac{\pi}{2} \infty$

$\infty$

N

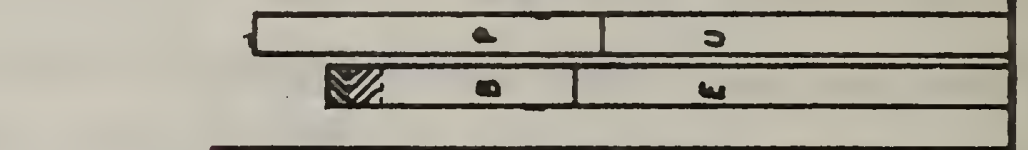

$\underset{2}{\infty}$

范

필 플

릴

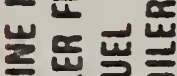

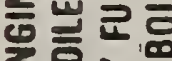

世 $\infty 2$

w

355

1152

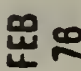

0

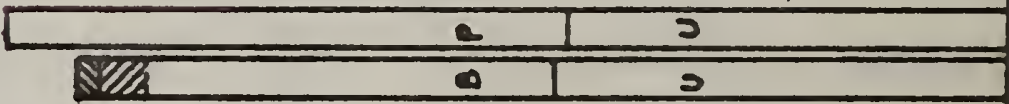

20

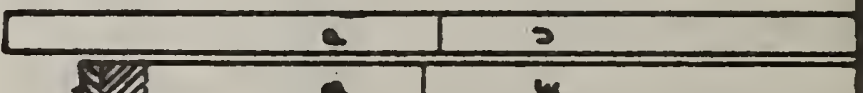

㟧

贾

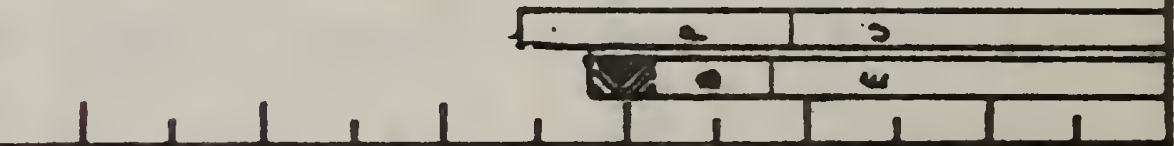

웅
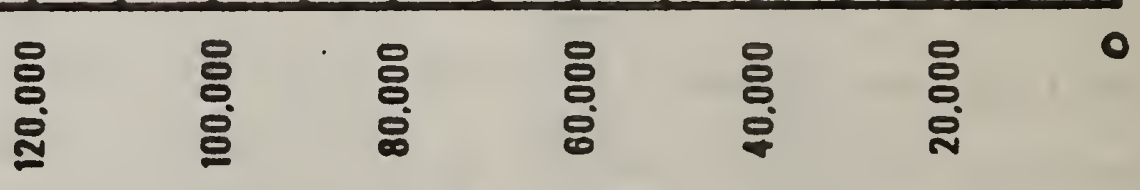

710 73กJ 10 SNOTTVS 
these changes continue to be implemented, the data will reflect the improvement and results will be published in future reports. 



\section{Work Material for Data Format}

Committee

The following information and planning will be useful in implementary the International Project Catalog of project descriptions.

a. Definition of MIUS type of projects to be included in the catalog. (See Attachment A for description of MIUS type of projects)

b. Organization of Catalog

The catalog should be organized by type of project with each topic arranged alphabetically. Recommended type of projects are as follow:

1. MIUS - an integrated utility system which provides five utility systems

2. Total Energy Systems

3. Integrated Utility Systems (other than MIUS and Total Energy)

4. District Heating

5. Utility Subsystem

(For example: wastewater treatment where water reuse results, or water system/plants incorporating the use of renovated water or water produced by integrated plants).

6. Component/Equipment

(For example: A boiler or heat pump that is specifically being developed to improve an integration process or to enhance an overall integrated system). 
c. Type of Graphics

The following design of the catalog is recommended.

1. One Volume

2. Typewr1tten

3. Organization should include three parts: Introduction;

Project Sumary Forms by type of project (6 toplcs);

$C$ ross-Index and a list of CaMS-MIUS Project committee attendees.

4. Looseleaf with mult1-ring binder. (Some coples will be bound as a "paper-back").

5. Printed with $8 \times 101 / 2$ pages

6. Illustrated cover.

7. One photograph of each demonstration fac1lity, operating plant, etc. may be Included if provided.

d. Contents of the Introduction (Front Matter)

The contents of the Introduction should include the following:

1. Purpose - Th1s paragraph w1ll describe the add purpose of the catalog and 1 ts intended use, and will indicate that it is the first level of a three level reporting system.

2. Scope - Th1s paragraph w1l1 describe the catalog's coverage ..... and w111 define MIUS type of projects.

3. History and Description of CCMS - This paragraph w11l describe CCMS and its origin. It w11l give the history of the Cais-MIUS Project, Including a short summary of each CCMS-MIUS Project Meeting.

4. Partilipating Countries - This paragraph w111 11st the countries participating in the CCMS-MIUS Project. It will erphasize that Information and particlpation is open to NATO and NON-NATO countries.

5. Organization of Catalog and How to Use the Catalog - A description of how the catalog is organized and why will be given. Instructions on how to use the catalog will be provided. The Identification numbers system w111 be described. Each participating country will be assigned an identifying number. 
6. Discussion of the Project Summary Form - The Project Summary Form will be described with a discussion of the information requested. Instructions on how to prepare a Project Summary Form will be given with provisions on how a participant may provide additional inputs.

7. Discussion of the Three Level Reporting System - Each level of reporting will be described. Information will be given on how one may acquire a Project Progress/Evaluation Report, Project Performance Data and other available information.

8. Updating - Information will be provided on how one may update his Project Summary Form and how the updating mechanism works.

9. Additional Copies - Information will be provided on how one may obtain additional topics.

10. Others - Additional information will be provided as needed or requested. A Preface and List of Acronyms will be provided prior to the introduction.

\section{e. Identification Number}

The identification number will aid in the identification of projects and will facilitate use of the cross-index. The cross-index will be a typical index to identify each project by type of project; utility service; hardware etc. The cross-index will be subject-to-identification number, and possibly identification-number-to-subject. A cross-index for each country will also be included.

The identification number will be a three part number, Section-CountrySequence. For example:

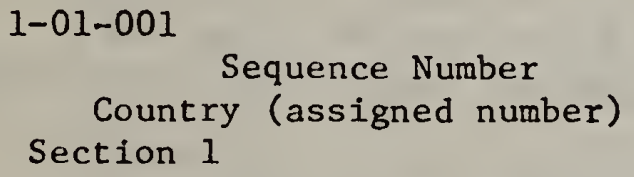

The Section number will identify each type of project (subject heading) such as MIUS Total Energy etc.

Each country participating will be assigned a number. This will aid in locating all of the projects in a particular country.

The sequence number will indicate the order in which projects are placed in each section. This will facilitate quick reference.

f. Publishing the Catalog

1. The U.S. proposes to print the first version of the catalog as a NBS Special Publication and place it in the U.S. Government Printing office (GPO) for sale to anyone. It would be made available in microfiche from the U.S. National Technical 
Information Service (NTIS) for about $\$ 3.00$ a copy. When the GPO paper copies become exhausted (out-of-print), copies would be made available from NTIS at their regular price according to page count.

2. 1000 coples would be printed for free distribution by the Secretariat. 500 coples would be losseleaf, multi-ring, 500 coples would be paperback with holes punched to facilitate binding by the user. GPO would print enough copies for sale.

3. Each country's representative actually participating would recelve 15 copies, looseleaf. All other particlpants would recelve 2 coples loose-leaf. Recipents would be designated persons to whom supplements or revisions could be mailed. They would be responsible for any further distribution in their country.

4. 300 paperback copies would be mailed to Brussels for distribution at their discretion to organizations"such as technical institutions and universities. Brussels would be responsible for malling out updates to those whom they have made distribution.

5. Updates would be published as punched supplements, Supplement $1,2,3$, etc. They essentially could be put into the loose-leaf binders as replacement pages. Those with paperback coples would have the option of using the basic document and its supplement in conjunction with each other or place them together in their own loose-leaf binder. (It might be necessary for us to publish all coples paperback with punched holes and to supply a loose-leaf binder with selected copies as we distribute).

6. The catalog w111 be published without copyrights. (The Comitee at the last meeting did not favor publishing, with copy rights.

7. The Secretariat (U.S.) would stock the remaining copies and distribute them as the need arose.

8. Further distribution would be on a request basis to technical experts, or technical institutions, etc.

9. A notice should be included on the Title page to discourage anyone duplicating the material for commerical gain. 
Summary of Project Summary Forms
Received For

INTERNATIONAL PROJECT CATALOG

\begin{tabular}{|c|c|c|c|}
\hline \multirow{2}{*}{\multicolumn{4}{|c|}{ Country }} \\
\hline & & & \\
\hline $\begin{array}{l}\text { Canada } \\
\text { Denmark } \\
\text { Italy } \\
\text { U.S. }\end{array}$ & $\begin{array}{c}1 \\
2 \\
3 \\
4,5 \\
6,7 \\
\\
8 \\
9 \\
10 \\
11 \\
12 \\
13 \\
14 \\
15-18 \\
19-24 \\
\\
25 \\
34-37 \\
38-41 \\
42-45 \\
46-50 \\
51-52 \\
53 \\
36-31 \\
32 \\
\end{array}$ & 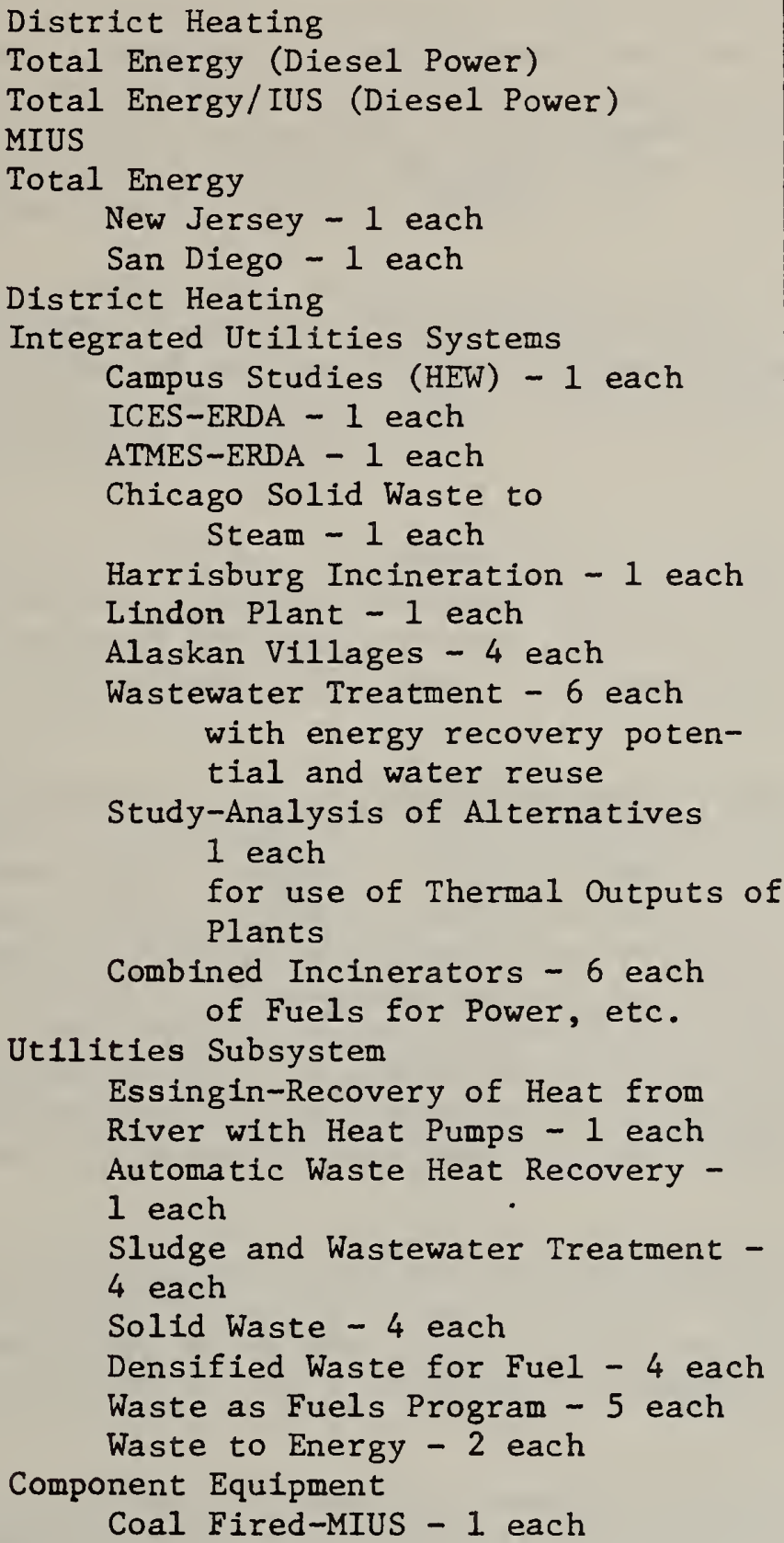 & do \\
\hline & & $\begin{array}{l}\text { TOTAL U.S. } \\
\text { TOTAL OTHER } \\
\text { GRAND TOTAL }\end{array}$ & $\begin{array}{r}50 \\
3 \\
53\end{array}$ \\
\hline
\end{tabular}



ATTACHMENT 5

\section{DEFINITION OF \\ "MIUS TYPE OF PROJECT"}

Although the Modular Integrated Utility System (MIUS) concept connotes or is thought of as the integration of five utility services to a small group of users, a MIUS type of project for CCMS purposes can be any of a broad range of utility/energy systems which are related to, or part of, a MIUS. Thus, a MIUS type of project is much broader than the rather restrictive concept definition of a "MIUS".

For the purpose of the International Project Catalog, a MIUS type of project is one that involves a utility system/subsystem that is, or has the potential to be, integrated with one or more utility system(s)/subsystem(s) to produce utility services more efficiently and economically than independent (non-integrated) systems.

Project

What constitutes a project? A project acceptable for inclusion in the International Project Catalog should be hardware oriented. A project may even be a study, such as a feasibility study, if it has major national significance or is one that could lead to the construction of an actual system.

An acceptable hardware system may be a research-oriented laboratory or pilot plant investigation, or it may be a demonstration or commercial facility which is serving actual community utility loads. A laboratory investigation would most likely be one for equipment or sub-system development, a pilot plant would be one for experimentation with future plants or system development in mind, a demonstration facility would be one constructed specially to prove feasibility of an actual real-life plant by acquisition and evaluation of data. A commercial facility serving an actual community or industry is highly desirable as a CCMS-MIUS project if basic operating data is available for evaluating performance.

Modular

The definition of the word Modular has caused some confusion over the exact type of projects which should be included. As a guide for CCMS-MIUS projects the meaning of the word "Modular" should not be a significant determinant in whether or not a project meets the criteria for inclusion in the Project Catalog.

What do we mean by Modular? Modular can have several meanings when applied to an integrated utility system. Some ideas that may be helpful in determining a CCMS-MIUS type of project are as follows:

1. Modular may connote a small community size plant serving a small community or part of a community. Thus, the modular system is part of the overall infrastructure. It could be a small facility serving a shopping center, a school, a hospital, an apartment complex or a combination of these. 
2. Modular may connote a small community size plant with the potential to grow in increments as the communities grow. Thus the added increment could bc considered a module.

3. Modular may represent the structure of the integrated utilities system itself as an integrated utilities system would consist of subsystems. Thus, a subsystem could be considered a module.

The following types of projects are to be considered MIUS type of projects:

1. MIUS - An integrated utility systems where all utility subsystems are integrated to provide utility services better, more economically and with less fuel consumption than a conventional system. A typical MIUS provides power, space heating/cooling, domestic hot water, solid waste processing, wastewater treatment and provisions for potable water. A MIUS recovers waste heat from power generation and refuse incineration, and reduces undesirable discharges to the environment.

2. Total Energy System - An integrated utility system that provides power, space heating/cooling and domestic hot water. It recovers waste heat from power generation.

3. Integrated Utility System (other than MIUS and Total Energy) - Two or more utility subsystems which are integrated. Examples are: use of renovated waste water for use in power plant cooling towers, solid waste processing with incineration and wastewater treatment, and wastewater treatment with water renovation or reuse. A MIUS and a Total Energy System are special cases of an integrated utility system.

4. District Heating - A system by which heat is supplied to buildings in an urban area through insulated pipelines from one or more heat sources situated external to the buildings. Any district heating system that has the potential or is to be integrated with another utility subsystem (refuse incineration or power generation, to provide better services at less cost should be included.

5. Utility Subsystem - A subsystem is generally one that furnishes a single utility service. A utility subsystem that is being improved or developed for integration with another utility system or one that is being improved to Improve the integration process should be considered. This would include, for example an improved method of recovering heat during power generation.

6. Component/Equipment - A component or piece of equipment that is being improved or developed specifically for.the purpose of improving the integrated utility subsystem system or the integration process. For example: Thermal Storage Systems, boilers, heat pumps, heat exchangers, etc. Note: A project to improve a component or piece of equipment such as a boiler or heat pump, with no specific objective related to integrated systems should not be considered. 
Scale

A1though modular in "MIUS" has sometimes been interpreted as being limited to small scale plants, this is not correct. For the purpose of identifying projects consider all size plants which follow the type of projects listed above.

\section{Status}

A project acceptable for inclusion in the International Project Catalog may be in the planning stage, on-going, or it may be one that has been completed. A project should not be considered complete until data has actually been evaluated and the final report published or released.

\section{Availability of Data}

A pilot plant, demonstration facility or commercial system should be one in which good quality data that will be useful in analyzing plant performance is being acquired and is readily accessible. The more data available the better, however, operational data such as that produced by a commercial system is adequate in choosing candidates for the project catalog.

Integrated

Integrated refers to use of a combined plant to furnish all utilities with a total system approach, whereby some resource requirements of one utility would be met by utilizing the effluent of another. 


\section{Layout of report: measuring systems for a MIUS}

1. General introduction

(formulation of the problem)

keywords :

- many MIUS projects, and objectives of MIUS projects

- project comparison with different goals

- assessment different approaches

- measurements in practice difficult in relation with cost

- for appropriate information, measurements are a necessity.

2. Purpose of the report

- minimum required information for comparison

- presentation of different objectives and the consequences on the measuring system (energy conservation, economics, pollution etc.)

- to form basis for information exchanges for the standardized format

- to present tine general experience

- to give guidance to the potential user of a MIUS system

- to indicate the state of the art in relation with cost, reliability, repeatability of measurements

- not the data acquisition system in extension

- not to present accepted standards in the countries

- to forecome mismatching of subsystems; optimisation of the MIUS system.

3. Approach of the technical problems

Basis: to generate information, measurements are necessary.

System approach - function oriented

- the MIUS as a whole system

- the subsystems classified in the function

- power generation

- heating/cooling/hot water

- solid vaste processing

- waste water treatment

- potable water production. 


\section{Subsystems}

For every class and subsystem

- function defined

- elements

- characteristics of in and outputs and performance

- interface with other subsystem

- parameters to be monitored.

5. The measurements

- always set of measurements from point of view of safety, control etc.

- from MIUS different possibilities and to present in a non numerical way

- the importance of the time element in the most important flows (daily mean, hourly, peak value, etc.)

- for the different flows (in general terms, as iuel input, electricity output, hot water output) or eventually classe of measurement for instance flow measurement temperature

a non numerical classification witn regard to

- accuracy under practical conditions to be expected

' repeatability of the measurements

- reliability of the measurements

- costs

- pinpointing white areas

- new developrents.

\section{Approach in practice}

To come to an exchange of information as soon as possible and taking into account that a full instrumented MIUS system and subsystems is only available when the system has a demonstration characteristic the following levels of the scope of measurement can be recognised:

A. MIUS system as a whole

- integrated inputs and outputs, as fuel consumption, electricity production, gas consumption, waste streams (?), potable water consumption etc.

(it is expected that most of the mentioned data are required for the charging of the inhabitants). 
B. The subsystem inputs and outputs

- integrated over a certain period (hourly, daily, weekly)

- momentarily to calculate performance and input for

- optimisation, control systems performance, interface problems etc.

For the comparison of the MIUS system with a conventional system or with other MIUS systems it is necessary to generate information regarding:

- the characteristics of the building, or complex of buildings etc.

- the weather conditions in an appropriate manner.

7. Data acquisition system

It is proposed to present this paragraph in a rather general way. Perhaps it is possible to give some indication of the possibilities, costs, pros and contras etc. only from a point of view of the user of the system.

In a demonstration type MIUS systems differ on the measuring set up strongly from the practice of the management of the system.

8. Influence objective

The objective of the measurements can be quite different as mentioned above (energy conservation, economics, pollution, optimisation system etc.). As user directed expose is required what the consequences are of a more specific objective on the measurements and data acquisition system.

\section{Conclusions}

10. Annexes 

APPENDIX J

MINUIES

OF THE

CCMS-MIUS PROJECT MEETING

July 1977 (Turin) 
The mirutes of the fifth CCMS-MIUS Project Meeting held July 12-14, 1977 at the FIAT Central Research Laboratory, Orbassano, Italy (near Turin) have not been completed and thus are not available for this report.

A summary of the meeting has been prepared for purposes of this report and are included herein. 
SUMMARY OF THE CCMS-MIUS PROJECT MEETING

July 12-14, 1977, near Turin, Italy at

FIAT Central Research Laboratory, Orbassano

Summary: Representatives from seven NATO countries attended the July 12-14, 1977 MIUS Project Meeting near Turin, Italy (the fifth and final meeting). The participants received reports from the various working committees (subgroups) approved the catalog and a procedure for the documents prepared by the working committees to be included in the final report for submittal to the October Plenary. The overall Committee will recommend to the Plenary that the committees' principal work continue that attention be given to the institutional problems associated with the implementation of integrated utility systems and that other international organization(s) be sought under whose auspices the work could continue.

1. The fifth and last meeting of the CCMS-MIUS Project was held July 12-14, 1977 at the FIAT Central Research Laboratory, Orbassano, Italy (near Turin).

2. Sixteen experts from seven NATO countries (Belgium, France, FRG, Italy, Netherlands, U.K. and U.S.) participated. Twenty-two observers from various Italian industries and research organizations attended part of the first day.

3. The experts first reported on MIUS-type of projects in their respective countries. U.S. delegates (Rothenberg and Phillips) reviewed the Total Energy demonstration project at Jersey City, N.J. and the planned MIUS demonstration project at St. Charles, Maryland. Patrick Folan, the U.S. CCMS Officer, provided an update of the other CCMS pilot studies.

4. The Data Format, Measurement Technology, Research Needs, and

"Incentives and Barriers" working committees met and subraitted their recommendations to the overall committee. The Ad Hoc Committee on the future activities of the project met, Monday, July 11, 1977 at 1600 hours and presented its recommendations to the overall committee.

5. The committee accomplished and decided the following:

(a) The final draft of the International Project Catalog and Addendum presented by the Data Format Comnittee was approved for submittal to the Plenary which will meet October 1977.

(b) Inputs received by the Secretariat by August 1, 1977 and comments received during the meeting will be incorporated into the final draft. 
(c) The completed catalog will be sent to NATO headquarters, September 1977 for submittal to the October Plenary. The Secretariat will publish the catalog upon approval by the Plenary.

(d) The outline of the final report for the October Plenary was reviewed, revised and approved. The final report need not be a published document. The final report will be prepared by the Secretariat and submitted to the NATO headquarters September 1977 for approval at the October Plenary.

(e) The draft of the standard methodology for measuring and reporting the performance of integrated utility systems was presented by the Measurement Technology Committee and approval for inclusion in the final report pending incorporation of comments. Additional comments are to be forwarded to the Committee Chairman by August I, 1977. The completed standard methodology is to be forwarded to the Secretariat by September 1, 1977 for inclusion in the final report.

(f) The recommendatjons of the Research Needs Committee for needed reserach in support of Integrated Utility System Technology were approved for inclusion in the final report. Any additional comments are to be forwarded to the Committee Chairman by August 1,1977. The completed recommendations are to be forwarded to the Secretariat by September 1, 1977 for inclusion in the final report.

(g) The Committee on "Incentives and Barriers" presented its paper on the incentives and barriers to the Implementation of Integrated Utilities Systems. Comments from the various participating countries are to be forwarded to the Chairman within 2 weeks. A second draft is to be prepared and circulated to the participants in attendance in about six months for comment and approval. The paper will not be available for inclusion in the final report to be submitted to the October (1977) Plenary but is being considered for inclusion in a subsequent follow-up report to the Plenary.

(h) The Ad Hoc Committee presented its recommendations on future activities to the overall Comittee for approval. The recommendations were revised and approved for inclusion in the final report to the Plenary.

(i) The CCMS-MIUS Project Committee will recommend to the CCMS Plenary that (a) Means for continuing the information exchange between countries be sought. (b) means for continuing the Project Catalog and the exchange of data from these projects, the standard methodology for measuring and reporting the performance of integrated utility systems and the work of the "Incentives and Rarriers" comittee (c) a mechanism be developed for informing countries of their need to change laws and regulations to receive the benefits of integrated utility systens (d) procedures be developed for the services of experts to assist and inform countries which request such assistance in the implementation of integrated utilities_(e) that research be carried out to 
satisfy the needs in integrated utility system technology identified in the CCMS-MIUS Project Final Report, and (f) other organization(s) be sought by the Secretariat under whose auspices project work could continued. Refer to the attached agenda. 
COMMITTEE ON THE CHALLENGES OF MODERN SOCIETY

RATIONAL USE OF ENERGY PILOT STUDY

MOUULAR INTEGRA'IED UTILITY SYSTEM (MIUS) PROJECT

\title{
CONFIRMATION NOTICE OF
}

SCHEDULED MEETING

\author{
Date: Tuesday, Wednesday and Thursday \\ July 12-14, 1977 \\ Place: FIAT Central Research Laboratory at Orbassano \\ (Strada Torino 50) near Turin, Italy (15 Km) \\ Official Host: Dr. Eng. Vincenzo Mazzaglia \\ Consiglio Nazionale dell Ricerche \\ Roma, Italy \\ Coordinator for: Dr. Angelo Rossi \\ Meeting \\ FIAT Central Research Laboratory \\ Meeting Chairman: C.W.Phillips, U.S.
}

Order for Business

TUESDAY, July 12

0830

Bus leaves hotel Turin Palace

0900

REGISTRATION, CALL TO ORDER AND WELCOME

Welcome to FIAT Research Center,

Prof. Ugo I. Businaro, Director CRF

Welcume to Italy and Consiglio Nazionale delle Ricerche, Prof. Mario Silvestro, President of Technological Committee, CNR

Welcome to CCMS-MIUS Project Meeting

C.W.Phillips, US

0930

UPDATE OF CCMS ACTIVITIES

Patrick Folan, Esq.

CCMS officer

O.S. Mission NATO Brussels 
J.H.Rothenberg, Manager, U.S. HUD-MIUS Program (HUD is the U.S.Department of Housing and Urban Development)

Mr. J.H.Rothenberg, Manager, U.S. HUD-MIUS Program, will describe the current status of the HUDMIUS Program including the Total Energy plant at Jersey City, New Jersey and the MIUS Demonstration at St. Charles, Md. and other related projects. Emphasis will be placed on (a) Evaluation of plants performance using data over a one year period (1975-1976) (b) Institutional constraints and incentives concerning the MIUS Demonstration at St. Charles. (c) Design alternatives.

\section{UPDATE OF INTEGRATED UTILITY SYSTEMS PROJECTS}

Experts in attendance are requested to present brief reports on ongoing projects in their respective countries. (Notice to presentors: Written reports for distribution to attendees will be helpful). Audiovisual equipment will be avallable for those who have slides, veiwgraphs, etc.

LUNCH (hot buffet; offered by CRF)

\section{TASK 1 DATA FORMAT COMMITTEE}

C.W.Phillips (USA), Chairman

(A11 CCMS-MIUS Project experts are requested to participate in the Data Format Committee Work Session.)

Discussion and review for approval:

a. Review and approval of Final Draft of International Project Catalog

(1) Content and Completeness of Introduction, (Part I)

(2) Organization and Format of Catalog,

- catagories by types of projects

- parts and sections

- number system by section and by characterization of project

- Index and cross referencing (Part II)

(3) Definition of "MIUS Type of Project"

(4) Project Descriptions, (Part III)

appropriateness of submitted Project Summary Forms

- Screening Process

- Comments on Accuracy and Completeness of Project Summary Forms

(5) Identification of New Projects and additional Project Summary Forms to be submitted

(6) Poll of countries for additional inputs to catalog 
b. Revlew and approval of Method of Production and Printing

- Typewritten

- Duplicated with punched holes for 3 ring binder

- Banded for distribution

c. Review and approval of Committee's recommendation for dissemination

d. Schedule for publishing catalog

e. Recommendations on Progress/Evaluation Reports for AD HOC Committee on Future Activities of Project.

- Need and Use

- Acquisition of Comments and Improvements

- Methodology for supplying Project/Evaluation Reports to participants, if necessary

- Milestones and Schedules, if necessary

f. Other recommendations for Ad Hoc Committee Consideration of :

- Catalog of Component Parts

- Update of International Project Catalog

DATA FORMAT COMMITTEE-

Canada (K.R.Solvason)

Italy (M.Mangialajo)

Netherlands (J.W.H.Van den Bergh)

United Kingdom (P.J.O'Nei11)

United States (C.W.Phillips)

ADJOURN DATA FORMAT COMMITTEE SESSION

Bus leaves for hotel Turin Palace 
- J.A.Knobbout (The Netherlands) Chairman (All CCMS-MIUS Project experts are requested to participate in the Measurement Technology Committee work session.)

Discussion and Review for approval:

a. General update of Committee goals and objectives

b. Review and approval of Final Draft of Standard Methodology for reporting the performance of MIUS type of systems and taking of and reporting of data.

c. Schedule for incorporating comments and submitting to Secretarial for inclusion in final report. The Final Report will be submitted to the CCMS Plenary for approval at their October, 1977 meeting.

d, Recommendation for Ad Hoc Committee on future activities,

\section{MEASUREMENT TECHNOLOGY COMMITTEE}

France (T. Grjebine)

Federal Republic of Germany (H. Klein or F. Richter)

Netherlands ( $\mathrm{J} . \mathrm{A}$. Knobbout)

Sweden (U. Renghold)

United States (C.W.Phillips)

\section{TASK 3 RESEARCH NEEDS COMMITTEE}

- J.A. Michel (Belglum), Chairman

(All participants are requested to provide input to the Research Needs Committee)

Discussion and review for approval:

a. Review and approval of Final Draft on Needs for research in support of Integrated Utility System Technology. (This is to be a prioritized list of research needs in integrated utility system technology for inclusion in the Final Report of the CCMS-MIUS Project. The Final Report will be submitted to the CCMS Plenary for approval at their Oct. 1977 meeting).

b. Additional Recommendations by Participants.

c. Schedule for incorporating comments and submitting to Secretariat for inclusion in final report.

d. Recommendations for Ad Hoc Committee on future activities. 


\section{RESEARCH COMMITTEE}

Belglum (J.A. Michel)

Federal Republic of Germany (W. Plller or Dr. H. Kle1n) United States (S. Cavros)

COMMITTEE ON "BARRIERS AND INCENTIVES"

Discussion and review for approval:

a. Review and approval of Paper on "Barriers and Incentives" (This is a paper discussing the barriers and incentives that impact on the implementation of a MIUS for inclusion in the Final Report of the CCMS-MIUS Project)

b. Add1tiona1 Recommendations by Participants

c. Schedule for incorporating comments and submitting paper to the Secretarlat for inclusion in final report.

The Firal Report w11l be submitted to the CCMS

Plenary for approval at their October 1977 meeting.

d. Recommendations for Ad Hoc Committee on future activities.

\section{COMMITTEE MEMBERS}

U.S. (S. Cavros)

France (T. Grjebine)

Italy (M. Manglalajo) 
Discussion and review:

a. Report of Committee - Recommendations on future activities of project. (This Committee is scheduled to meet Monday, July 11, 1977 at FIAT to prepare this report. All participants are invited to attend the Ad Hoc Committee meeting.

b. Report on Progress to continue Project activities under the auspices of another international organization.

c. Additional Recommendations of Participants

d. Schedule for submitting recommendations to Secretariat for inclusion in the final report. The Final Repprt will be submitted to the CCMS Plenary for approval at their October, 1977 meeting.

\section{COMMITTEE MEMBERS}

Patrick Folan

C.W.Phillips

J.H.Rothenberg

U. Plantikow

J.A. Knobbout

J.A.Miche1

\section{COMMITTEE SUMMARIES/APPROVAL}
a. Data Format Committee, Task 1
b. Measurement Technology Committee, Task 2
c. Research Needs Committee, Task 3
d. Committee on "Barriers and Incentives"

OTHER BUSINESS

a. Recommendations on Content of Final Report of the CCMS-MIUS Project Meeting

- Description of CCMS, CCMS-MIUS Project, Project Activities

- Description CCMS-MIUS Project Committee Accomplishments

- Chapters on Glossary Methodology of Reporting Performance, Research Needs, Barriers and Incentives and Recommendations for Future Activities

b. Action on Recommendations of $\mathrm{AD}$ HOC Commiteee regarding:

- Future Activities

- Other organizations for MIUS Project Activities

- Future Meetings

c. Summary of CCMS-MIUS Project Accomplishments

C.W.Phillips, Chairman 


\section{$\overline{\text { EVENING OPEN }}$}

THURSDAY, July 14, 1977

0830

0900

1245

1430

Bus leaves from hotel Turin Palace for Laboratories

TECHNICAL TOUR OF FIAT CENTRAL RESEARCH LABORATORIES AT ORBASSANO

The itinerary for visiting the laboratories will be determined on the first day of the project meeting, Tuesday, July 12, 1977. Participants in attendance will be given an opportunity to recommend additional projects which they may wish to visit. Participants may wish to include visits to other research projects at other remote facilities on an individual basis. In this event CRF will assist those participants as appropriate in making the necessary arrangements for those factlities that are avallable.

FIAT - CRF Energy Activities:

- TOTEM (Smal1 power Total Energy Module)

- Diesel powered heat pump for ambient climatization (a realization totally supported by CNR)

- Organic fluid Rankine cycle for waste heat utilization (an activity partially supported by the European Economic Commission)

LUNCH

CEOSING OF T'HE MEEIING

(A bus leaves for town) 


\section{$\underline{\text { Registration }}$}

Each participant is requested to register prior to the meeting by completing the self-addressed card enclosed with this agenda and mailing it to C.W.Phillips, Chairman, National Bureau of Standards, Building 225, Room A146, Washington, D.C. 20234. Early registration will be most helpful to the host in making preparations for the meeting. Please register by June 1, 1977.

\section{Accommodations}

Hotel reservations are made by each participant. The host has made arrangement with the travel agency VENTANA in Turin for participants to contact them directly for their hotel reservations. The suggested date for making your reservations through VENTANA was June 15, 1977. However, if you have not already made your reservations, it is suggested that you contact VENTANA immediately.

Please send request for reservations to:

VENTANA

Galleria San Federico, 16

10121 Torino, Italy

Attn: Mr. Brusa - Telex 23239

Be sure to indicate that you will be attending the CCMS-MIUS Project meeting at FIAT Central Research Laboratory at Orbassano.

The following hotel and room options are suggested:

$$
\begin{aligned}
& \text { Hotel Turin Palace } \\
& \text { Singlebath: LIT. } 30,000 \\
& \text { Doublebath: LIT. } 45,000 \\
& \text { Hotel Suisse } \\
& \text { Singlebath: LIT. } 14,600 \\
& \text { Doublebath: LIT. } 23,000 \\
& \text { Hotel Luxor: } \\
& \text { Singlebath: LIT. } 12,500 \\
& \text { Doublebath: LIT. } 19,000
\end{aligned}
$$

Above rates include continental breakfast and taxes.

Agency Fee: LIT 1,500 per room.

VENTANA, upon receipt of requests for accommodations will forward a confirmation and additional information concerning travel and tourism.

Travel from Hotels to Laboratories

FIAT will furnish transportation to and from the hotels to the laboratories. A bus will depart from the TURIN PALACE at 830 for the laboratories, and from the laboratories at 1700 for the hotels. The three suggested hotels are within walking distance from each other. Those staying at the Suisse and Luxor will need to walk to the Turin Palace for connections. 
Each participant will need to arrange and supply his/her own travel from the arriving airports to the hotel in Turin.

For Milan arrivals, transportation by train is available to Turin from Milan, approximately a 2 hour trip. Bus transportation is available from both Milan airports to the train station. (MALPENSA - Intercontinental flights, LINATE - European flights)

For Turin arrivals, bus transportation is available from the Turin airport (CASELLE) to the hotel.

\section{Flights to Turin and Milan}

Several daily flights arrive at Milan - Linate from Frankfurt, London and Paris. Evening flights arrive in Turin from Frankfurt, London and Paris.

\section{Contacts}

If you have any questions concerning the CCMS-MIUS Project, please get in touch with the Project Chairman, C.W.Phillips, Room A146, Bldg. 225, National Bureau of Standards, Washington, D.C. 20234, U.S.A., telephone 202-921-3741. The NBS telex number is $89-8493$.

If you have any questions concerning your travel and accommodations please get in touch with Dr. Rossi, the meeting coordinator for FIAT at the FIAT Central Research Lab at Orbassano near Turin. His' telephone number is $901.14 .01 / 2 / 3 / 4 / 5$. The telex number is 22289 Fiatlabs. 
NBS-114A IREV. 7-73)

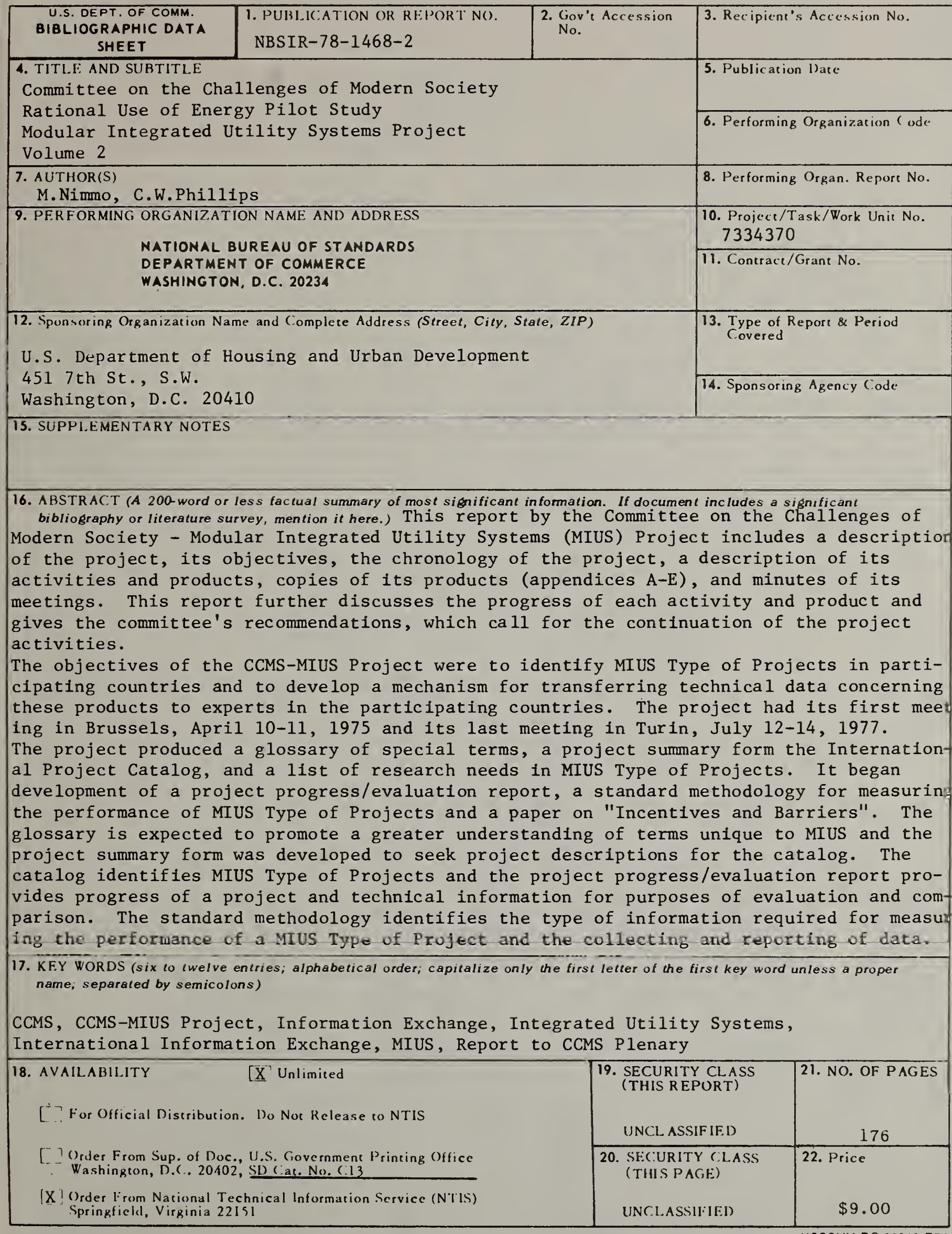


